Copyright

by

Gaurav Sharma

2011 
The Thesis Committee for Gaurav Sharma

Certifies that this is the approved version of the following thesis:

\title{
Wettability Alteration in High Temperature and High Salinity Carbonate Reservoirs
}

\begin{abstract}
APPROVED BY
SUPERVISING COMMITTEE:
\end{abstract}

Supervisor:

Kishore K. Mohanty

Gary A. Pope 


\title{
Wettability Alteration in High Temperature and High Salinity Carbonate Reservoirs
}

$$
\text { by }
$$

Gaurav Sharma, B.Tech.

\author{
Thesis \\ Presented to the Faculty of the Graduate School of \\ The University of Texas at Austin \\ in Partial Fulfillment \\ of the Requirements \\ for the Degree of
}

Masters of Science in Engineering

The University of Texas at Austin

August 2011 


\section{Dedication}

To my parents Shakuntala and Vasudev Sharma and my sister Neelam Sharma. 


\section{Acknowledgements}

I would like to express my sincere gratitude to Dr. Kishore K. Mohanty, who has been my advisor during the course of this study. His regular guidance and ideas helped me to better approach the research problem, and give it a good shape in timely manner. He also provided editorial advice during the writing of this thesis. I would also thank Dr. Gary A. Pope who agreed to read this thesis and provide valuable feedbacks.

I would like to thank Dr. Eric Dao for providing technical knowhow of laboratory experimentation and equipments and Chris Britton \& Ray Zhao for providing assistance with various experiments.

Finally I would like to thank all my lab-mates whose presence made research and experimentation work more fun and easy. 


\title{
Abstract \\ Wettability Alteration in High Temperature and High Salinity Carbonate Reservoirs
}

\author{
Gaurav Sharma, M.S.E. \\ The University of Texas at Austin, 2011
}

Supervisor: Kishore K. Mohanty

The goal of this work is to change the wettability of a carbonate rock from oil wet-mixed-wet towards water-wet at high temperature and high salinity. Only simple surfactant systems (single surfactant, dual surfactants) in dilute concentration were tried for this purpose. It was thought that the change in wettability would help to recover more oil during secondary surfactant flood as compared to regular waterflood. Three types of surfactants, anionic, non-ionic and cationic surfactants in dilute concentrations $(<0.2$ $w t \%)$ were used. Initial surfactant screening was done on the basis of aqueous stability at these harsh conditions. Contact angle experiments on aged calcite plates were done to narrow down the list of surfactants and spontaneous imbibition experiments were conducted on field cores for promising surfactants. Secondary waterflooding was conducted in cores with and without the wettability altering surfactants.

It was observed that barring a few surfactants, most were aqueous unstable by themselves at these harsh conditions. Dual surfactant systems, a mixture of a non-ionic and a cationic surfactant increased the aqueous stability of the non-ionic surfactants. One 
of the dual surfactant system, a mixture of Tergitol NP-10 and Dodecyl trimethyl ammonium bromide, proved very effective for wettability alteration and could recover $70-80 \%$ of OOIP during spontaneous imbibition. Secondary waterflooding with the wettability altering surfactant (without alkali or polymer) increased the oil recovery over the waterflooding without the surfactants (from $29 \%$ to $40 \%$ OOIP). Surfactant adsorption calculated during the coreflood showed an adsorption of $0.24 \mathrm{mg} \mathrm{NP}-10 / \mathrm{gm}$ of rock and $0.20 \mathrm{mg} \mathrm{DTAB} / \mathrm{gm}$ of rock. A waterflood done after the surfactant flood revealed change in the relative permeability before and after the surfactant flood suggesting change in wettability towards water-wet. 


\section{Table of Contents}

List of Tables ........................................................................................

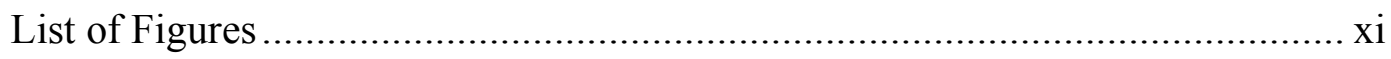

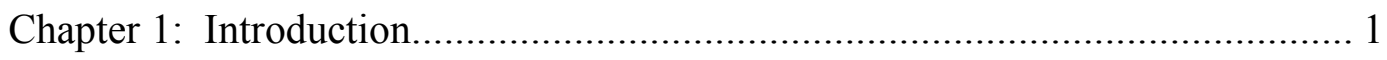

1.1 Goal of this study ............................................................... 1

1.2 Outline of this thesis ................................................................. 2

Chapter 2: Background .............................................................................. 3

2.1 Enhanced oil Recovery ........................................................... 3

2.2 Reservoir Wettability ............................................................... 4

2.2.1 Types of reservoir wettability ......................................... 5

2.3 Factors affecting the original wettability ..................................... 7

2.4 Effect of wettability on waterflooding .............................................. 8

2.5 Mechanism for Wettability alteration in oil-wet carbonates............... 12

2.6 Laboratory measurement of wettability ....................................... 17

2.6.1 Contact angle method ................................................... 19

2.6.2 Amott test.................................................................. 21

2.6.3 Spontaneous Imbibition.............................................. 23

2.6.3.1 Scaling of Spontaneous Imbibition............................ 24

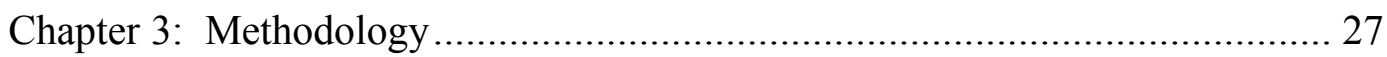

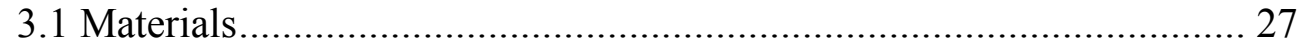

3.1.1 Formation and Injection brine ..................................... 27

3.1.2 Reservoir core plugs.................................................. 28

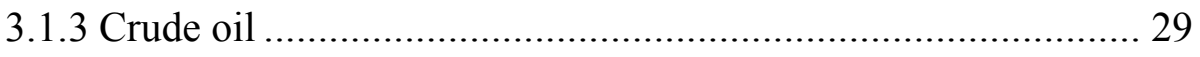

3.1.4 Surfactants ............................................................... 30

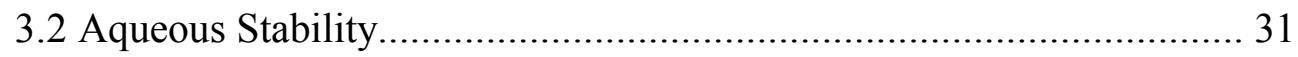

3.3 Contact Angle Studies.............................................................. 33

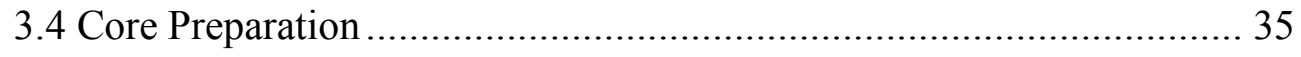

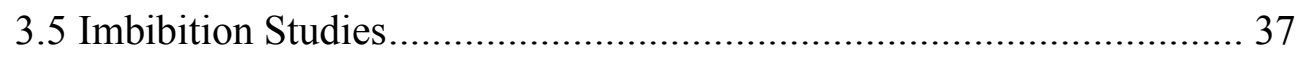

viii 
3.6 Water flood and secondary surfactant flood ..................................... 38

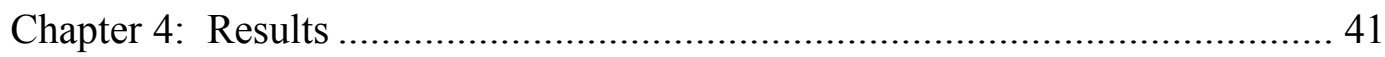

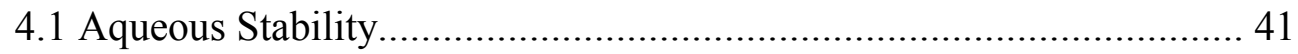

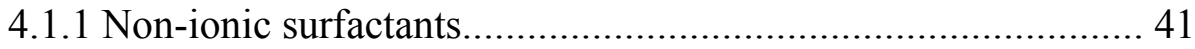

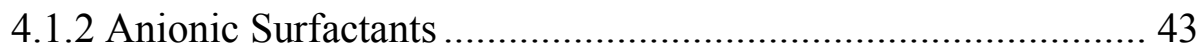

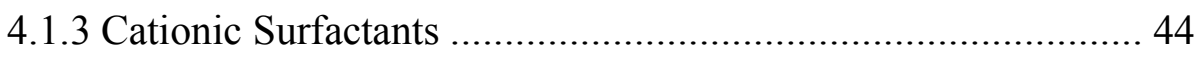

4.1.4 Dual Surfactant Systems........................................................ 45

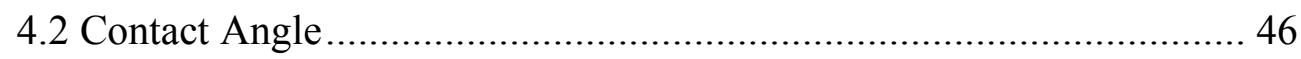

4.2.1 Non-ionic surfactants........................................................... 47

4.2.2 Anionic Surfactants .............................................................. 48

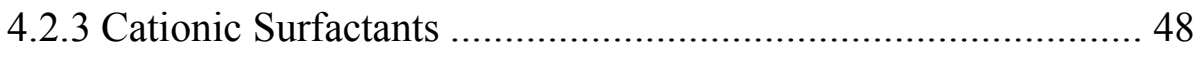

4.2.4 Dual surfactant systems ..................................................... 55

4.2.5 Effect of divalent ions on wettability alteration........................ 56

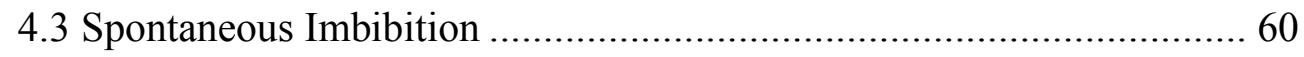

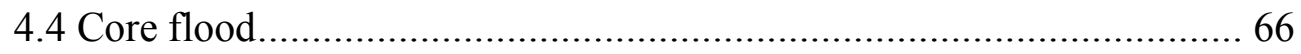

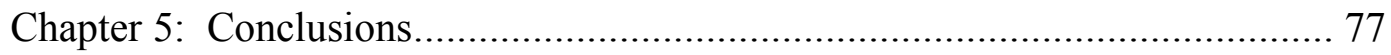

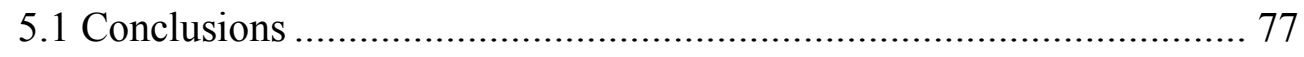

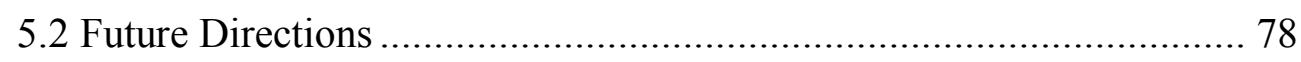

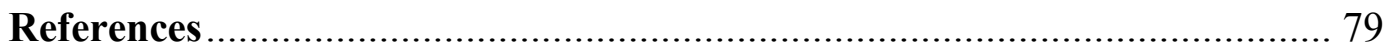




\section{List of Tables}

Table 3-1: Composition of injection and formation brines .............................. 28

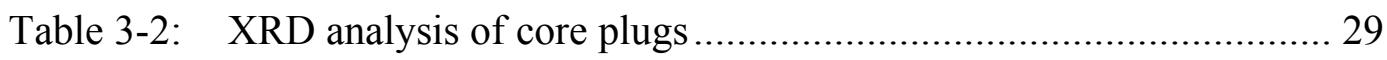

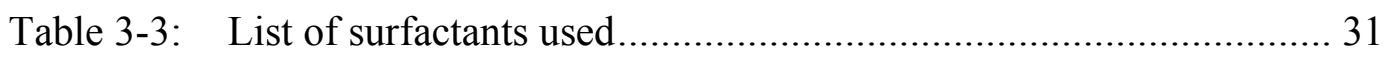

Table 4-1: Interfacial tension of the surfactants tested at $0.2 \mathrm{wt} \%$ surfactant concentration with oil to injection brine ratio of $\sim 100$ at $25^{\circ} \mathrm{C} \ldots . . .45$

Table 4-2: Properties of dual surfactant mixtures tested.................................. 46

Table 4-3: Composition of brines with varying divalent ion concentration ..... 56

Table 4-4: Results of contact angle experiments ........................................... 57

Table 4-5: Spontaneous imbibition tests with and without surfactants ............ 62

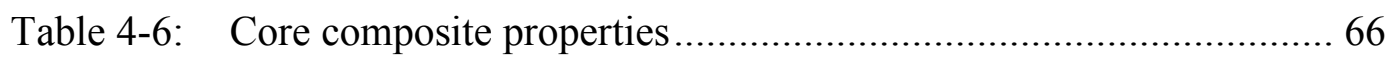

Table 4-7: Summary of core flood results......................................................... 69

Table 4-8: Summary of core flood results....................................................... 72 


\section{List of Figures}

Figure 2-1: Capillary pressure curves for a strongly water-wet (left) and strongly oilwet rock (right) (Anderson 1987) 5

Figure 2-2: Pore scale fluid distribution in the rocks with different types of wetness 6

Figure 2-3: Effect of wettability on relative permeability (Anderson 1987)........ 9

Figure 2-4: Oil recovery vs. brine injected for waterfloods with Amott-Harvery wettability index between 1.0 to -0.5 (Morrow 1990) 10

Figure 2-5: Oil recovery (a) and Sor (b) vs. wettability for 50 slow rate waterfloods (Jadhunandan and Morrow 1995) 12

Figure 2-6: Suggested mechanism for the wettability alteration induced by seawater (Tweheyo, 2006) 13

Figure 2-7: Increase in water wetness by dilution of seawater evident by contact angle (Yousef 2010). 14

Figure 2-8: Increase in oil recovery with sequential flooding using diluted seawater (Yousef 2010) 15

Figure 2-9: Mechanism for spontaneous imbibition of anionic surfactant into oil-wet carbonate. (Red circles are anionic surfactant head groups, black squares are polar components from the crude oil ) 16

Figure 2-10: Mechanism for spontaneous imbibition of cationic surfactant into oilwet carbonate (Blue circles are cationic surfactant head groups; black squares are polar components from crude oil)............................... 16

Figure 2-11: Qualitative methods for wettability measurement ........................... 18

Figure 2-12: Quantitative methods for wettability measurement ......................... 18 
Figure 2-13: Contact angle and force balance on oil/water/rock 19

Figure 2-14: Difference between true and apparent contact angle on rough surface20

Figure 2-15: Capillary pressure curve illustrating the steps/parameters needed for calculation of Amott-Harvey index. 23

Figure 3-1: Sequence of experimental steps performed during this study ........ 27

Figure 3-2: SARA analysis of dead oil ................................................... 30

Figure 3-3: $0.2 \mathrm{wt} \%$ of NP-10 in DI water (left) and in injection brine (right) at $50^{\circ} \mathrm{C}$ 32

Figure 3-4: Polished calcite plates 33

Figure 3-5: An optical cell (left) and closeup of calcite plate inside an optical cell containing surfactant solution. 34

Figure 3-6: Imbibition cell (left), closeup of core in surfactant solution (middle) and closeup of core in formation brine (right) ................................ 37

Figure 3-7: Schematic of core flood apparatus ...................................... 38

Figure 4-1: Cloud point of NP ethoxylates as a function of the number of ethoxy groups 42

Figure 4-2: Cloud point of 15-S-ethoxylates as a function of the number of ethoxy groups 43

Figure 4-3: Contact angle in Nonyl Phenol ethoxylates............................. 50

Figure 4-4: Contact angle in 15-S ethoxylates......................................... 52

Figure 4-5: Contact angle in anionic surfactants ....................................... 53

Figure 4-6: Contact angle in cationic surfactants...................................... 54

Figure 4-7: Contact angle in dual surfactant systems ................................. 55

Figure 4-8: Contact angle experiment using various brines ........................... 60

Figure 4-9: Oil recovery during imbibition vs. time .................................. 65

$$
\text { xii }
$$


Figure 4-10: Oil recovery during imbibition vs. dimensionless time ................6 65

Figure 4-11: Oil recovery during water-flood and modified water-flood ........... 67

Figure 4-12: Pressure drop during water-flood and modified water-flood ......... 67

Figure 4-13: Surfactant concentration in effluent for modified water flood ........ 70

Figure 4-14: Relative permeability calculation for waterflood before surfactant flood

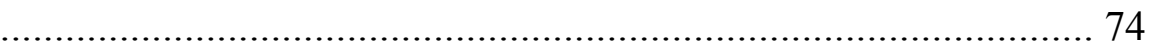

Figure 4-15: Relative permeability calculation for waterflood post surfactant flood74

Figure 4-16: Whole BPR (left), fluid chamber (middle) and spring loaded piston

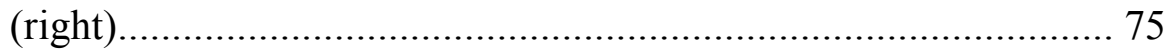




\section{Chapter 1: Introduction}

Approximately half of the world's discovered oil reserves are in carbonate reservoirs and many of these reservoirs are naturally fractured (Roehl and Choquette 1985). With about 3,000 billion barrels of remaining oil in place and more than 3,000 trillion cubic feet of gas in place, carbonates present us with some of the greatest challenges and opportunities to develop new technologies and processes or refine existing ones (Schlumberger, 2011). Majority of fields among the top 10 oil fields (by recoverable reserves) are carbonates. Carbonate reservoirs often have a high degree of heterogeneity and the pore structure is complex. Due to microscopic oil trapping and macroscopic bypassing, waterflooding in carbonate reservoirs is often poor (Manrique et. al. 2006). Improved oil recovery from oil-wet, low-permeability carbonate reservoirs is a great challenge.

Wettability alteration is one of the methods to improve the oil recovery from carbonate reservoirs. The carbonate rocks are often mixed-wet to oil-wet because of the positive zeta potential of the rock surface, the hardness of the brine and the presence of apshaltenes and organic acids in the oil. Recovery from oil-wet reservoirs by water flooding tends to be slower than that of water-wet reservoirs. By altering the wettability of the reservoir to preferentially water-wet (by the addition of surfactants or other chemicals) one can enhance the rate of oil recovery and reduce the amount of macroscopic bypassing.

\subsection{GOAL OF THIS STUDY}

The goal of this study is to identify a wettability altering agent that can be added to waterflood which would change wettability and improve oil recovery in a secondary waterflooding in a non-fractured carbonate rock. Surfactants targeted are the ones which 
when used in dilute concentration with injection brine (sea water) are able to alter wettability for a high temperature, high salinity carbonate reservoir. The motivation behind this approach is to keep the injection architecture similar to that of waterflood. This would involve much lower capital investment and operating costs, leading to favorable economics compared to other EOR methods.

The reservoir studied in these experiments is a carbonate reservoir (mainly limestone with a small amount of dolomite and trace amounts of quartz and clays). The reservoir temperature is $100{ }^{\circ} \mathrm{C}\left(212^{\circ} \mathrm{F}\right)$. The salinity of the connate water is about $200,000 \mathrm{ppm}$ and the reservoir is currently being waterflooded with with a brine of lower salinity $\left(\sim 60,000 \mathrm{ppm}\right.$ salinity with $650 \mathrm{ppm}$ of $\mathrm{Ca}^{+2}$ and $2110 \mathrm{ppm}$ of $\left.\mathrm{Mg}^{+2}\right)$. The surfactants tried for this study were mainly non-ionic with a few anionic and cationic surfactants. During this research, mostly simple surfactant systems (single surfactant, dual surfactants) were tried; no alcohols or polymers were used. A few surfactant systems have been identified on the basis of their aqueous stability and wettability alteration. A study on the effect of ions in injection brine on wettabilitty alteration for this reservoir was also done. Finally, waterfloods were conducted with or without these surfactants.

\subsection{OUTLINE OF THIS THESIS}

This chapter gives the introduction and objective of the thesis. Chapter 2 discusses the definition and background of various concepts used in this work. Literature review is done in each section to develop the understanding of the topic. Chapter 3 introduces the experimental materials, equipments and experimental procedures used in this work. In chapter 4 experimental results are presented and discussed. Chapter 5 lists the conclusions drawn from this study and recommendation of future work is also included. The references used in the thesis are listed at the end. 


\section{Chapter 2: Background}

This chapter defines reservoir wettability and covers the background on the importance of wettability alteration for waterflooding. It also reviews methods for laboratory estimation of wettability and mechanisms to alter wettability.

\subsection{ENHANCED OIL RECOVERY}

There are 3 stages of oil production from oil reservoirs: primary, secondary, and tertiary recovery. Primary recovery is the first stage of oil production due to the pressure of the reservoir and it requires no external assistance. The oil driving mechanisms include: natural water from aquifer displacing oil upward into the well, expansion of the natural gas at the top of the reservoir, expansion of gas initially dissolved in the crude oil, and gravity drainage resulting from the movement of oil within the reservoir where the wells are located. Recovery factor during the primary recovery stage is typically $5-15 \%$.

Secondary recovery methods are applied to a well after primary oil recovery when the reservoir is not able to produce oil on its own. These recovery methods supply external energy into the reservoir in the form of injecting fluids to maintain reservoir pressure, hence replacing or increasing the natural reservoir drive. This is achieved chiefly by injection of water (sea water or aquifer water). On average, the recovery after primary and secondary oil recovery operations is between 20 and $40 \%$ of the initial oil in place.

After secondary oil recovery, oil is left in the zones that were not swept by the water during waterflood. Major reasons can be attributed to bypassing of oil in lowpermeability strata or areas, coning or fingering, under running or over-riding by water or gas in displacing more viscous oils, and channeling through natural or induced fractures. Also, there is a significant amount of oil left in the flooded part where oil is trapped in 
reservoir pores due to surface and interfacial forces as residual oil. Tertiary oil recovery methods are applied to recover extra oil from the reservoir after the secondary recovery. Tertiary oil recovery methods are also called Enhanced Oil Recovery (EOR) methods.

Enhanced oil recovery methods can broadly be classified as: thermal, chemical, gas and other methods. Economics plays a major role in considering tertiary methods as they are more expensive than both secondary and primary methods of oil recovery. The enhanced oil recovery method which was used during the course of this study to improve oil recovery from laboratory coreflood of carbonate rocks (at high temperature and high salinity) is wettability alteration.

\subsection{RESERVOIR WETTABILITY}

Wettability is defined as "the tendency of one fluid to spread on or adhere to a solid surface in the presence of other immiscible fluids. Reservoir wettability state refers to the interaction between reservoir rock, brine and crude oil at reservoir temperature and pressure. Wettability is a major factor controlling the location, flow, and distribution of fluids in a reservoir. The wettability of a reservoir sample affects its capillary pressure, relative permeability, waterflood behavior, dispersion, and electrical properties (Anderson 1986). Figure 2-1 shows the reversal in capillary pressure from positive to negative by wettability alteration from strongly water-wet to strongly oil-wet. 

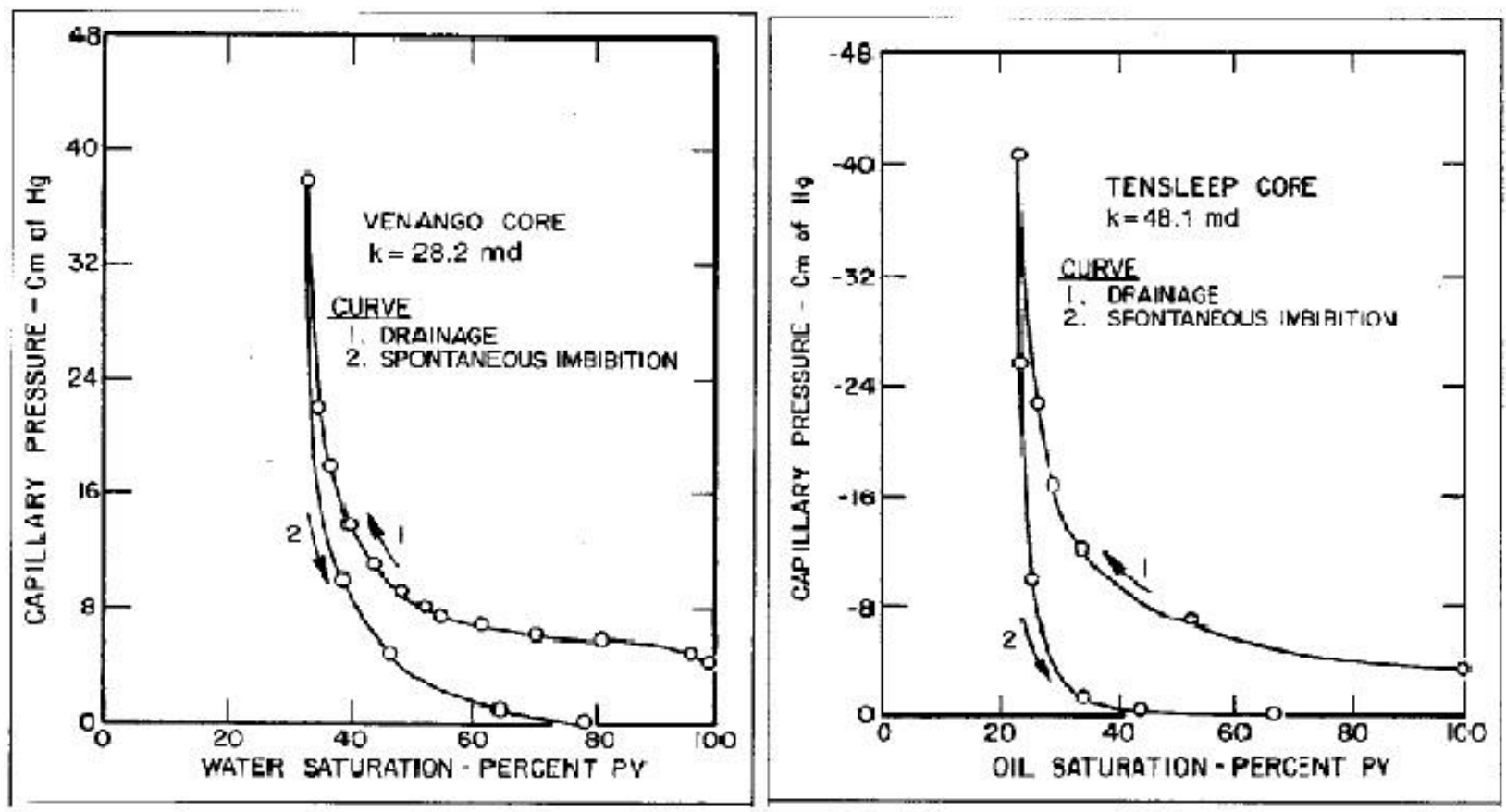

Figure 2-1: Capillary pressure curves for a strongly water-wet (left) and strongly oil-wet rock (right) (Anderson 1987)

\subsubsection{Types of reservoir wettability}

Historically reservoir wettability states have been divided into four main categories by researchers; oil-wet, water-wet, intermediate-wet and fractional wettability. In a rock/oil/brine system, the wettability state defines which fluid is preferentially wetting the rock. If the rock is water-wet, rock has more affinity to the water then oil. So the water spreads onto the rock surface occupying the small pores. The oil remains in the center of pore-space and does not wet the rock surface.

In an oil-wet rock, the rock has more affinity to the oil then water. And the location of the fluids is reversed as compared to water-wet rock.

In a neutrally wet rock, the rock has no strong affinity to both oil and water present in the pore space. This is also known as intermediate wettability. 
Fractional wettabilty is a fourth kind of wettability state when heterogeneous forms of wettability exist in reservoir rock. In fractional wettability, oil is strongly adsorbed in certain areas of rock, so a portion of rock is strongly oil-wet, while the rest is strongly water-wet. Generally, the internal surface of reservoir rock is composed of many minerals with different surface chemistry and adsorption properties, which may lead to variations in wettability (Anderson 1986). Figure 2-2 is a cartoon of water-wet, mixed wet and oil-wet rock at pore level.
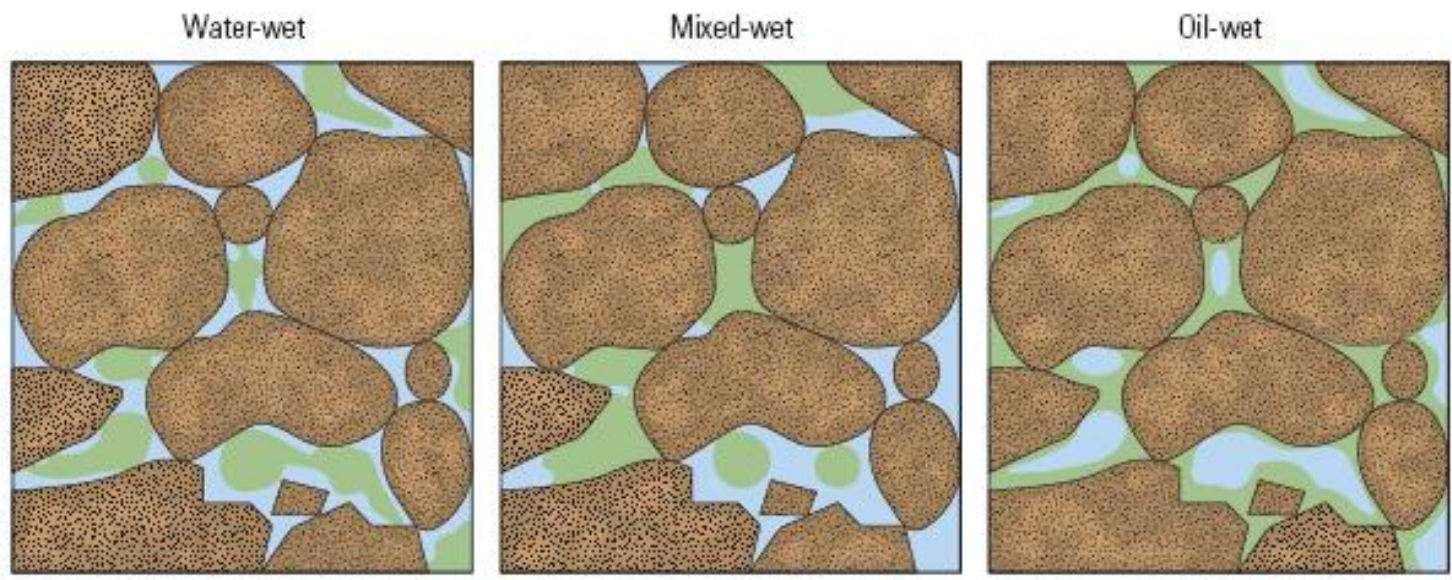

$\square$ 0il $\square$ Brine (water) $\square$ Rock grains

Figure 2-2: Pore scale fluid distribution in the rocks with different types of wetness

Salathiel (1973) introduced the concept of mixed wettability which is a special kind of fractional wettability. In mixed wettability as proposed, the water occupies the small pores of the rock and wets them. But the oil occupies the big pores of the rock and wets them resulting into a small but finite non-zero permeability to oil at very low oil saturations. The oil films in the big pores are connected to give such a drainage phenomenon. When oil invades water filled rock, it occupies the big pores but is not able to invade smaller pores due to capillary pressure. Salathiel (1973) has emphasized on the 
dependence of surface-active agents present in crude oil to render the surface oil wet. But it is important to understand how the thin water films present even in the big pores break and give away to the oil continuously invading the rock. Researchers have worked on stability of these water films and the issue of critical thickness when they break.

\subsection{FACTORS AFFECTING THE ORIGINAL WETTABILITY}

Most of the reservoir minerals are originally strongly water-wet. The surface active agents present in crude oil (polar compounds containing oxygen, nitrogen, sulphur) are responsible to alter the wettability of these minerals. These compounds contain polar end which sticks to the rock surface as well as hydrocarbon end which interacts with bulk oil making the mineral oil-wet. These compounds are more prevalent in heavier fractions of crude oil such as resins and asphaltenes. The oxygen compounds are acidic in nature and include phenol and carboxylic acids. The nitrogen compounds such as amides, pyridines, carbazoles, quinolines and porphyrins are generally basic. There are other factors which influence the original reservoir wettability. When the oil invades the rock, the thin water films separate rock surface from the oil. If the oil contains surface active agents which can easily diffuse through the water film, it is easy to render the surface oil wet. Natural surfactants in crude are often sufficiently soluble in water to adsorb onto rock surface after passing through a thin layer of water (Anderson 1986).

Type of mineral surface also determines wettability. Treiber et al. (1972) and Chilingar and Yen (1983) found that carbonate reservoirs are typically more oil-wet than sandstone reservoirs. This occurs because sandstone has a negative surface charge (acidic surface) in water near neutral $\mathrm{pH}$ and carbonates have positively charged weakly basic surfaces. These surfaces preferentially adsorb compounds of opposite polarity through acid-base reactions. The polar compounds (nitrogenous, basic) found in crude oil render 
sandstone oil-wet whereas the acidic compounds (naphthenic acid, carboxylic acid) found in crude oil render carbonates oil-wet.

The salinity, ionic composition and $\mathrm{pH}$ of brine also affect the original reservoir wettability. It was mentioned before how the $\mathrm{pH}$ affects surface charge on mineral surface and thus the adsorption of specific polar compounds in crude oil. There exists $\mathrm{pH}$ below which Sandstones and carbonates have positive surface charge and above which they have negative surface charged. This value is known as point of zero charge (PZC), which is around 2-3 for sandstone and 8-9 for carbonates. The multivalent ions present in brine can reduce the solubility of natural surfactants (polar compounds) in crude and brine thus promoting oil-wetting. They may also enhance the adsorption of these natural surfactants onto rock surface by acting as a bridge between the mineral surface and the adsorbing surfactant (Anderson 1986).

\subsection{EFFECT OF WETTABILITY ON WATERFLOODING}

Reservoir wettability plays an important role during waterflooding. The effect of wettability on oil recovery has been investigated through laboratory displacement tests. Several early examples of laboratory water floods show oil recovery decreasing with decreasing water-wetness. This can be explained as the strong wetting preference of rock for water and associated strong capillary imbibitions forces give the most efficient oil displacement (Morrow 1990).

In a water-wet reservoir, the water relative permeability is low and oil relative permeability is high. In water-flooding strongly water-wet core samples, except for high oil/water viscosity ratios, most of the recoverable oil is produced before water breakthrough; there is very little oil production after water breakthrough. The remaining oil remains trapped by capillary forces as discontinuous droplets of irregular bodies of oil 
separated by continuous water. In an oil-wet (or mixed-wet) reservoir, the water relative permeability is high and oil relative permeability is low. Figure 2-3 and 2-4 compare relative permeability for oil-wet and water-wet rock and plot oil recovery vs. pore volume of brine injected for many laboratory corefloods.

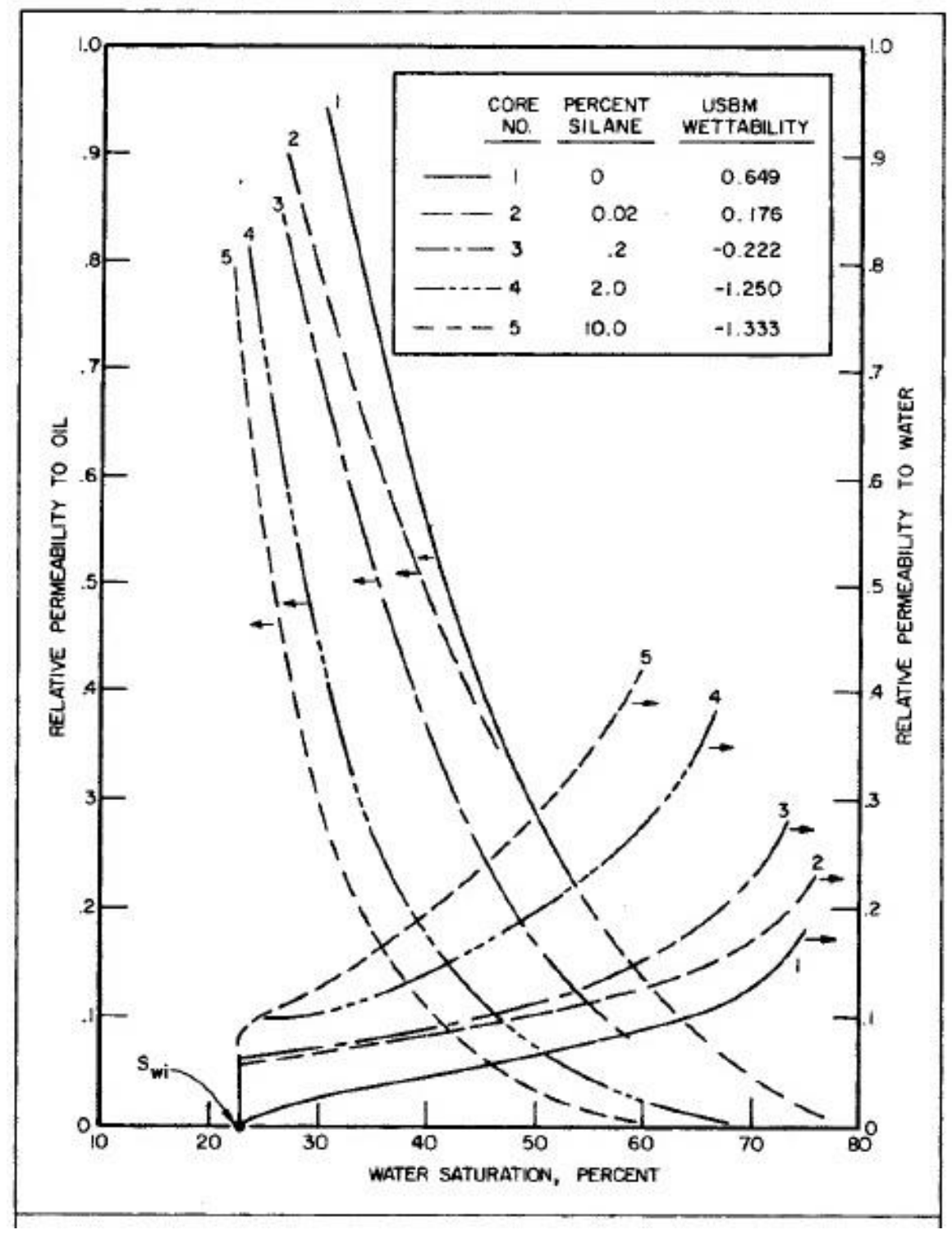

Figure 2-3: Effect of wettability on relative permeability (Anderson 1987) 


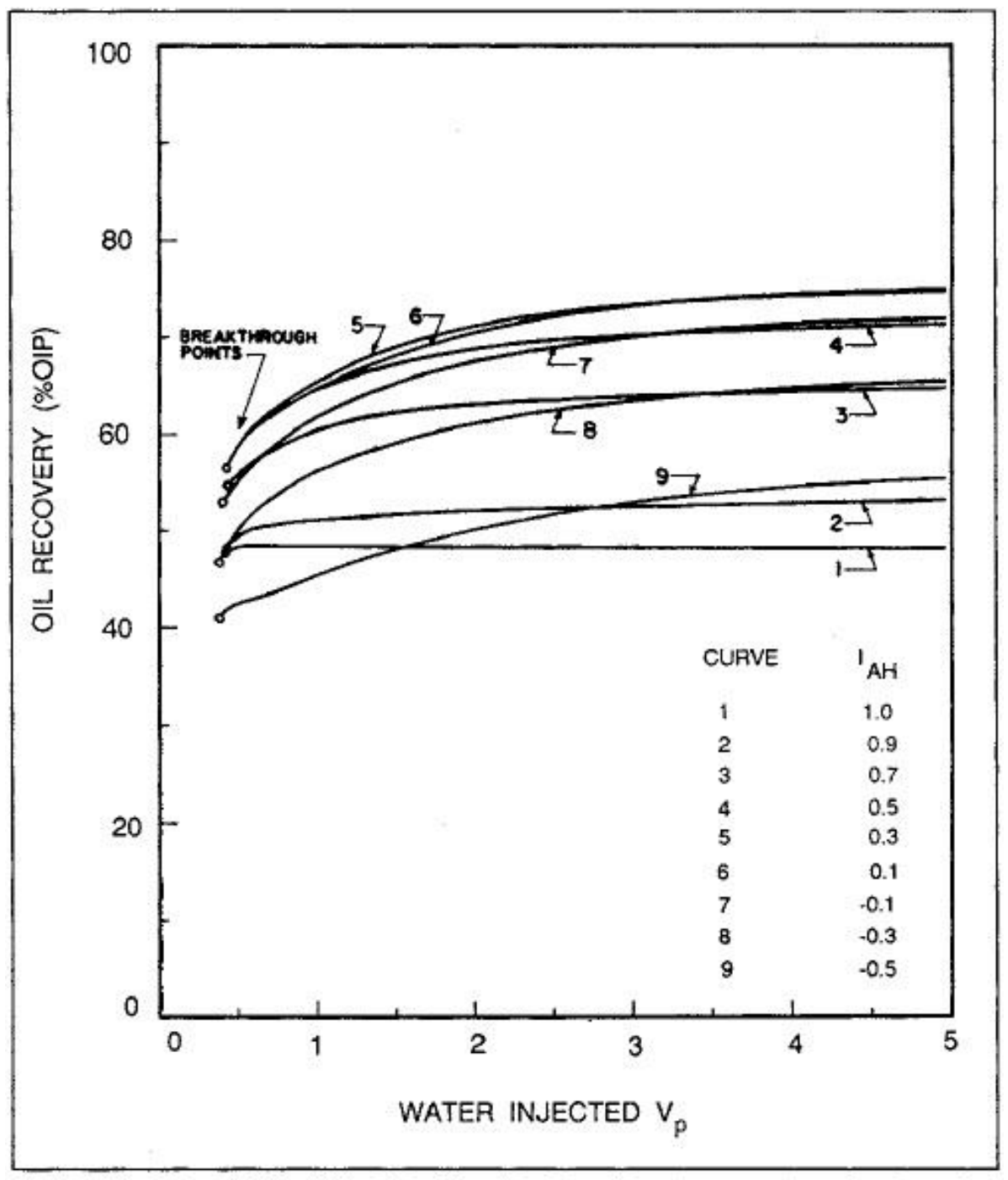

Figure 2-4: Oil recovery vs. brine injected for waterfloods with Amott-Harvery wettability index between 1.0 to -0.5 (Morrow 1990)

In laboratory waterfloods on strongly oil-wet cores, water breaks through early and oil is co-produced with water for many pore volume of water injected. Here, a moderate residual oil saturation (corresponding to the irreducible water saturation of a water-wet sample) remains after extended flooding, and much of the residual oil is retained by capillary forces in the smaller pores and at grain contacts (Salathiel 1973). 
In a mixed-wettability system proposed by Salathiel (1973) which has been explained earlier, very low residual oil saturations can be reached as the water could displace oil from the large pores and little or no oil would be held by capillary forces in small pores or at grain contacts. The residual oil saturation depends on wettability with a minimum for a mixed-wettability lower than either strongly water-wet or oil-wet rock (Salathiel et al. 1973, Jadhunandan and Morrow 1995). It is observed that departure from strongly water-wet conditions significantly reduce oil entrapment. While a variety of distributions were found in systems other than strongly water-wet, none of them showed the extensive trapping of oil in pore bodies that is characteristic of strongly water-wet systems. Morrow (1990) has observed that the mechanism of crude-oil displacement responsible for trapping (snap-off) is inhibited in other systems. Reservoir wettability also affects the bypassing of oil in lower permeability zones. In a water-wet medium, water can be imbibed into bypassed zones by capillary forces and reduce bypassing. In oil-wet media, bypassing is expected to be higher because capillary forces discourage water to invade these bypassed zones. Figure 2-5 below summarizes the results of oil recovery for 50 slow-rate waterfloods with various wettability states at different timestamps (Jadhunandan and Morrow 1995). 

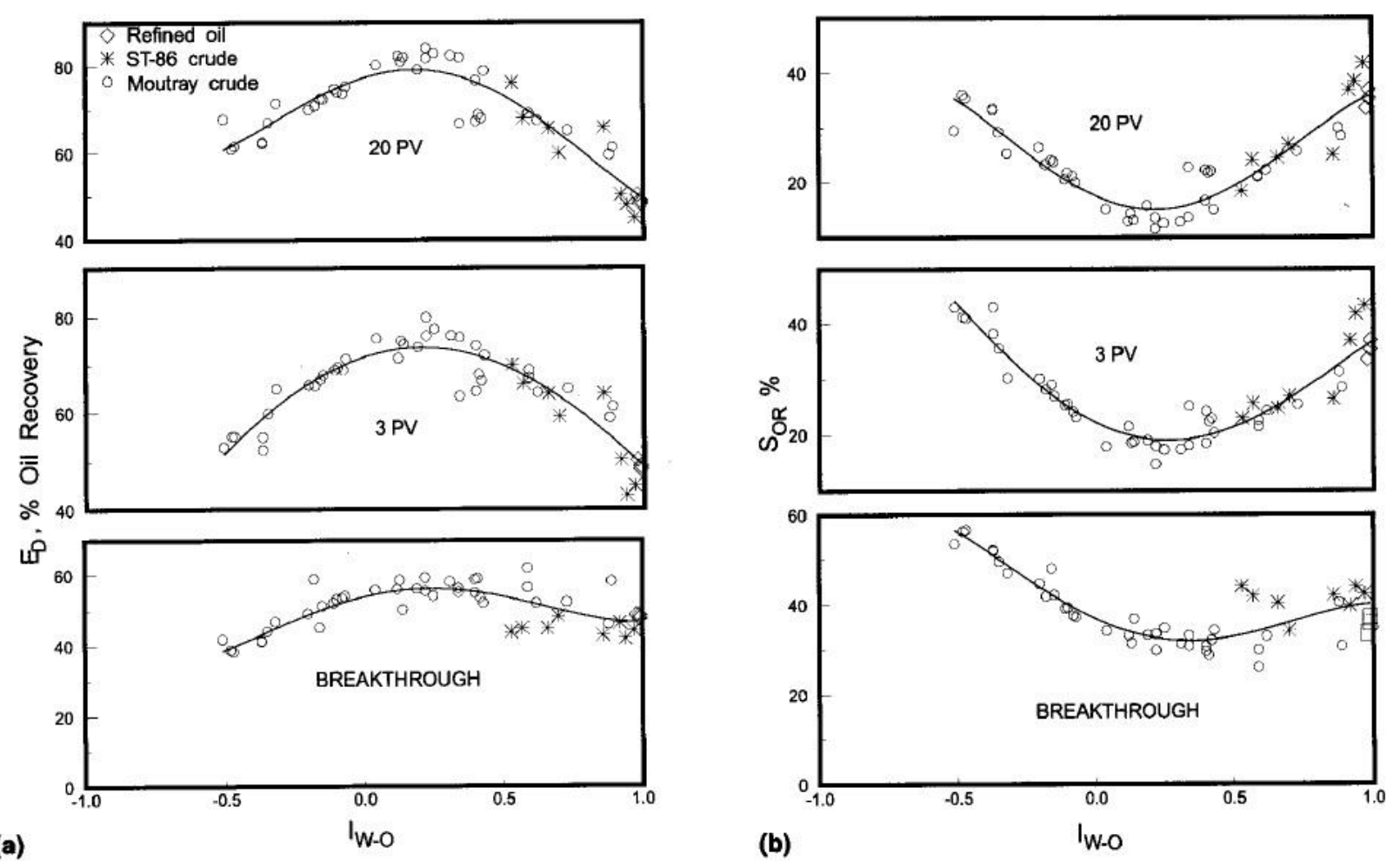

Figure 2-5: Oil recovery (a) and Sor (b) vs. wettability for 50 slow rate waterfloods (Jadhunandan and Morrow 1995)

\subsection{MECHANISM FOR WETTABILITY ALTERATION IN OIL-WET CARBONATES}

There are two main approaches to wettability alteration in originally oil-wet carbonate rocks. The first approach is through a change in the brine ionic composition. Strand et al. $(2006,2008)$ have shown that addition of sulfate and other potential determining ions can change the wettability of originally oil-wet chalk cores at high temperatures (above $90^{\circ} \mathrm{C}$ ). Increase in water-wetness was demonstrated by imbibitions of these brines into originally oil-wet chalk cores. It is hypothesized that sulfate ions replace the adsorbed negatively charged organic acid groups thus making the surface more water-wet. High temperature is important for fast enough kinetics for this ion exchange. 


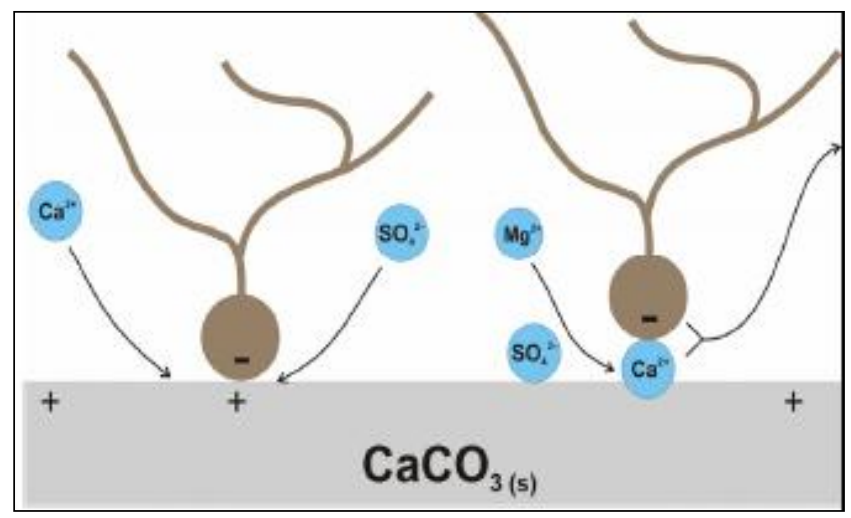

Figure 2-6: Suggested mechanism for the wettability alteration induced by seawater (Tweheyo, 2006)

Tweheyo et al. (2006) has worked on the effect of the ratio of $\mathrm{Ca}^{2+}$ to $\mathrm{SO}^{4-}$ (defined $\beta$ ) in the brine as well as the temperature on wettability alteration and oil recovery through imbibtion in chalks. He has shown that the three ions present in sea water, $\mathrm{Ca}^{2+}, \mathrm{Mg}^{2+}$ and $\mathrm{SO}^{4-}$ acts as potential determining ions, which means that they attach to the rock surface and change its surface charge. The mechanism suggested for wettability alteration on the basis of experiments (Figure 2-6) was that sulphate ions attach to the positively charged chalk surface and balance some of the positive charge on the surface. It promotes the calcium ions present in the brine to get near to the surface (as the electrostatic repulsion is reduced) and bond with the organic compounds adsorbed on the surface, thus detaching them from the surface. The following reaction illustrated the displacement mechanism;

$$
\mathrm{RCOO}^{-}-\mathrm{CaCO}_{3}(\mathrm{~s})+\mathrm{Ca}^{2+}+\mathrm{SO}^{2-}=\mathrm{RCOOCa}^{+}+\mathrm{CaCO}_{3}(\mathrm{~s})+\mathrm{SO}^{2-}
$$

The role of sulphate ions is like a catalyst to promote concentration of calcium ions near the surface. He has also suggested that the $\mathrm{Mg}^{2+}$ ions present in the brine displace $\mathrm{Ca}^{2+}$ ions on the rock surface (which are bonding with the organic molecules). This reaction is also catalysed by the presence of $\mathrm{SO}^{2-}$ ions. 
Yousef et al. (2010) have shown that diluting the injection brine salinity for a high temperature and high salinity carbonate reservoir improves the wettability towards more water-wet (Figure 2-7) and gives an additional oil recovery of almost 20\% over waterflooding using sea brine (Figure 2-8). They found that the incremental recovery over waterflooding (tertiary recovery) can be attributed to wettability alteration which was confirmed by nuclear magnetic resonance (NMR) measurements. They found that the connectivity between micropores and macropores was improved as a result of microscopic dissolution by diluting the injection brine.
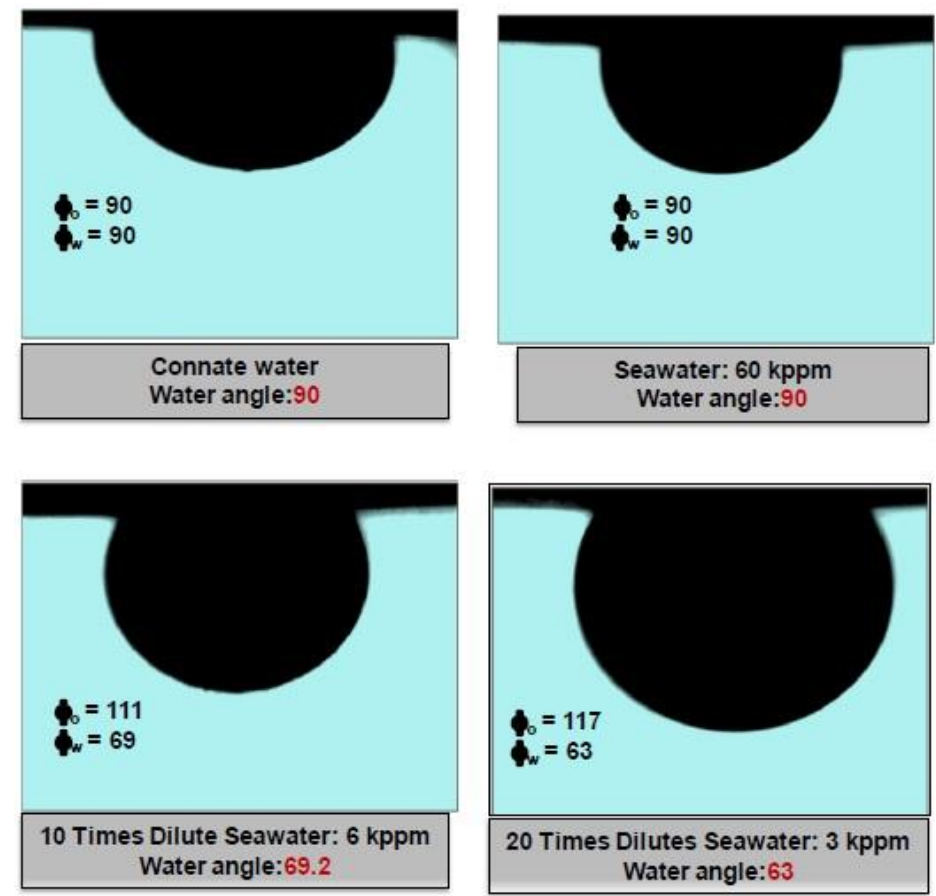
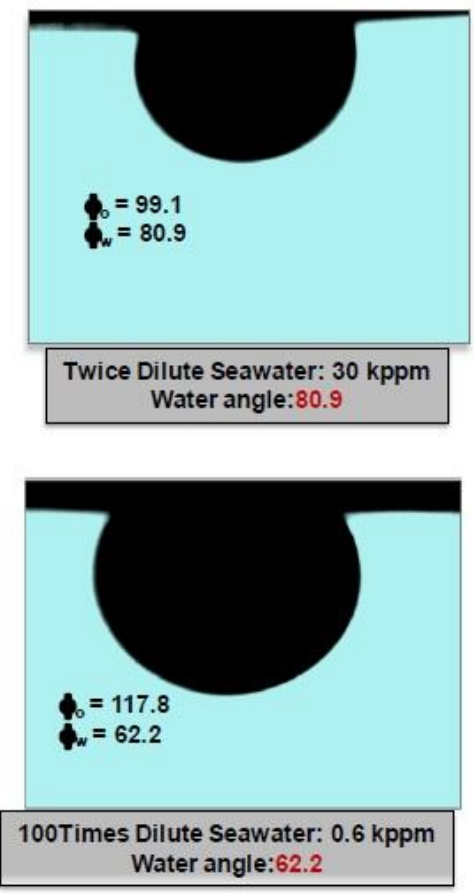

Figure 2-7: Increase in water wetness by dilution of seawater evident by contact angle (Yousef 2010) 


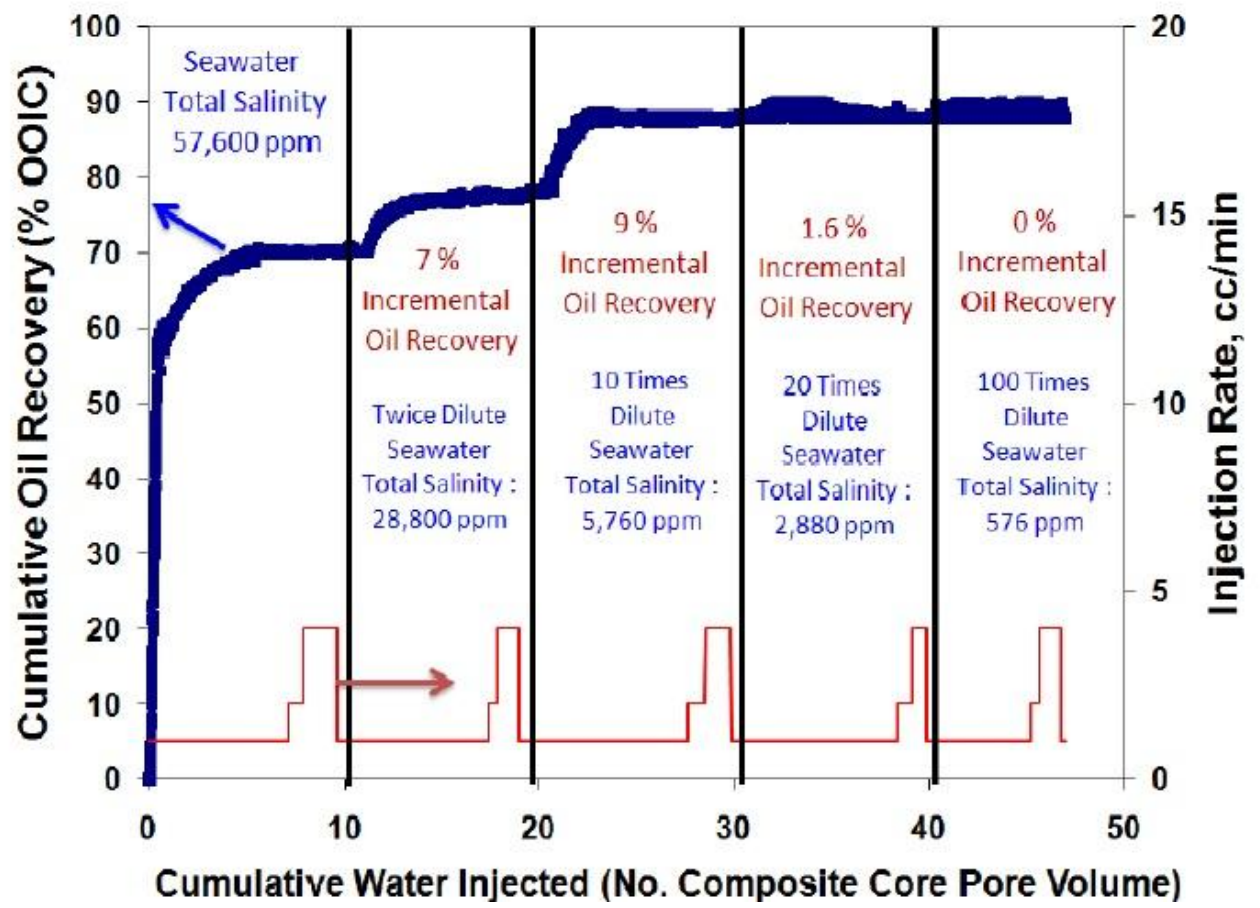

Figure 2-8: Increase in oil recovery with sequential flooding using diluted seawater (Yousef 2010)

The second approach involves surfactants to alter the wettability of carbonate rocks, generally from oil-wet to intermediate or water-wet. Standnes and Austad (2000, 2003) have conducted a series of studies on oil recovery from oil-wet chalk cores by use of cationic surfactant solutions. They have shown that cationic surfactants, such as Dodecyl trimethyl ammonium bromide (DTAB), are quite effective (recovery $\sim 70 \%$ OOIP) in imbibing water into originally oil-wet cores at concentrations higher than their CMC $(\sim 1 \mathrm{wt} \%)$. The imbibition mechanism is proposed as the formation of ion-pairs by the interaction between surfactant monomers and adsorbed organic carboxylates from the crude oil (Figure 2-9). They have shown that the oil recovery from imbibition experiments is delayed as the salinity increases because of a decrease in the CMC of the 
surfactant, which further proves their hypothesis on interaction of surfactant monomers and adsorbed organic molecules. This process can be effective at low temperatures.

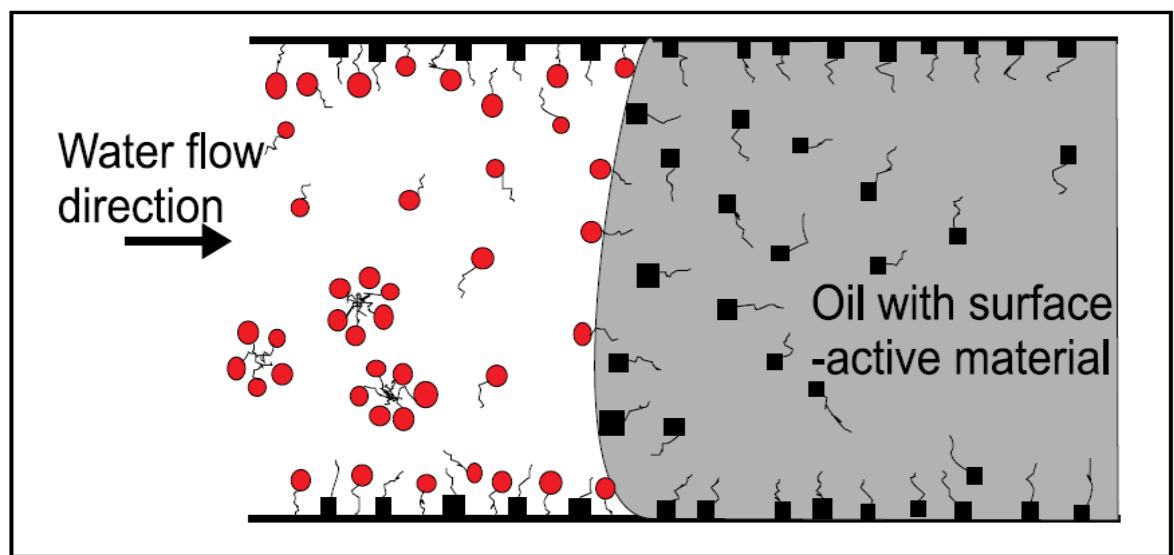

Figure 2-9: Mechanism for spontaneous imbibition of anionic surfactant into oil-wet carbonate. (Red circles are anionic surfactant head groups, black squares are polar components from the crude oil )

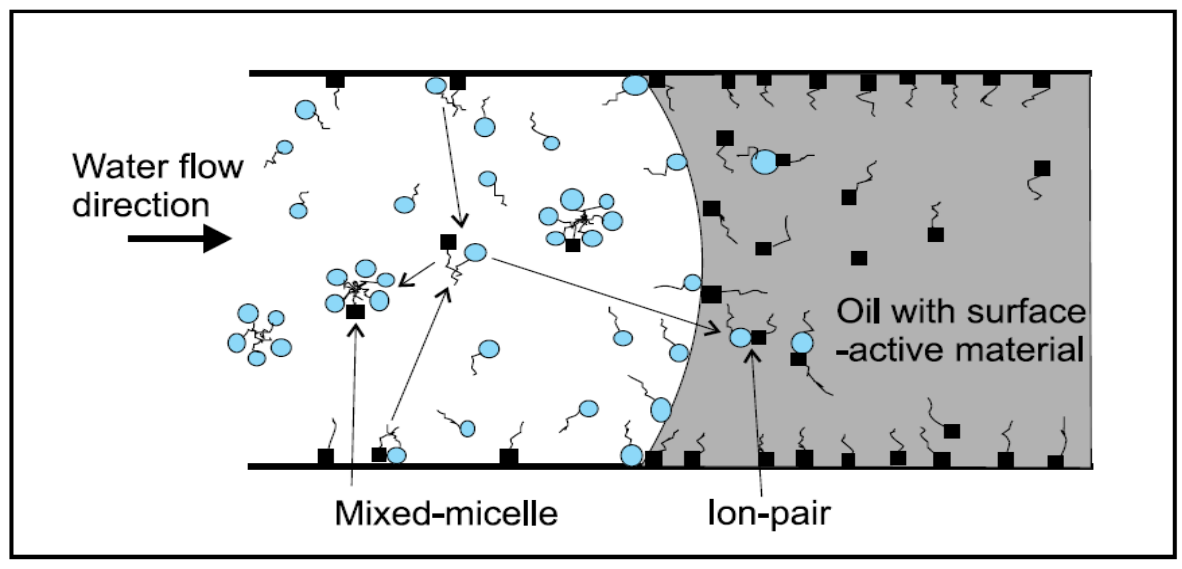

Figure 2-10: Mechanism for spontaneous imbibition of cationic surfactant into oil-wet carbonate (Blue circles are cationic surfactant head groups; black squares are polar components from crude oil)

Anionic (Seethepalli et al. 2004; Adibhatla \& Mohanty 2008; Hirasalki \& Zhang 2004) and nonionic (Xie et al. 2004; Wu et al. 2006) surfactants have also been identified which alter wettability of originally oil-wet carbonate rocks. These surfactants alter the 
wettability by micellar solubilization of adsorbed hydrophobic components. More than $60 \%$ of the original oil can be recovered from initially oil-wet cores by dilute $(0.05 \mathrm{wt} \%)$ alkaline surfactant solution imbibition at the room temperature (Seethepalli et al. 2004). The adsorption of anionic surfactants on calcite mineral can be suppressed by the addition of an alkali. The anionic surfactant solution imbibition process has been modeled and the simulator results match the experimental results at the laboratory-scale (Adibhatla \& Mohanty 2008). The simulations show that increase in water-wettability increases oil relative permeability which enhances the rate of oil drainage by gravity. Anionic surfactant solution imbibes from the sides (and the bottom) and oil is recovered from the top in imbibitions experiments. Gupta \& Mohanty (2010) have studied the effect of temperature on the wettability alteration with anionic and nonionic surfactants at low salinity and hardness of the brine.

Not much literature is available on wettability altering surfactant formulations for carbonate reservoirs at high temperature $(>90 \mathrm{C})$ and high salinity $(>50,000 \mathrm{ppm}$ with hardness). Harsh conditions like high temperature and salinity restrict the use of many surfactants mainly due to aqueous instability. During this research, it was tried to look for simple surfactant systems (single, dual surfactants) which would change the wettability of carbonate reservoir at harsh conditions. For some of the surfactants like the homologous series of Nonyl phenol surfactants and Tergitrol surfactants, we have varied one structural property (which is the no. of ethoxy groups) and observed the trend in wettability alteration. More work can be done on why some surfactants work for carbonate reservoirs at these conditions and why some don't.

\subsection{LABORATORY MEASUREMENT OF WETTABILITY}


There are various methods available to measure wettability under laboratory conditions. Anderson (1986) divides them into quantitative and qualitative methods. Some of the methods are shown in the figure below (Figure 2-11 and Figure 2-12);

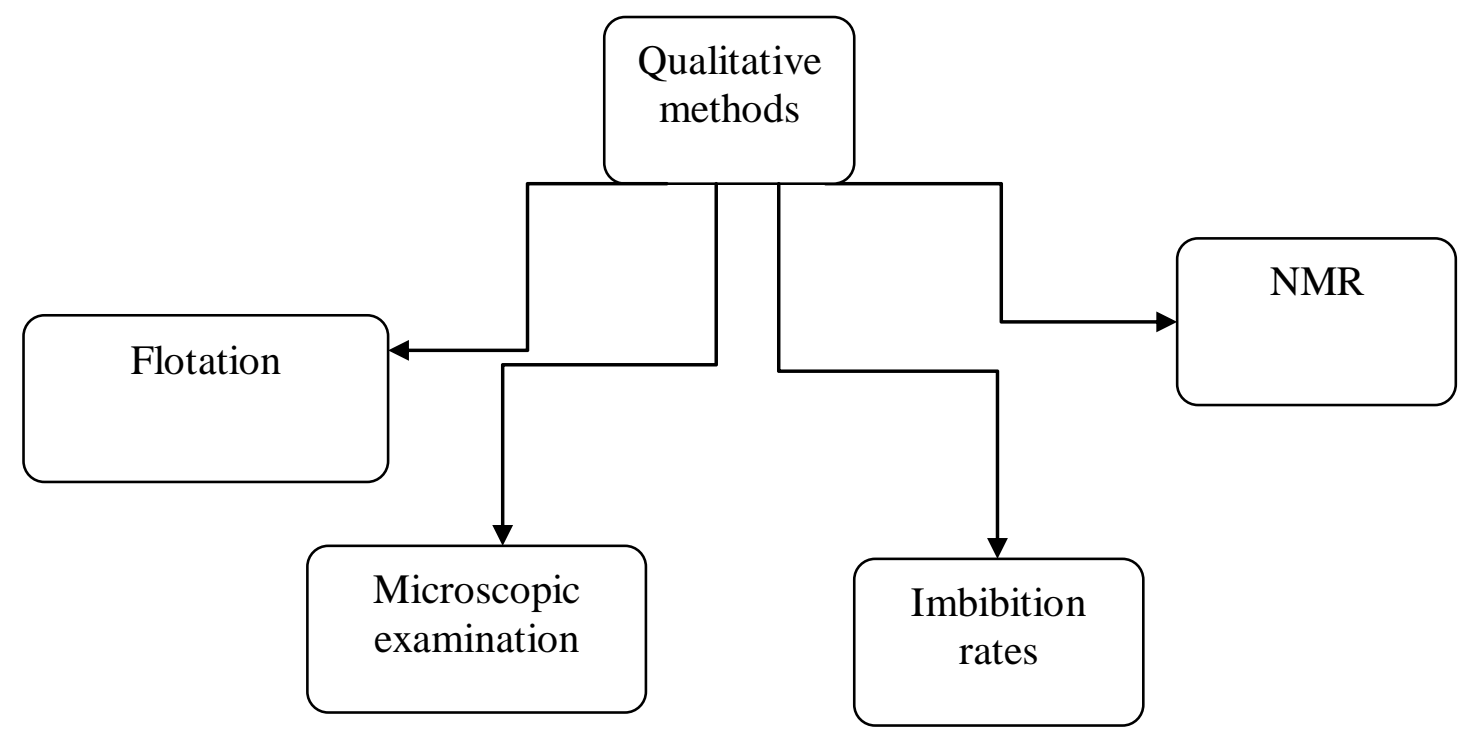

Figure 2-11: Qualitative methods for wettability measurement

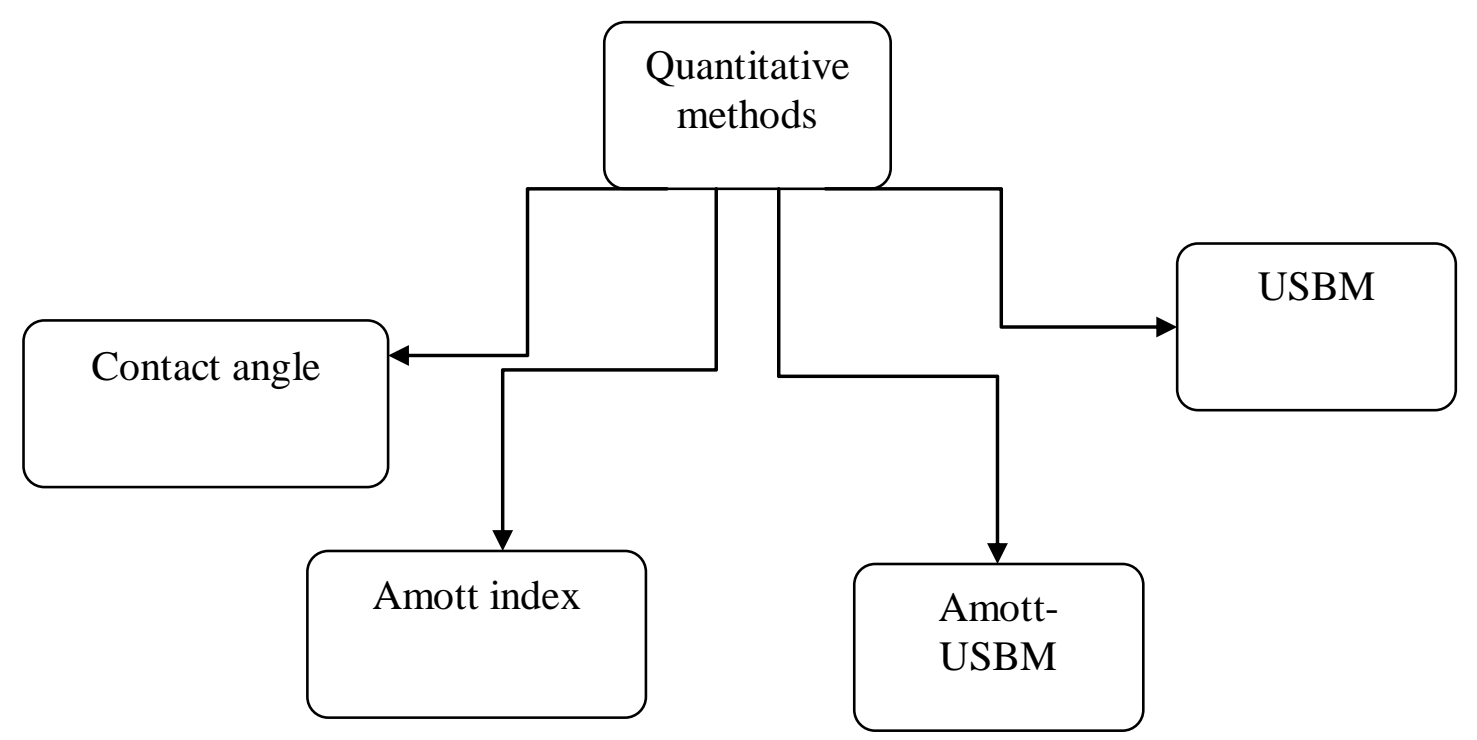

Figure 2-12: Quantitative methods for wettability measurement 


\subsubsection{Contact angle method}

Contact angle measurement is one the widely used method to observe the wettability as well as wettability alteration (as we will discuss in the methodology section).As per the definition of wettability, it is the tendency of one fluid to spread over the solid in presence of another fluid. Figure 2-13 depicting a drop of oil on the solid in presence of water.

\section{A) Water-Wet}

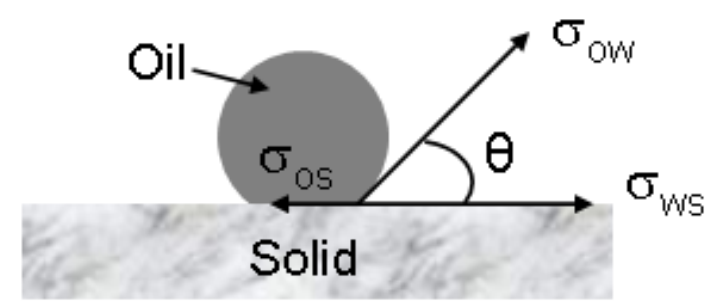

B) Oil-Wet

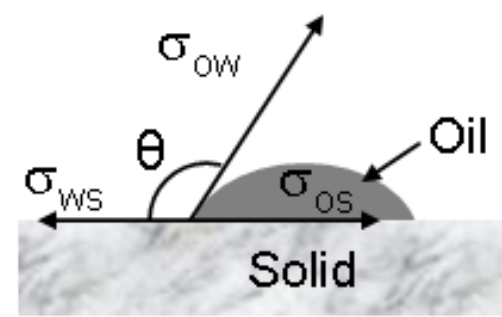

Figure 2-13: Contact angle and force balance on oil/water/rock

Here water is present in excess. A force balance on this system would give us the Young's equation,

$$
\sigma_{o w} \cos \vartheta=\sigma_{o s}-\sigma_{w s}
$$

Where,

$\sigma_{o w}=$ interfacial tension between the oil and water

$\sigma_{o s}=$ interfacial tension between the oil and solid

$\sigma_{w s}=$ interfacial tension between the water and solid

In above equation, theta is a measurable quantity which gives a quantitative measure of wettability. It is the contact angle which oil makes with the solid. By convention, contact angle is measured through water. When the contact angle is less than 
$70^{\circ}$, the rock surface is water-wet, it is oil-wet when the contact angle is above $120^{\circ}$ and intermediate wet when the contact angle is $70^{\circ}-120^{\circ}$.

In the laboratory, a surface aged with oil is allowed to form drops in presence of water/surfactant solution. For a true contact angle to be observed, the oil droplet should have reached adsorption equilibrium with the surface which might require thousands of hours of interface-aging time. Mineral crystals are used in place of reservoir rock (calcite crystal for carbonates and quartz for sandstone reservoirs) and if possible core samples with very low permeability are grinded and polished for use in this method. It is important to have a smooth surface for a good estimation of contact angle. Rough surface, contains peaks and valleys (Figure 2-14), so the liquid drop will generally be attached to a surface that is not horizontal.
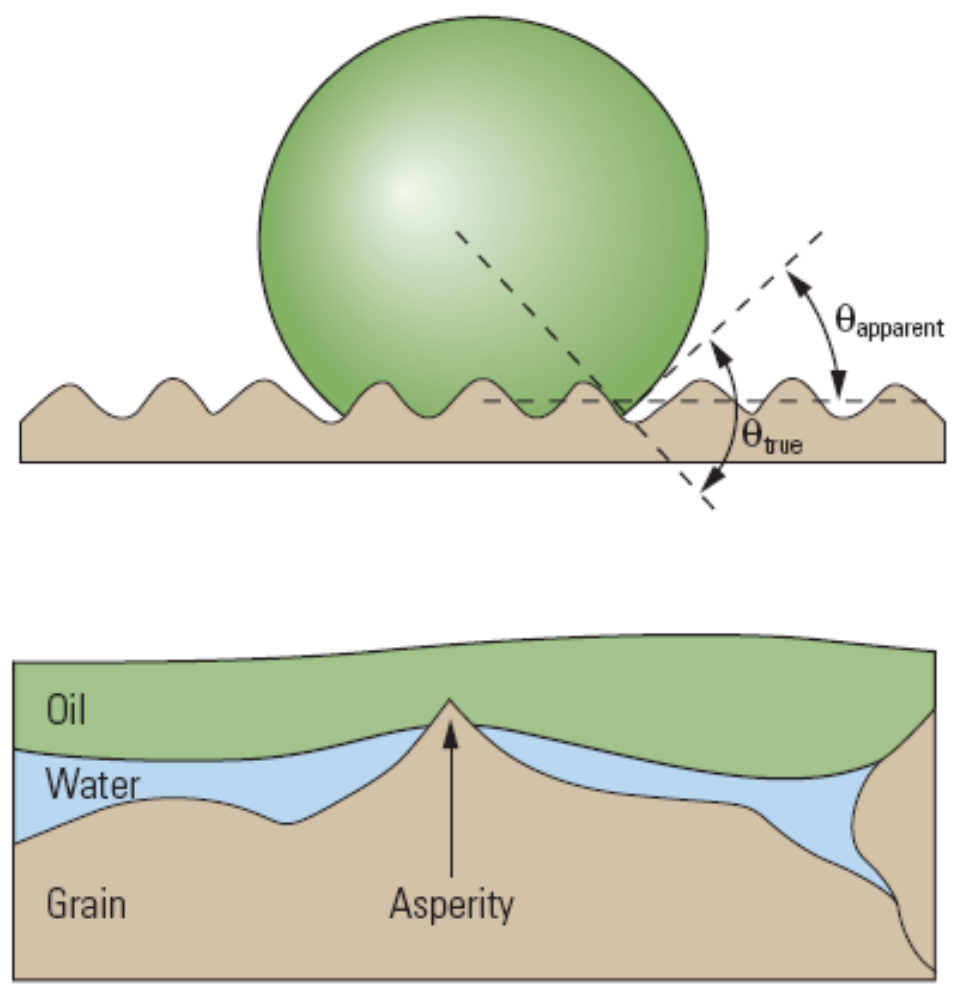

Figure 2-14: Difference between true and apparent contact angle on rough surface 
The macroscopically observed contact angle will not be the same as the true contact angle on a microscopic scale. Rough surface provides large number of metastable states of the drop to exist with different contact angles. It is also important to avoid contamination (on the solid surface in form of strongly adsorbed coatings, in the bulk fluid) while doing the experiment because it is sensitive to that. Measurements made on reservoir rocks cannot take into account the heterogeneity of the rock surface. For these reasons, contact angle measurements have the issue of hysteresis and moderate repeatability. Hence this experiment was used as a first screening test to evaluate surfactants for wettability alteration.

\subsubsection{Amott test}

Amott test is based on the spontaneous imbibition and forced imbibition of wetting fluid in the rock sample (generally cylindrical in shape). It is a relative displacement index of wetting fluid to non-wetting fluid. The ratio of spontaneous imbibtion to forced imbibition is used to reduce the influence of other factors, such as relative permeability, viscosity, and the initial saturation of the rock. The core prepared by centrifuging under brine until the residual oil saturation (ROS) is reached. AmottHarvey test is the extension of Amott test, which is divided into four steps-

1) Spontaneous imbibition of water in the prepared core to reach Sws; and measure the volume of oil displaced spontaneously.

2) Centrifuge the core with water to reach residual oil saturation Sor; and measure the amount of oil displaced under force.

3) Spontaneous imbibition of oil to reach Sos; and measure the volume of water displaced spontaneously. 
4) Centrifuge the core with oil to reach residual water saturation Swr; and measure the amount of water displaced under force.

Amott-Harvey index is the ratio of displacement by water minus the ratio of displacement by oil and is given by the expression

$$
\begin{gathered}
I_{A-H}=I_{W}-I_{O} \\
I_{W}=\frac{S w s-S w r}{S w f-S w r}=\frac{A B}{A C} \\
I_{O}=\frac{S o s-S o r}{S o f-S o r}=\frac{C D}{A C}
\end{gathered}
$$

Where;

$S w r=$ residual water saturation

$S w s=$ water saturation after spontaneous imbibition of water in the prepared core

$S w f=$ water saturation after forced imbibition of water in the core

Sor $=$ residual oil saturation

Sos $=$ oil saturation after spontaneous imbibition of oil in the prepared core

Sof $=$ oil saturation after forced imbibition of oil in the core

$\mathrm{AB}, \mathrm{AC}, \mathrm{CD}$ are show in Figure 2-15. The Amott-Harvey index measures the imbibition potential of water and oil and varies from +1 for strongly water-wet rocks to 1 for strongly oil-wet rocks. The main drawback of Amott test is that it is insensitive near neutral wettability since neither of the fluid will spontaneously imbibe and displace the other. 


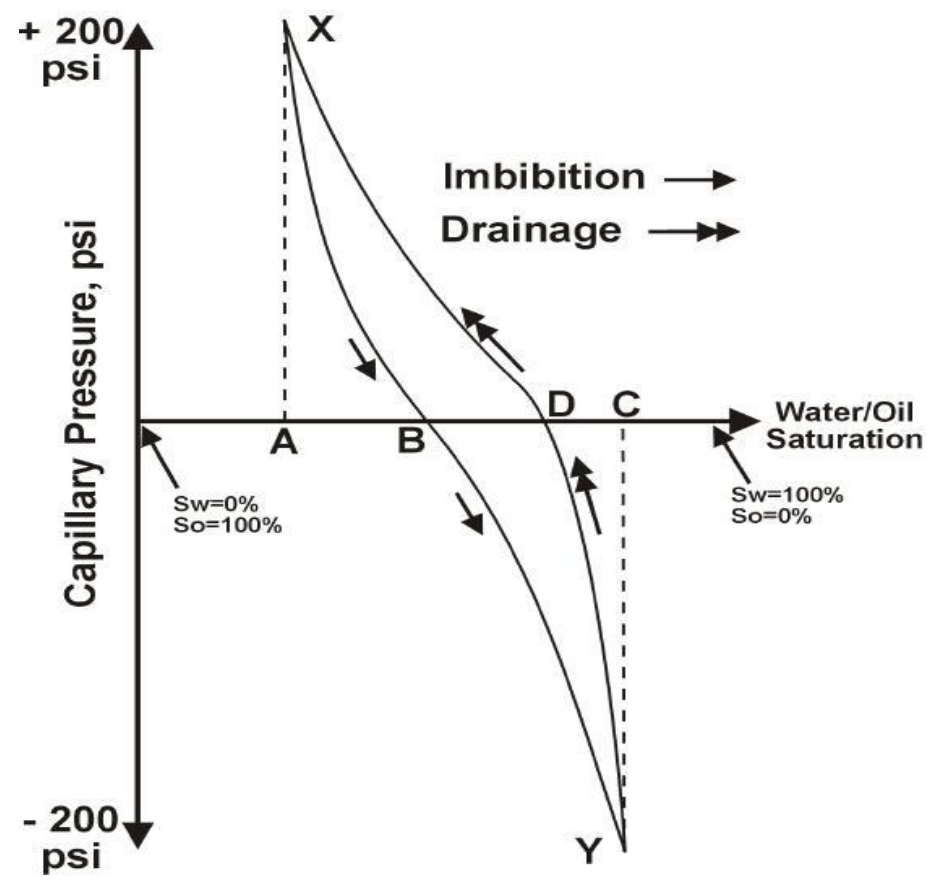

Figure 2-15: Capillary pressure curve illustrating the steps/parameters needed for calculation of Amott-Harvey index

\subsubsection{Spontaneous Imbibition}

During our research, we have conducted extensive spontaneous imbibition tests but not Amott tests. These are slight variant of the Amott tests. These are mainly done on an aged core (having oil-wet character) in the presence of brine or brine containing surfactant. Since the core has oil wet character and residual water saturation to start with (which imitates the original wettability and saturation state for the reservoir), formation brine would not imbibe into the core.

The experiment is usually done at reservoir temperature, but can be done at other temperatures to understand the effect of temperature on imbibition. Detailed procedure has been explained in the methodology section. In brief, the aged core is placed in a brine/brine containing surfactant solution in a specially designed cell (cylindrical shape with calibrated tall neck) which is placed in oven at reservoir temperature. The recovery 
of oil with time is observed in this experiment. Even for the case of imbibition in formation brine, $10-15 \%$ of oil comes out, some of which can be explained on the basis of thermal expansion at reservoir temperature. And the oil which comes out of the core sticks to the core like oil film.

There are 2 types of imbibition possible in this experiment; countercurrent and cocurrent. Co-current imbibition occurs when both the inlet and outlet are open to an invading fluid, or in other words both displacing and displaced fluid moves in the same direction. Countercurrent imbibition occurs when only one of the ends (inlet) is open, or displacing and displaced fluid moves in opposite direction. Both imbibition mechanisms are of equal importance in understanding reservoir imbibition phenomenon.

During our research we observed that under laboratory conditions, if the brine/brine containing surfactant is able to alter the wettability of the core to water-wet, the imbibition is mostly counter-current (because of negative capillary pressure) and the oil comes out from the top as well as from the sides of the cylindrical core in form of small drops which have beaded on the surface. If the brine containing surfactant has ultra low IFT with the oil, then we never observed oil drops on the sticking to the core surface. In this case since the IFT is very low, oil recovery also takes place by gravity drainage.

\subsubsection{Scaling of Spontaneous Imbibition}

Mattax and Kyte (1962) proposed the following equation for scaling of imbibition results for different oil/brine/rock systems

$$
t_{d}=C t \sqrt{\frac{k}{\phi}} \frac{\sigma}{\mu_{w}} \frac{1}{L^{2}}
$$

where $t_{d}$ is dimensionless time, $C$ the unit conversion factor $(C=0.018849), t$ the imbibitions time in minutes, $k$ permeability in $\mathrm{md}, \Phi$ fractional porosity, $\sigma$ the IFT in 
dynes/cm, $\mu_{\mathrm{w}}$ water viscosity in $\mathrm{cp}$ and $L$ a characteristic length of the core plug. This equation assumes that

1) Gravity effects can be neglected

2) The sample shapes (and boundary conditions) must be identical

3) The oil/water viscosity ratio is duplicated

4) Intial fluid distributions must be duplicated

5) The relative permeability functions must be the same

6) And capillary pressure functions must be directly proportional

According to Morrow (1993), the 4), 5) and 6) assumptions implies that the wettability must be same and the pore structures are similar. Ma et al. (1999) have proposed a modified scaling group which is given as:

$$
t_{P c}=\frac{\sqrt{\frac{k}{\phi} \sigma}}{\sqrt{\mu_{o} \mu_{w}} L_{c}^{2}} t ; \quad L_{c}=\frac{L d}{2 \sqrt{d^{2}+2 L^{2}}}
$$

where, $t_{P c}$ is dimensionless time, $t$ is the actual time of imbibition, $\phi$ is porosity, $k$ is permeability, $\sigma$ is interfacial tension, $\mu_{w}$ is viscosity of the displacing fluid, $\mu_{o}$ is viscosity of the displaced fluid, $\mathrm{d}$ is the diameter of the core and $L$ is the length of core sample. It's implied in this equation that the imbibition rate decreases if interfacial tension $\sigma$ decreases. Using this dimensionless time, the experimental results obtained for water-wet cases fit into a unique curve, which is referred to as the very strongly water wet (VSWW) curve.

To include the influence of gravity forces on the oil production rate, Xie and Morrow (2000) proposed a scaling law for this case:

$$
t_{D}(c+g)=t \frac{k / \phi}{L_{c}^{2} \sqrt{\mu_{w} \mu_{o}}}\left(\frac{\sigma}{\sqrt{k / \phi}} f(\theta)+\frac{\Delta \rho g L_{c}^{2}}{L}\right)
$$


where, $t_{D}(c+g)$ is dimensionless time including capillary and gravity forces, $\mathrm{f}(\theta)$ is wettability factor. For an oil wet rock, recovery happens mostly by gravity drainage. Hagoort (1980) has analyzed the 1-D gravity driven oil drainage by a gas, and the expressions for dimensionless time is given by

$$
t_{D g}=\frac{k k_{r o}^{0} \Delta \rho}{\left(S_{o i}-S_{o r}\right) \phi \mu_{o} L} t
$$

Where, $k_{r o}^{0}$ is the end point oil relative permeability and $S_{o i}$ is initial oil saturation and $S_{o r}$ is the residual oil saturation. This analysis does not take into account varying wettability and IFT. It also does not include displacing fluid viscosity because it was developed for an inviscid displacing fluid.

To understand the contribution of each driving force, the ratio of capillary to gravitational forces was derived by Schechter $e t$ al. as an inverse Bond number $N_{B}^{-1}$ :

$$
N_{B}^{-1}=C \frac{\sqrt{\frac{\phi}{k}} \sigma}{\Delta \rho g L}
$$

where, $\mathrm{C}$ is dimensionless constant for capillary tube model $(\mathrm{C}=0.4)$. For a system with well defined wetting properties, Schechter (1994) found that capillary forces are dominant for $N_{B}^{-1}>5$ and gravity forces are dominant for $N_{B}^{-1}<<1$. In the intermediate range, $0.2<N_{B}^{-1}<5$, both capillary and gravity forces can be active in the displacement. 


\section{Chapter 3: Methodology}

This chapter describes the methodology followed to arrive at a good surfactant formulation for wettability alteration of carbonate rock at high temperature and high salinity. The flow chart below (Figure 3-1) shows the sequence of steps followed. There is progressive screening of surfactants at each step from aqueous stability experiments to contact angle studies to imbibitions studies. The best formulation is then used for core flood experiments.

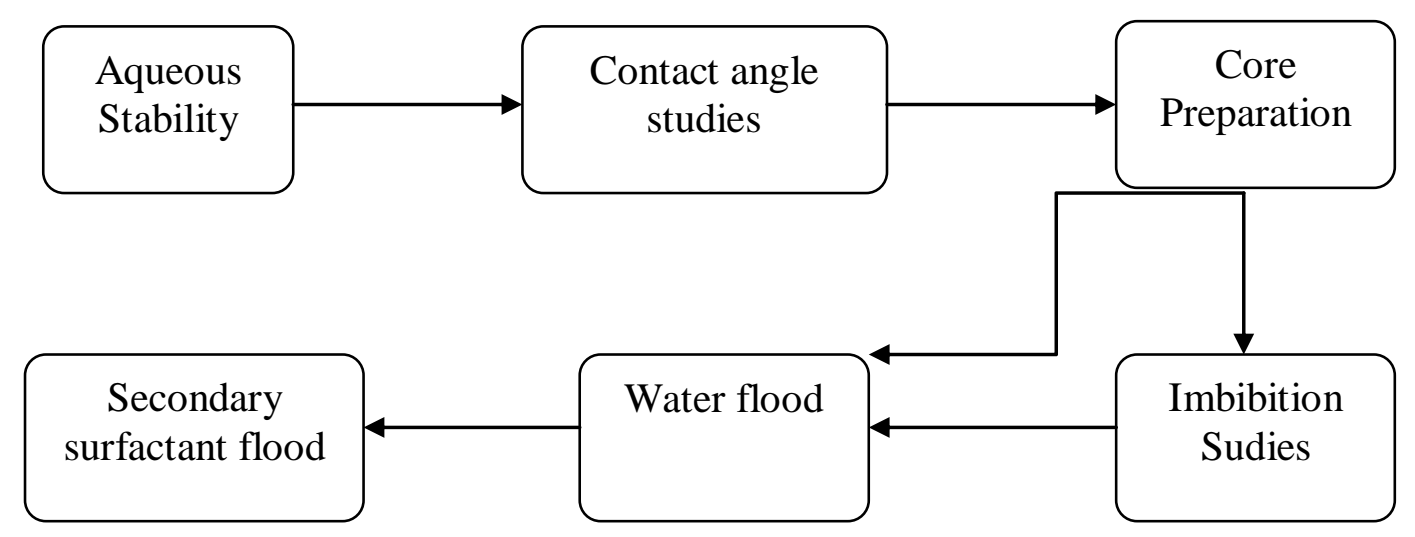

Figure 3-1: Sequence of experimental steps performed during this study

\subsection{MATERIALS}

\subsubsection{Formation and Injection brine}

Table 3-1 lists the ionic composition of the injection and the formation brine. All the salts to make both the brines were supplied by Fisher Chemicals. Even though the formation brine contains $0.5 \mathrm{gm}$ of $\mathrm{NaHCO}_{3}$ per liter (as per ion analysis done at the site of reservoir), every time $\mathrm{NaHCO}_{3}$ was mixed to the rest of the solution, precipitation was observed which did not disappear at reservoir temperature of $100^{\circ} \mathrm{C}$. So $\mathrm{NaHCO}_{3}$ was 
omitted in the recipe of formation brine. The density of formation and injection brine is $1.16 \mathrm{gm} / \mathrm{cc}$ and $1.03 \mathrm{gm} / \mathrm{cc}$ respectively.

\begin{tabular}{|c|c|c|}
\hline & Injection brine & Formation brine \\
\hline $\mathrm{NaHCO}_{3}(\mathrm{gm} /$ liter $)$ & 0.2 & - \\
\hline $\begin{array}{c}\mathrm{Na}_{2} \mathrm{SO}_{4}(\mathrm{gm} / \mathrm{liter}) \\
\left(\mathrm{ggCl} / \mathrm{liter}_{2}\right)\end{array}$ & 6.4 & 0.5 \\
\hline $\begin{array}{c}\mathrm{CaCl} \\
(\mathrm{gm} / \mathrm{liter})\end{array}$ & 17.9 & 20.6 \\
\hline $\begin{array}{c}\mathrm{NaCl}(\mathrm{gm} / \mathrm{liter}) \\
\mathrm{TDS}(\mathrm{ppm})\end{array}$ & 2.4 & 70.0 \\
\hline
\end{tabular}

Table 3-1: Composition of injection and formation brines

\subsubsection{Reservoir core plugs}

The core plugs used during this study were mostly limestone in composition. Table 3-2 lists the mineral composition (XRD data) of two core plugs which looked very different from each other. 


\begin{tabular}{|c|c|c|c|c|}
\hline Core plug & Clays (\%wt) & Quartz (\%wt) & Calcite (\%wt) & Dolomite (\%wt) \\
\hline$\# 1$ & 1 & 0 & 83 & 16 \\
\hline$\# 2$ & 2 & 17 & 66 & 12 \\
\hline
\end{tabular}

Table 3-2: XRD analysis of core plugs

On visual inspection, the cores look more homogenous than typical dolomitic rock and less than a chalk or typical sandstone rock. Porosity and permeability of the core plugs used during this study vary from $19 \%-28 \%$ and from $30 \mathrm{md}-780 \mathrm{md}$ respectively. The core plugs are cylindrical in shape with a diameter of 1.5 " and length between $1.5 "-2 "$. Individual core plugs are used during imbibition experiments where as a core composite (made by butting together 3-4 core plugs) is used for core floods.

\subsubsection{Crude oil}

The crude oil used during this research is a dead oil with $32.6^{\circ}$ API. It is a light oil with a viscosity of $15-16 \mathrm{cp}$ at room temperature and $2 \mathrm{cp}$ at $100{ }^{\circ} \mathrm{C}$. Due to the complex composition of crude oils, characterization by the individual molecular types is not possible. Instead, hydrocarbon group type analysis is commonly employed. The SARA-separation is an example of such a group type analysis, separating the crude oils into four main chemical classes based on differences in solubility and polarity. The four SARA-fractions are saturates (S), aromatics (A), resins (R), and asphaltenes (A). Figure 3-2 shows the SARA analysis of the dead oil. 


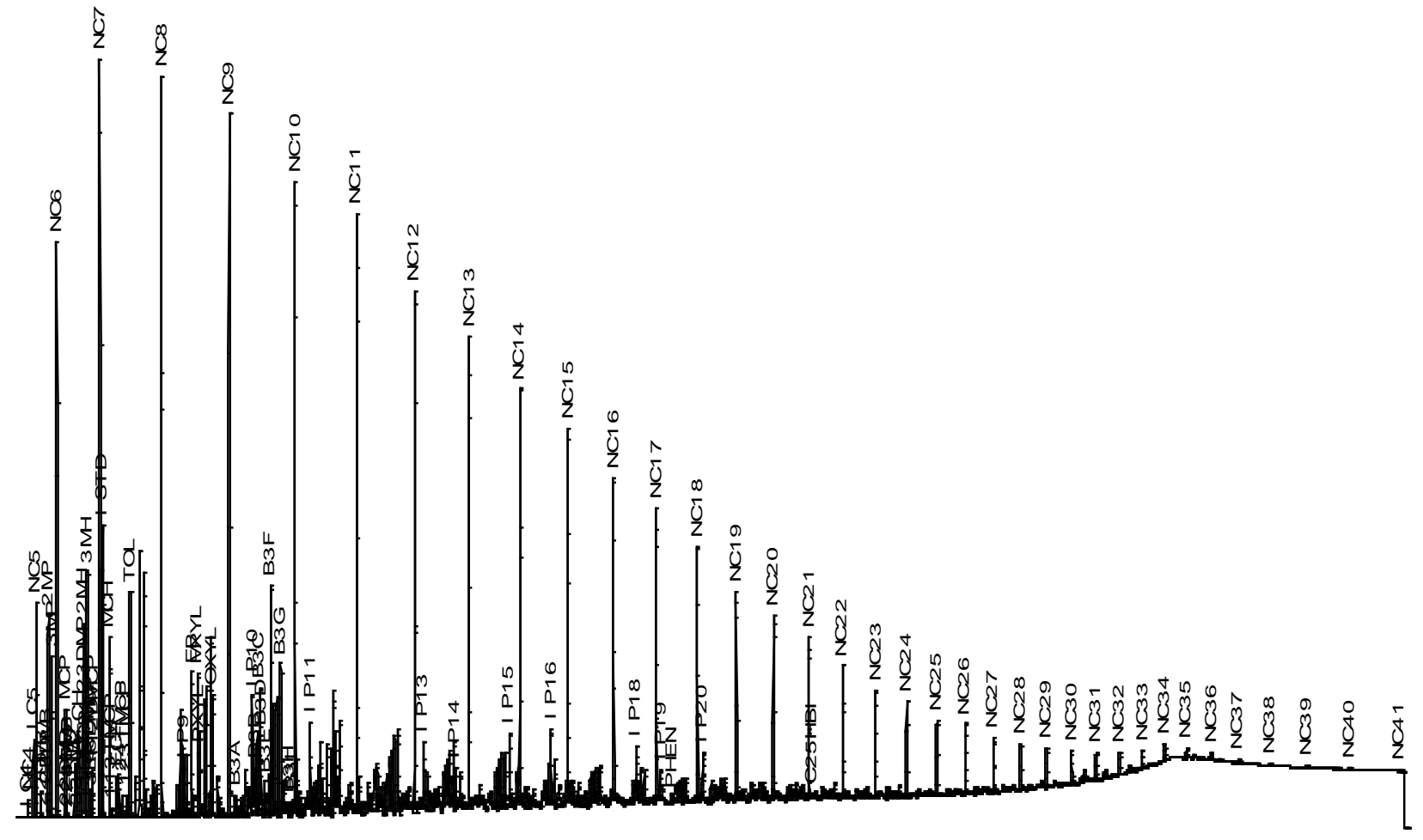

Figure 3-2: SARA analysis of dead oil

\subsubsection{Surfactants}

The surfactants used during this study are of three types: cationic, anionic and non-ionic. Table 3-3 below lists the surfactants frequently used during this study; 


\begin{tabular}{|c|c|c|c|}
\hline & Company & Trade Name & Structure \\
\hline \multirow{3}{*}{ Non-ionic } & Dow & Tergitol NP series & NonylPhenol Ethoxylate \\
\hline & Dow & $\begin{array}{l}\text { Tergitol 15-S } \\
\text { series }\end{array}$ & $\begin{array}{l}\text { Ethoxylated C11-C15 } \\
\text { secondary alcohol }\end{array}$ \\
\hline & Sasol & TDA 30 EO & $\begin{array}{c}\text { Tridecyl alcohol } 30 \\
\text { Ethoxylate }\end{array}$ \\
\hline \multirow{2}{*}{ Anionic } & BASF & Avanel S70 & $\begin{array}{l}\text { Sodium Alkyl Ether } \\
\text { (7EO) Sulfonate, C12- } \\
\text { C15 }\end{array}$ \\
\hline & BASF & Avanel S150 & $\begin{array}{l}\text { Sodium Alkyl Ether } \\
\text { (15EO) Sulfonate, C12- } \\
\text { C15 }\end{array}$ \\
\hline \multirow{3}{*}{ Cationic } & Alfa Aesar & DTAB & $\begin{array}{l}\text { Dodecyl Trimethyl } \\
\text { Ammonium Bromide }\end{array}$ \\
\hline & Akzo Nobel & Arquad C-50 & $\begin{array}{c}\text { Coconut oil alkyl (C12- } \\
\text { C14) } \\
\text { trimethylammonium } \\
\text { chloride }\end{array}$ \\
\hline & Akzo Nobel & Arquad T-50 & $\begin{array}{c}\text { Trimethyl tallowalkyl } \\
\text { (C16-C18) ammonium } \\
\text { chloride }\end{array}$ \\
\hline
\end{tabular}

Table 3-3: List of surfactants used

\subsection{AQUEOUS STABILITY}

Various surfactants are tested for aqueous stability with the injection brine and the formation brine at the reservoir temperature $\left(212^{\circ} \mathrm{F}\right)$. Non-ionic surfactants, anionic surfactants, cationic surfactants and dual surfactants (non-ionic/cationic, non- 
ionic/anionic) are mixed with injection/formation brine in dilute concentration $(\sim 0.2$ $\mathrm{wt} \%$ ) and tested for aqueous stability around the reservoir temperature.

Non-ionic surfactants have cloud point (temperature above which the aqueous solution turns hazy) which is dependent on brine salinity. Anionic and Cationic surfactants are either aqueous stable or precipitate due to interaction with the ions in brine or high temperature. These issues will be discussed in detail under results (Chapter 4).

Figure 3-3 shows a picture of aqueous stable NP-10 in DI water and aqueous unstable NP-10 in injection brine at $50^{\circ} \mathrm{C}$.

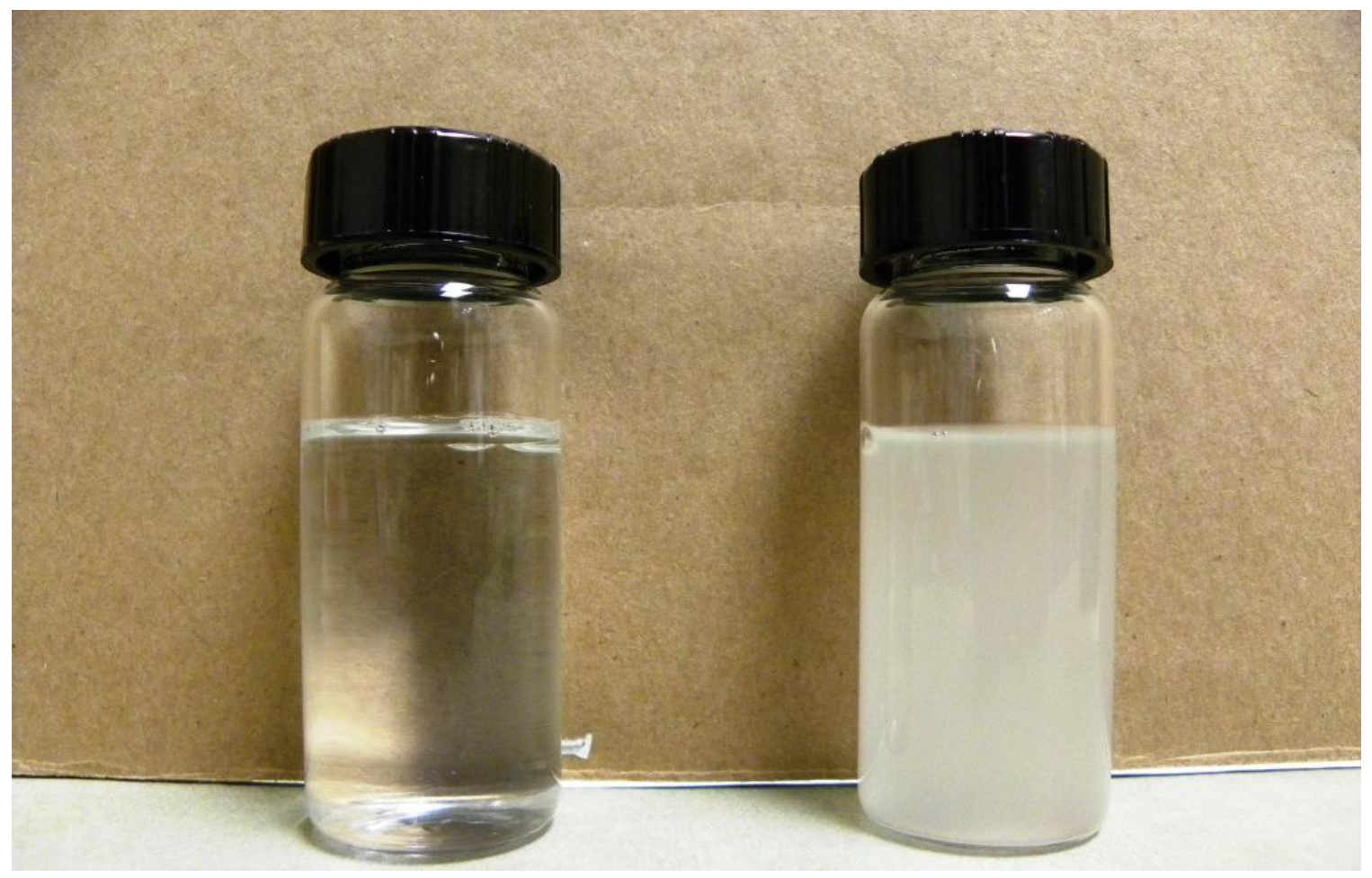

Figure 3-3: $0.2 \mathrm{wt} \%$ of NP-10 in DI water (left) and in injection brine (right) at $50^{\circ} \mathrm{C}$ 


\subsection{Contact Angle Studies}

The wettability alteration of oil-aged calcite mineral plates is tested in various surfactant solutions. These studies are done prior to imbibtion studies as there are many surfactants which passed the aqueous stability tests and only a few reservoir cores are available for imbibitions studies. The calcite (from Ward's Natural Science) acts as a proxy for the carbonate reservoir. Below are the steps followed during these studies;

1) The plates (approximately $1 " \mathrm{X} 1 " \mathrm{X} 0.25 "$ in size) are cut from a calcite block along the cleavage plane. The top and bottom surfaces of these plates are given a rough finish using a diamond plate and then polished using a set of coarse \& fine polishing plates (200\#, 400\# and 600\#).

2) Polished calcite plates (Figure 3-4) are aged in the formation brine for a day at 80 ${ }^{\circ} \mathrm{C}$.

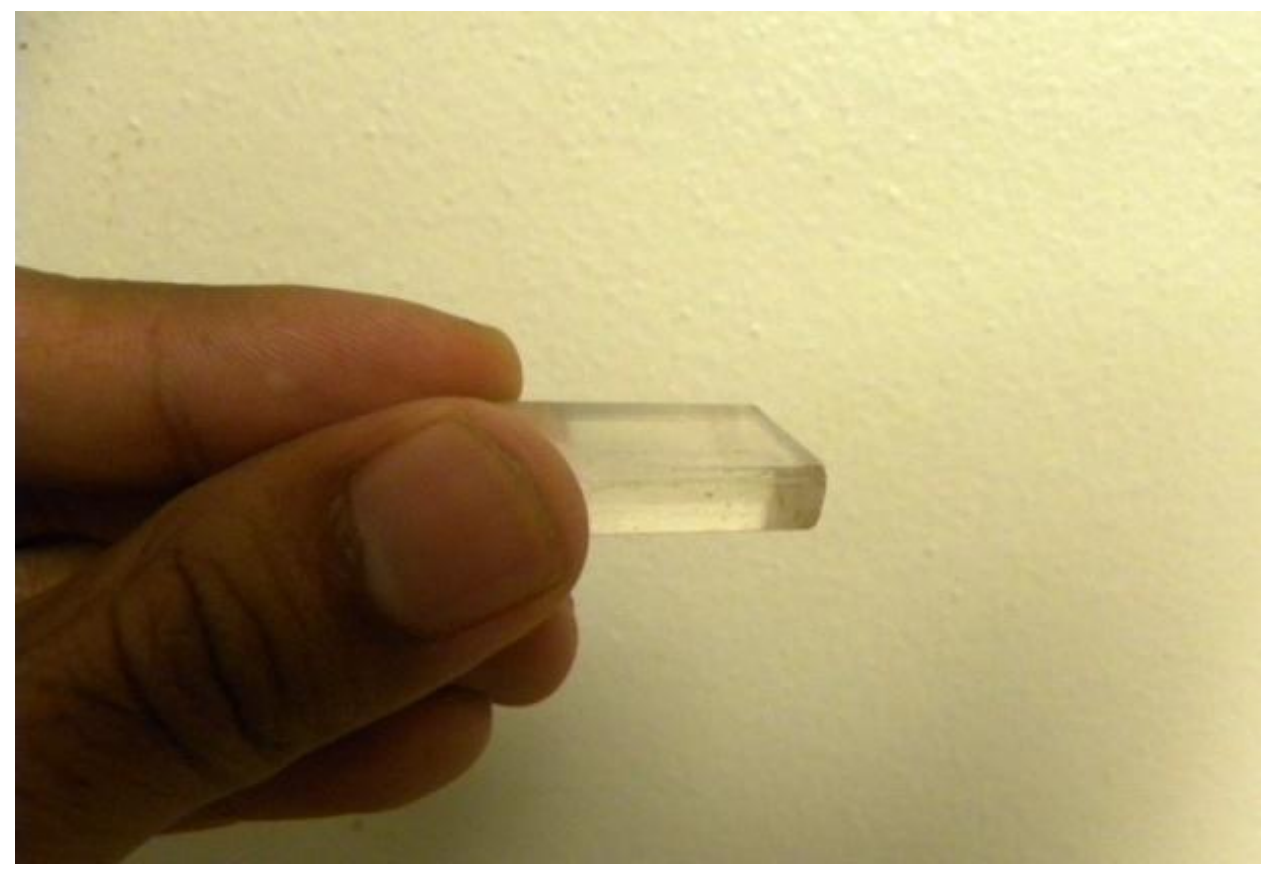

Figure 3-4: Polished calcite plates 
3) Then the plates are taken out from the formation brine, the excess water is dripped off the plates, and they are immersed in the crude oil.

4) These plates are then aged for 5-7 days at $80{ }^{\circ} \mathrm{C}$.

5) Various surfactant solutions prepared by mixing surfactant and injection brine are poured in an optical cell (from Hellma).

6) The aged plates are first immersed momentarily in another beaker containing formation brine and then if the oil sticks to the surface of calcite plates, they are placed in the optical cell containing surfactant solutions (Figure 3-5). These plates rest on the top of a teflon bar placed inside the optical cell.
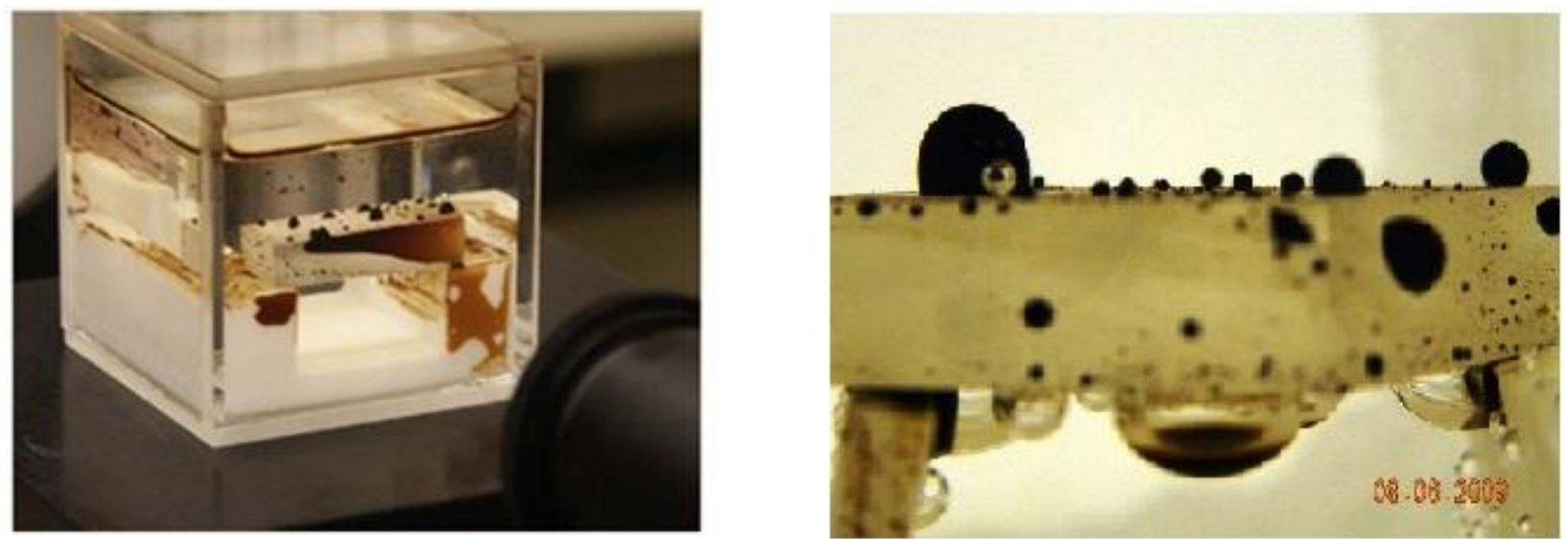

Figure 3-5: An optical cell (left) and closeup of calcite plate inside an optical cell containing surfactant solution

7) The optical cell is then sealed and placed in an oven at $80{ }^{\circ} \mathrm{C}$.

8) Thereafter, the contact angles of oil drops sitting on the calcite plate are observed for at least a couple of days. The reservoir temperature is $100{ }^{\circ} \mathrm{C}$, but these experiments were conducted at $80{ }^{\circ} \mathrm{C}$ to avoid evaporation issues. 


\subsection{Core Preparation}

The procedure to prepare cores used for imbibitions studies as well as core flood is explained here. The idea behind core preparation is to restore the core back to its original wettability (which in our case is mixed wet-oil wet) and saturation state (connate water saturation). Below are the steps followed to prepare the reservoir cores;

1) A clean core plug is dried in oven at $120^{\circ} \mathrm{C}$ and the change in weight before and after drying is observed.

2) The core is placed inside a Hassler type coreholder at room temperature under a confining pressure of 500 psig.

3) The porosity and permeability of core plug to nitrogen is calculated. The porosity is calculated using Boyle's law by pressurizing the core holder to different pressures (using a pump) and observing the change in volume of the pump. We get more accuracy in porosity estimation when the initial pump pressure, $P_{1}$ is high enough ( 200-300 psig) and the change in pump volume, $\Delta V_{\text {pump }}$ is high enough $(\sim 100-200 \mathrm{ml})$. The permeability is calculated by flowing nitrogen at various inlet pressures 5-30 psig (low enough to observe Darcy flow) and measuring the flow using air flow meter.

$$
\begin{gathered}
P_{1} \times\left(V_{\text {pump }}\right)=P_{2} \times\left(V_{\text {coreplug }}+V_{\text {coreplug }}\right) \\
P_{2} \times\left(V_{\text {coreplug }}+V_{\text {pump }}\right)=P_{3} \times\left(V_{\text {coreplug }}+V_{\text {pump }}-\Delta V_{\text {pump }}\right)
\end{gathered}
$$

$P_{1}=$ initial pressure of pump

$P_{2}=$ final pressure of after pump is connected to core holder

$P_{3}=$ pressure after change in pump colume

$V_{\text {coreplug }}=$ volume of core plug (plus dead volume)

$V_{\text {pump }}=$ initial volume of pump 
$\Delta V_{\text {pump }}=$ known change in pump volume

4) The core holder is then disconnected to nitrogen supply and connected to a vacuum pump for $\sim 1$ day. Carbon dioxide is pumped intermittently inside the core holder to displace the remaining nitrogen.

5) The vacuum is broken by pumping in formation brine in the core holder (from bottom to top).

6) After pumping $\sim 5 \mathrm{PV}$ of formation brine at low rates, we assume that the core is now in equilibrium with the brine. Then the permeability of core to brine is calculated.

7) Dead oil is then injected at a high pressure ( 200-300 psi) from top to bring the core to the residual water saturation. It usually takes 2-3 pore volume of oil to displace all the mobile water. After preparing few cores, it was observed that the Soi was not very high $(\sim 60 \%)$ even though the drainage of brine using oil was done at room temperature $(\mu o: \mu w \approx 15: 1)$. This can be attributed to the complex pore structure of the cores being used. It was then decided to replace this step by centrifuging the core (4000 rpm for 4-5 hours) to saturate it with oil. After centrifugation, the initial oil saturation was of the order of $70 \%-80 \%$.

8) The permeability to oil (at $\left.S_{w}=S_{w r}\right)$ is measured.

9) Then core plug is taken out of the core holder, placed in glass jar containing crude oil, and kept in an oven at $80{ }^{\circ} \mathrm{C}$ for at least 1 month.

10) This process ages the reservoir core and we presume that it restores it back to its original wettability and saturation state. 


\subsection{IMBIBITION STUDIES}

The surfactant solutions which appear promising in contact angle experiments are then used for imbibitions experiments on reservoir core plugs. The aged core plug (refer the core preparation step) is placed at the reservoir temperature $\left(100{ }^{\circ} \mathrm{C}\right)$ in specially designed imbibition cells containing brine or surfactant solutions. Below are the steps followed for imbibitions experiment.

1) The core plug is first placed in the formation brine for 7-10 days to confirm the oil wetness of the core plug. In the original state of the core plug, only $10-15 \%$ oil (of OOIP) is recovered (attains plateau in 2-3 days) and the oil sticks to the surface like films.
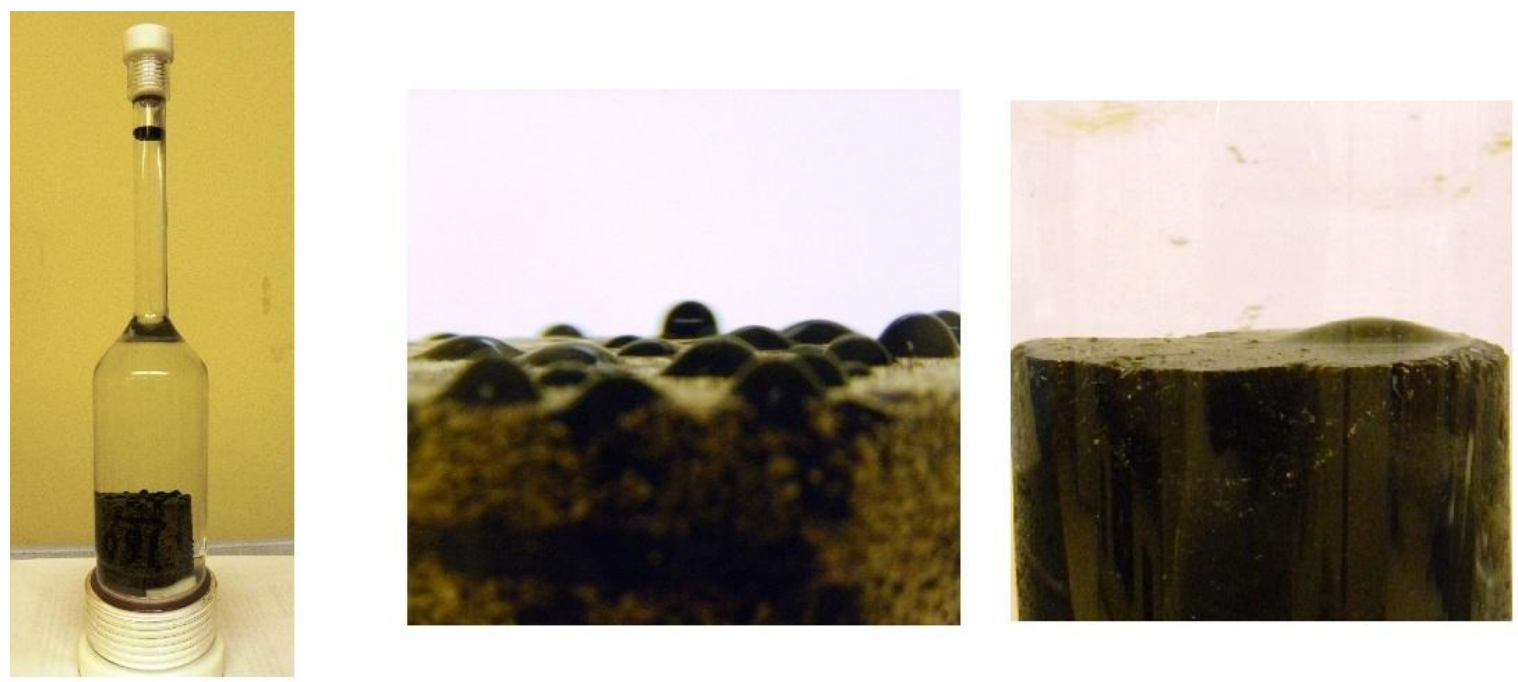

Figure 3-6: Imbibition cell (left), closeup of core in surfactant solution (middle) and closeup of core in formation brine (right)

2) This restored-state core plug is then placed in a surfactant solution. If the surfactant solution imbibes into the core plug then oil is pushed out of the core plug and collects in the neck of these glass cells which are calibrated to indicate the volume of collected. 
3) Depending on the efficacy of the surfactant solution, this experiment continues for 1-2 months until no more oil is expelled from the plug.

\subsection{WATER FLOOD AND SECONDARY SURFACTANT FLOOD}

The purpose of this experiment is to compare the efficacy of the dilute surfactant formulation in a secondary flood with that of an ordinary water-flood of a restored state core (for oil recovery and recovery rate). The secondary flood using dilute surfactant formulation is referred to here as a modified water-flood. The surfactant formulation (used in dilute concentration) which gave higher oil recovery/recovery rate during imbibition experiments is selected for this coreflood. Figure 3-7 is the schematic of experimental setup during coreflood;

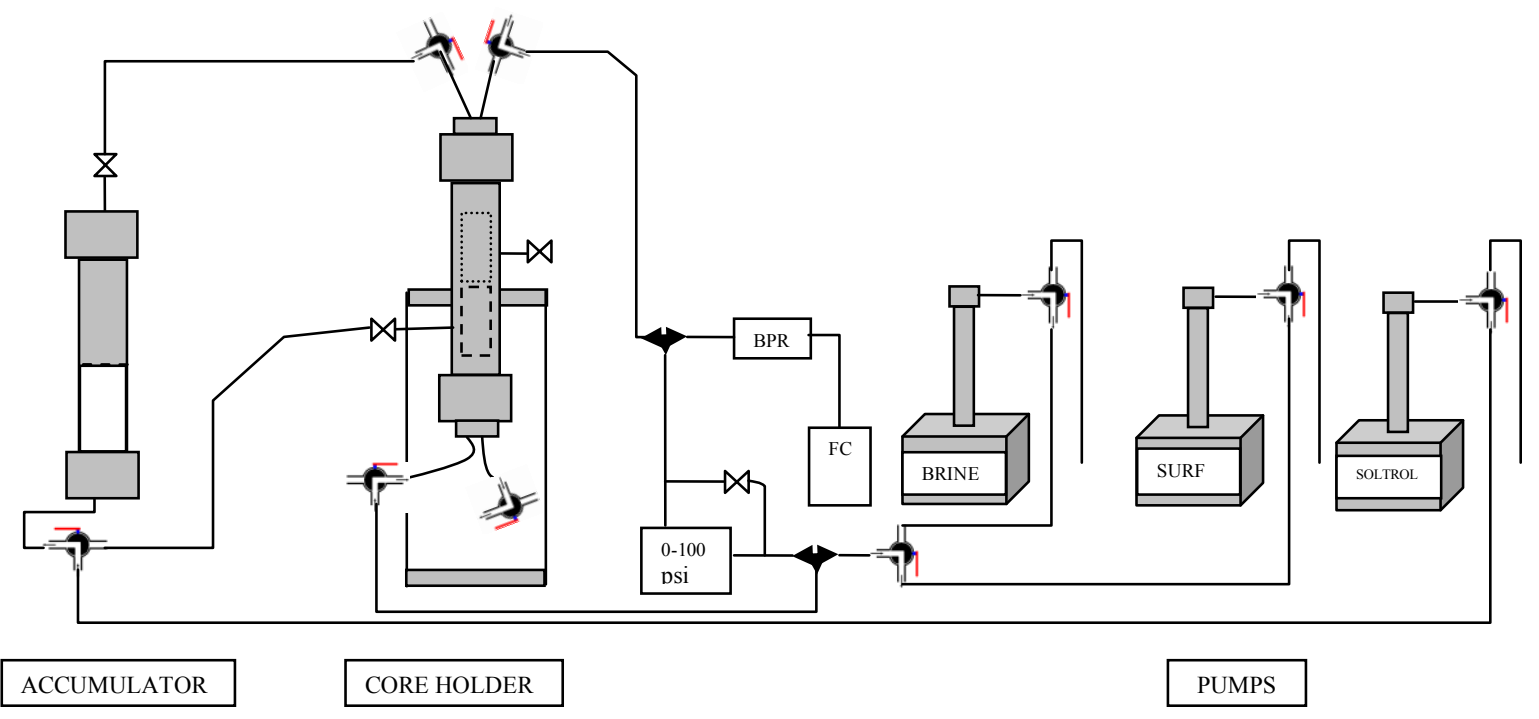

Figure 3-7: Schematic of core flood apparatus

The following steps summarize the procedure for this experiment; 
1) Few aged core plugs (refer core preparation) are butted together to make a core composite of $\sim 6$ " in length (tissue paper is placed in between the core plugs for capillary continuity). A heat shrink Teflon tape is put around the core composite and it is placed in a Hassler type core holder under a confining pressure of 500 psig at $100^{\circ} \mathrm{C}$.

2) Dead oil is pumped in the core holder for $2-3$ pore volume to replace the oil inside the core composite (which has lost some of its lighter components during core aging process) with fresh oil.

3) The permeability to oil is calculated at these conditions.

4) During the water-flood, $5 \mathrm{PV}$ of injection brine is pumped in first at a constant flow rate of $0.06 \mathrm{ml} / \mathrm{min}(\sim 1 \mathrm{ft} /$ day of interstitial velocity). The core composite stops producing oil around 1-3 PV.

5) Then the flow rate is increased to $1 \mathrm{ml} / \mathrm{min}$ and additional $5 \mathrm{PV}$ of injection brine are pumped.

6) Further the flow rate is increased to $10 \mathrm{ml} / \mathrm{min}$ and another $10 \mathrm{PV}$ of injection brine are pumped. Since these are carbonate cores with heterogenous pore structure, higher flow rates also recover additional oil because of increasing but low capillary number (Kamath et al. 2001).

7) The core composite is again saturated with formation brine by pumping in $\sim 10$ $\mathrm{PV}$ of formation brine at high flow rates $(\sim 10 \mathrm{ml} / \mathrm{min})$. This helps to prepare the core composite for the modified water flood.

8) After the water-flood, core composite is taken out of the core holder and resaturated with crude oil by centrifugation at $4000 \mathrm{rpm}$ for $4-5$ hours. This brings it back to its original saturation state and prepares it for the modified water-flood.

9) Repeat steps 1-3 for modified water flood. 
10) In the modified water-flood, the surfactant-brine is injected for $1 \mathrm{PV}$ followed by $4 \mathrm{PV}$ of surfactant-free injection brine at a constant flow rate of $0.06 \mathrm{ml} / \mathrm{min}$.

11) Repeat steps 5 and 6 with surfactant-free injection brine.

The oil recovery and oil cut of the water-flood are compared with those of the modified water-flood. 


\section{Chapter 4: Results}

This chapter presents the results of various aqueous stability experiments, calcite plate experiments, imbibition experiments and 3 core flood experiments conducted during this study. At the end of imbibition experiments, we found a promising dual surfactant system $(0.2 \mathrm{wt} \% \mathrm{NP}-10+0.2 \mathrm{wt} \%$ DTAB$)$ which was used for the coreflood experiments.

\subsection{AqueOUS StabiLity}

\subsubsection{Non-ionic surfactants}

The non-ionic surfactants used during this study are of the form R-EOx where $\mathrm{R}$ is a hydrocarbon chain (Nonyl, Tridecyl etc.) attached to a chain containing several EO (ethoxy or $-\mathrm{CH}_{2} \mathrm{CH}_{2} \mathrm{O}$-) groups. Surfactants which contain the same R but a different number of EO groups are part of the same homologous series of surfactants. Nonionic surfactants are supposed to have a cloud point, i.e., a temperature above which they do ionic not give a clear solution in brine. The cloud point increases as the degree of ethoxylation increases for the same homologous series, but after certain no. of EO groups, further ethoxylation doesn't increase the cloud point. The curves resemble Langmuir adsorption isotherms as well as second-order swelling kinetics of semicrystalline polymers (Schott 2003). For a homologous series of non-ionic surfactants, the relation which govern the cloud point is;

$$
\left(\frac{p-p^{o}}{C P-C P^{o}}\right)=\left(\frac{p-p^{o}}{C P}\right)
$$

$p^{o}=\min . \mathrm{EO}$ groups when the surfactant is insoluble in water at $0^{\circ} \mathrm{C}$

$p-p^{o}=$ excess degree of ethoxylation

$C P=$ cloud point 
$C P^{o}=0^{\circ} \mathrm{C}$

The cloud point is a function of the molecular structure and brine ionic composition (Schott \& Royce 1984). We mixed the noionic surfactants with deionized (DI) water or the injection brine, monitored the clarity of the solution as a function of temperature, and determined the cloud points. Figure 4-1 shows the cloud point (CP) of NP ethoxylate homologous series in DI water and injection brine. As the number of ethoxy group increases, the cloud point increases, but reaches a plateau beyond about 30 ethoxy groups. As the salinity of the brine increases, the cloud point decreases. The electrolytes present in the injection brine reduce the amount of water molecules available for hydration of ethoxy moiety of the surfactant.

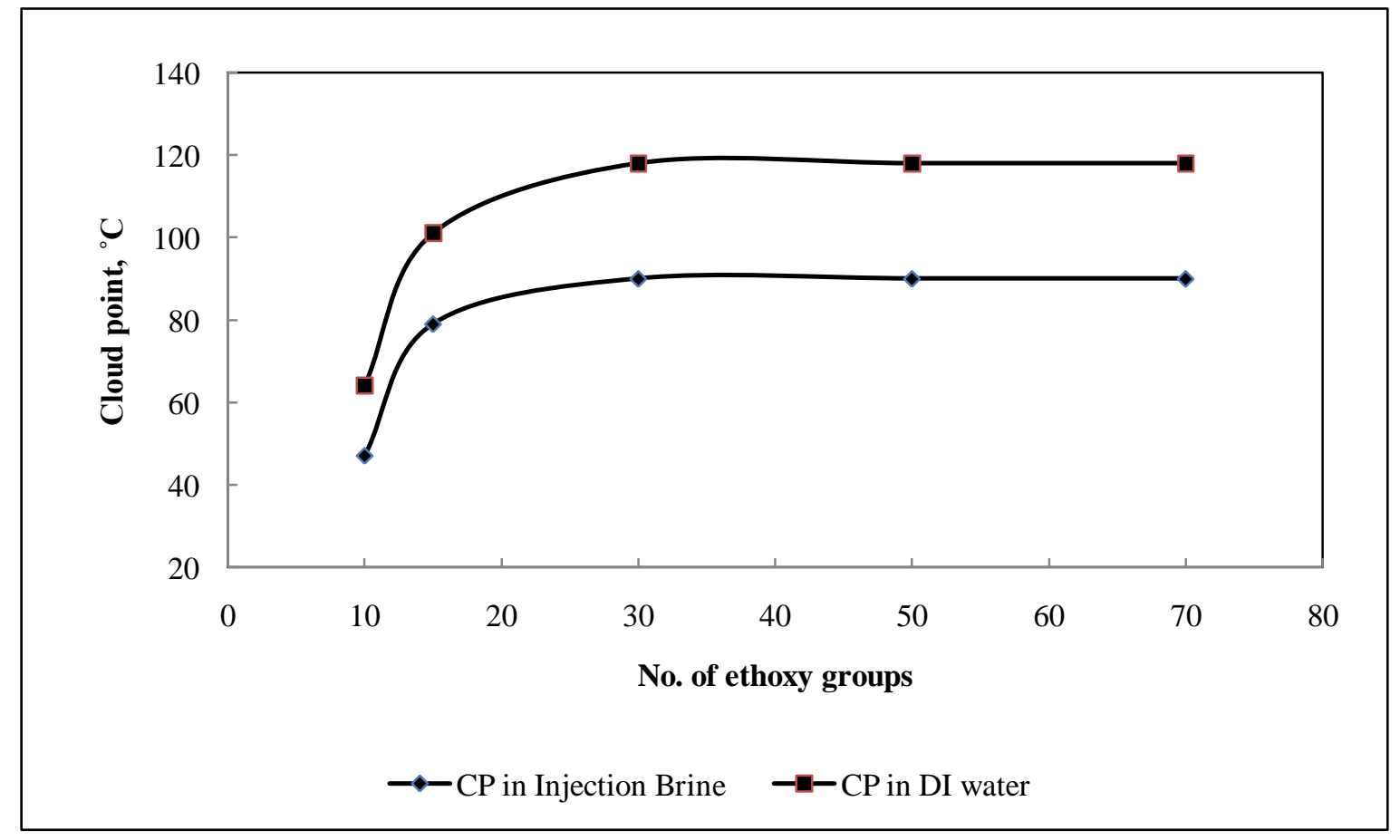

Figure 4-1: Cloud point of NP ethoxylates as a function of the number of ethoxy groups 


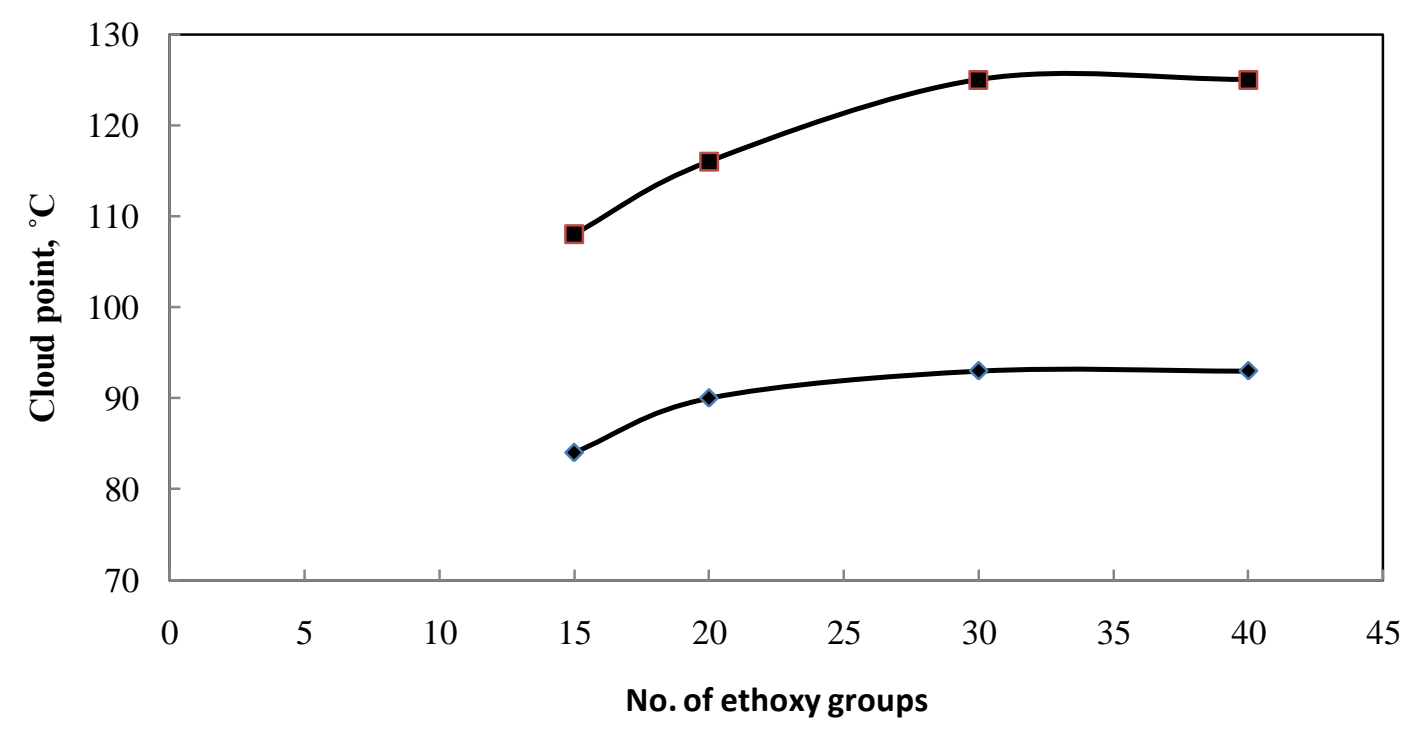

$\longrightarrow$ CP in Injection Brine $\quad \rightarrow-\mathrm{CP}$ in DI water

Figure 4-2: Cloud point of 15-S-ethoxylates as a function of the number of ethoxy groups

Figure 4-2 shows the cloud point (CP) of 15-S-ethoxylate homologous series in DI water and injection brine. Again, as the number of ethoxy group increases, the cloud point increases, but reaches a plateau beyond about 30 ethoxy groups. TDA 30EO had a cloud point of $110^{\circ} \mathrm{C}$ in DI water but $85^{\circ} \mathrm{C}$ in injection brine. Even though the listed (DI water) cloud points of most of these surfactants were above $100{ }^{\circ} \mathrm{C}$, in presence of injection brine the cloud points are below $100{ }^{\circ} \mathrm{C}$, hence making them unsuitable for injection as a single surfactant.

\subsubsection{Anionic Surfactants}

A few anionic surfactants were tested during this research. Most of the commercially available anionic surfactants consist of a hydrocarbon chain and sulfonates or sulfates; they may also contain -EO, -PO, or -BO groups in between. At a high 
temperature, the sulfates tend undergo hydrolysis, many anionic surfactants precipitate in the presence of divalent ions $\mathrm{Ca}^{+2} / \mathrm{Mg}^{+2}$ and also adsorb carbonate minerals. Thus we chose only two anionic surfactants, AV-70 and AV-150 which are ethoxylated sulphonates. These surfactants were soluble and stable with the injection brine at $100{ }^{\circ} \mathrm{C}$.

\subsubsection{Cationic Surfactants}

Many commercially available cationic surfactants are ammonium salts of a hydrocarbon chain. Cationic surfactants tested were CTAB, DTAB, Arquad C-50 and Arquad T-50. Their solutions with the injection brine were clear and stable at $100{ }^{\circ} \mathrm{C}$.

The interfacial tension of the injection brine with the single surfactants $(0.2 \mathrm{wt} \%)$ tested and field dead oil at a large water-oil-ratio $(\sim 100)$ at $25^{\circ} \mathrm{C}$ is shown in Table 4-1.

\begin{tabular}{|c|c|c|c|}
\hline Surfactants & $\begin{array}{c}\text { IFT With Crude } \\
\text { Oil (dynes/cm) }\end{array}$ & Surfactants & $\begin{array}{c}\text { IFT With Crude } \\
\text { Oil (dynes/cm) }\end{array}$ \\
\hline \multicolumn{2}{|c|}{ Non-ionic surfactants } & \multicolumn{2}{|c|}{ Anionic surfactants } \\
\hline NP-10 & 0.4 & AV-70 & $2.9-3.1$ \\
\hline NP-30 & 6.7 & AV-150 & $4.2-4.3$ \\
\hline NP-50 & 9.6 & \multicolumn{2}{|c|}{ Cationic surfactants } \\
\hline NP-70 & 10.9 & CTAB (1 wt\%) & $3.9-4.1$ \\
\hline
\end{tabular}


Table 4-1 (continued)

\begin{tabular}{|c|c|c|c|}
\hline $15-\mathrm{S}-15$ & 2.7 & DTAB (1 wt $\%)$ & $1-1.05$ \\
\hline $15-\mathrm{S}-20$ & 3.9 & $\begin{array}{c}\text { Arquad C-50 (1 } \\
\mathrm{wt} \%)\end{array}$ & 1 \\
\hline $15-\mathrm{S}-30$ & 6.7 & $\begin{array}{c}\text { Arquad T-50(1 } \\
\text { wt } \%)\end{array}$ & \\
\hline $15-\mathrm{S}-40$ & 8.6 & & \\
\hline TDA 30EO & 5.0 & & \\
\hline
\end{tabular}

Table 4-1: Interfacial tension of the surfactants tested at $0.2 \mathrm{wt} \%$ surfactant concentration with oil to injection brine ratio of $\sim 100$ at $25^{\circ} \mathrm{C}$

\subsubsection{Dual Surfactant Systems}

As most of the non-ionic surfactants used were not aqueous stable at $100{ }^{\circ} \mathrm{C}$, we decided to test some dual-surfactant systems. The cloud points and interfacial tension with the injection brine and the field dead oil at a water-oil-ratio of $\sim 100$ at $25{ }^{\circ} \mathrm{C}$ are shown in Table 4-2. Addition of small amounts of anionic or cationic surfactants to an aqueous solution of non-ionic surfactants increases the cloud points of the nonionic surfactants (Schott and Royce 1984). This effect is also known as salting in of the nonionic surfactant which is opposite of the salting out effect. The non-ionic surfactants form mixed micelles with the other surfactant and become aqueous stable. Dual surfactant systems tested here have cloud points greater than $100{ }^{\circ} \mathrm{C}$ and thus can be used with the injection brine. 


\begin{tabular}{|c|c|c|c|c|}
\hline Non-ionic & Cationic & $\begin{array}{c}\text { Cloud Point } \\
\left({ }^{\circ} \mathbf{C}\right)\end{array}$ & $\begin{array}{c}\text { Increase in } \\
\text { cloud Point } \\
\left({ }^{\circ} \mathbf{C}\right)\end{array}$ & $\begin{array}{c}\text { IFT } \\
\text { (dynes/cm) }\end{array}$ \\
\hline $0.2 \mathrm{wt} \% \mathrm{NP}-10$ & $0.2 \mathrm{wt} \%$ DTAB & $125-130$ & $80-85$ & 1 \\
\hline $0.1 \mathrm{wt} \% \mathrm{NP}-10$ & $0.2 \mathrm{wt} \%$ DTAB & $>130$ & $>85$ & $1.2-1.25$ \\
\hline $0.2 \mathrm{wt} \% \mathrm{NP}-10$ & $0.2 \mathrm{wt} \% \mathrm{C}-50$ & $>130$ & $>85$ & $<5$ \\
\hline $0.2 \mathrm{wt} \%$ NP-10 & $0.2 \mathrm{wt} \% \mathrm{~T}-50$ & $>130$ & $>85$ & $<5$ \\
\hline $\begin{array}{c}0.2 \mathrm{wt} \% 15-\mathrm{S}- \\
15\end{array}$ & $0.1 \mathrm{wt} \%$ DTAB & $95-100$ & $10-15$ & 2.4 \\
\hline $0.2 \mathrm{wt} \% 15-\mathrm{S}-$ & $0.1 \mathrm{wt} \%$ DTAB & $105-110$ & $15-20$ & $<5$ \\
\hline
\end{tabular}

Table 4-2: Properties of dual surfactant mixtures tested

\subsection{Contact AngLe}

Calcite plates act as good substitutes for the field carbonate rocks for wettability screening. After a week of aging the plate with crude oil, it shows strongly oil-wet character in formation brine. The oil sticks to the plate like films on the surface. It also shows an oil-wet character when placed even in injection brine. Hence it became logical to add dilute surfactants to injection brine to change wettability from oil-wet to waterwet. All the surfactants tried changed the contact angle on the calcite plate to varied degree. Some surfactants hardly altered contact angle while some altered it more. The 
calcite plate is oil-wet if the contact angle is $>110^{\circ}$, intermediate-wet for $70^{\circ}-110^{\circ}$ and water-wet for contact angle $<70^{\circ}$.

The assessment of wettability alteration on calcite plate is a subjective process as many oil drops stick to the calcite plate and they vary in their final contact angle. We have assessed the wettability alteration on calcite plate qualitatively rather than by directly measuring the contact angle of each oil drop on the surface and then averaging it. Also, most of the experiments were repeated; the original and the repeat experiments were similar, but not identical. This might be attributed to different levels of surface irregularity, surface contamination, and the contamination of the optical glass box containing the dilute surfactant solution. For all these above reasons, we use calcite plate experiment as a qualitative screening step.

\subsubsection{Non-ionic surfactants}

Since the non-ionic surfactants were not aqueous stable at the reservoir temperature $\left(100{ }^{\circ} \mathrm{C}\right)$, these experiments were conducted at $80{ }^{\circ} \mathrm{C}$. These experiments helped us to understand the trend of wettability alteration with increasing number of ethoxylates for the same homologous series. It also helped us avoid issues of evaporation from the optical cell at the higher temperature.

Dilute concentration $(<0.2 \mathrm{wt} \%)$ of TDA $30 \mathrm{EO}$ changes the contact angle to intermediate-wet (not shown). We also observed variation in wettability alteration when the concentration of TDA $30 \mathrm{EO}$ was varied. It was observed that as the concentration of TDA 30EO was decreased from $1 \mathrm{wt} \%$ to $0.02 \mathrm{wt} \%$, the wettability alteration increased

(i.e., the calcite plate became more water-wet in $0.02 \%$ TDA 30EO). Similar observations have also been made by Robin et al. (2010) with different surfactants. 
Figure 4-3 shows the contact angles on aged calcite plates for the surfactants in the homologous series of NP-ethoxylates (as well as 15-S-ethoxylates); it was observed that wettability alteration was reduced as the number of EO groups increased Figure 4-4 shows the contact angles on aged calcite plates for the surfactants in the homologous series of 15-S-ethoxylates. Again, the surface was more water-wet for surfactants with a smaller number of EO groups. Also the IFT of these surfactant solutions increased as the number of EO groups increased for the both the homologous series (Table 1). The NPethoxylates and 15-S-ethoxylates used could alter the wettability to intermediate-wet only.

\subsubsection{Anionic Surfactants}

Among the two anionic surfactants tried at dilute concentration $(0.1 \mathrm{wt} \%)$, both AV-70 and AV-150 altered the wettability to intermediate wet (Figure 4-5). The wettability using AV-150 looked more water-wet than that of AV-70.

\subsubsection{Cationic Surfactants}

DTAB was mixed with injection brine to make a $1 \mathrm{wt} \%$ solution. The wettability alteration observed with this was from initial oil-wet to final intermediate wet, as shown in Figure 4-6. CTAB is not aqueous stable at $100{ }^{\circ} \mathrm{C}$ and was not used. Arquad C-50 and T-50 did not show any wettability alteration on the aged calcite plate (Figure 4-6). 


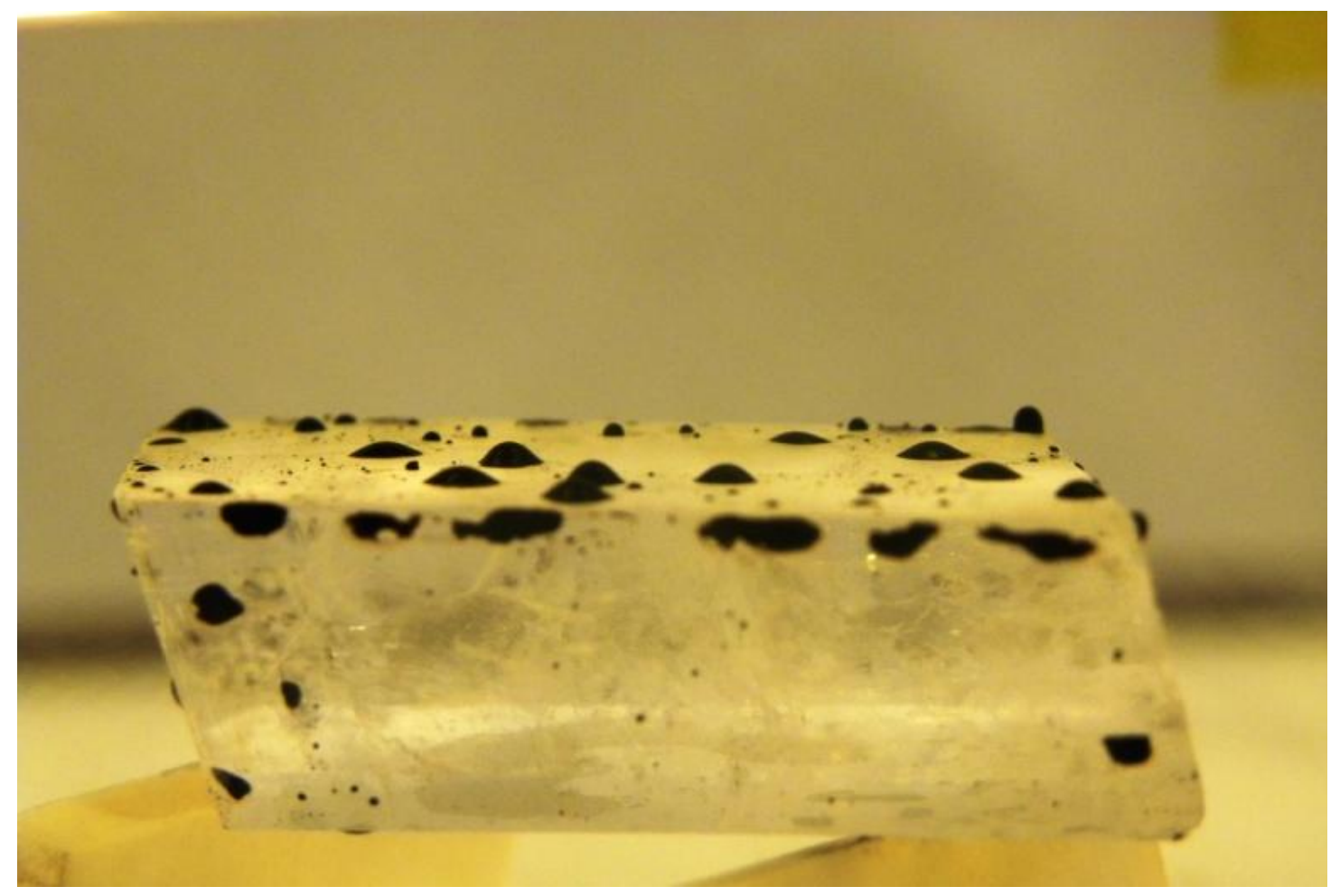

$0.2 \mathrm{wt} \% \mathrm{NP}-10$ in injection brine

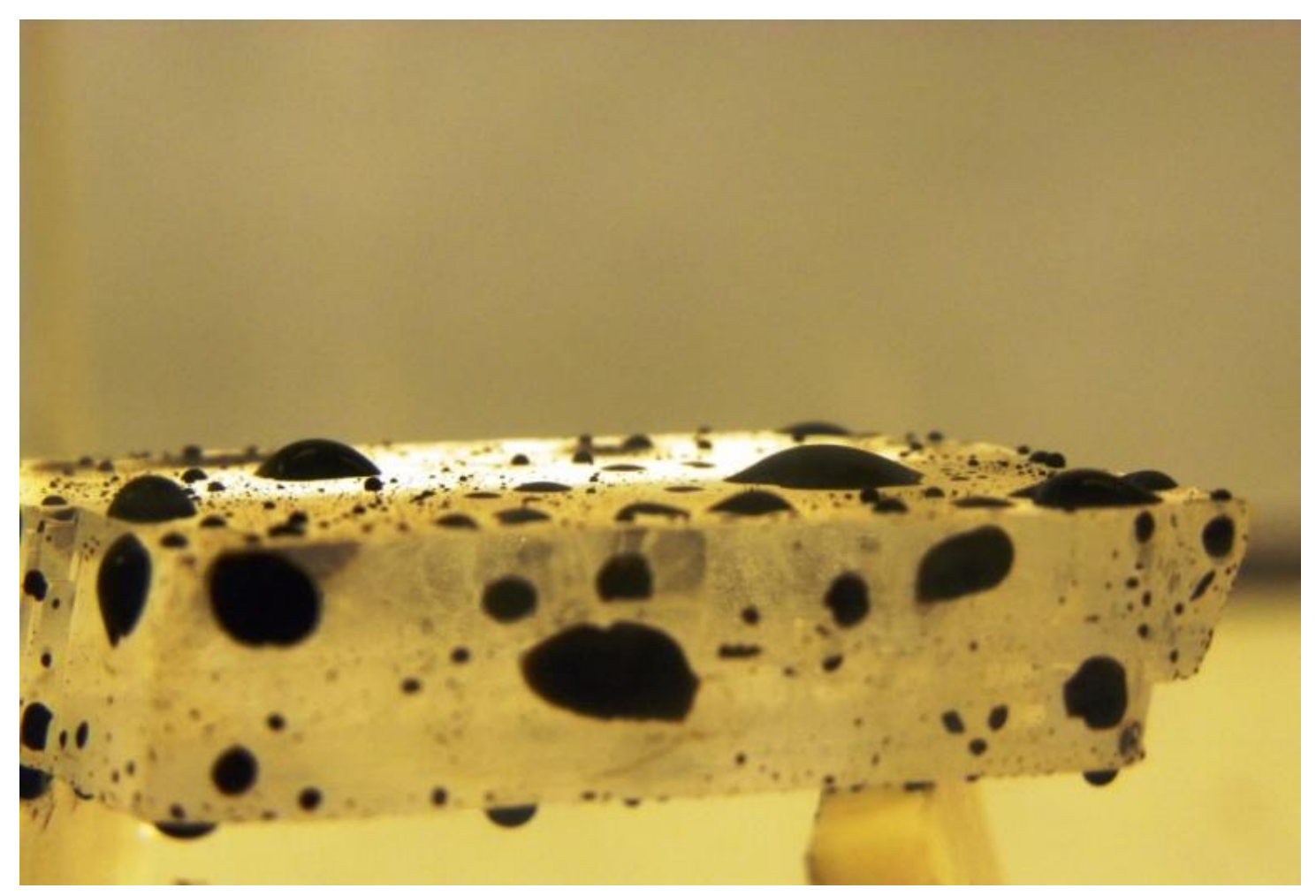

$0.2 \mathrm{wt} \% \mathrm{NP}-30$ in injection brine 


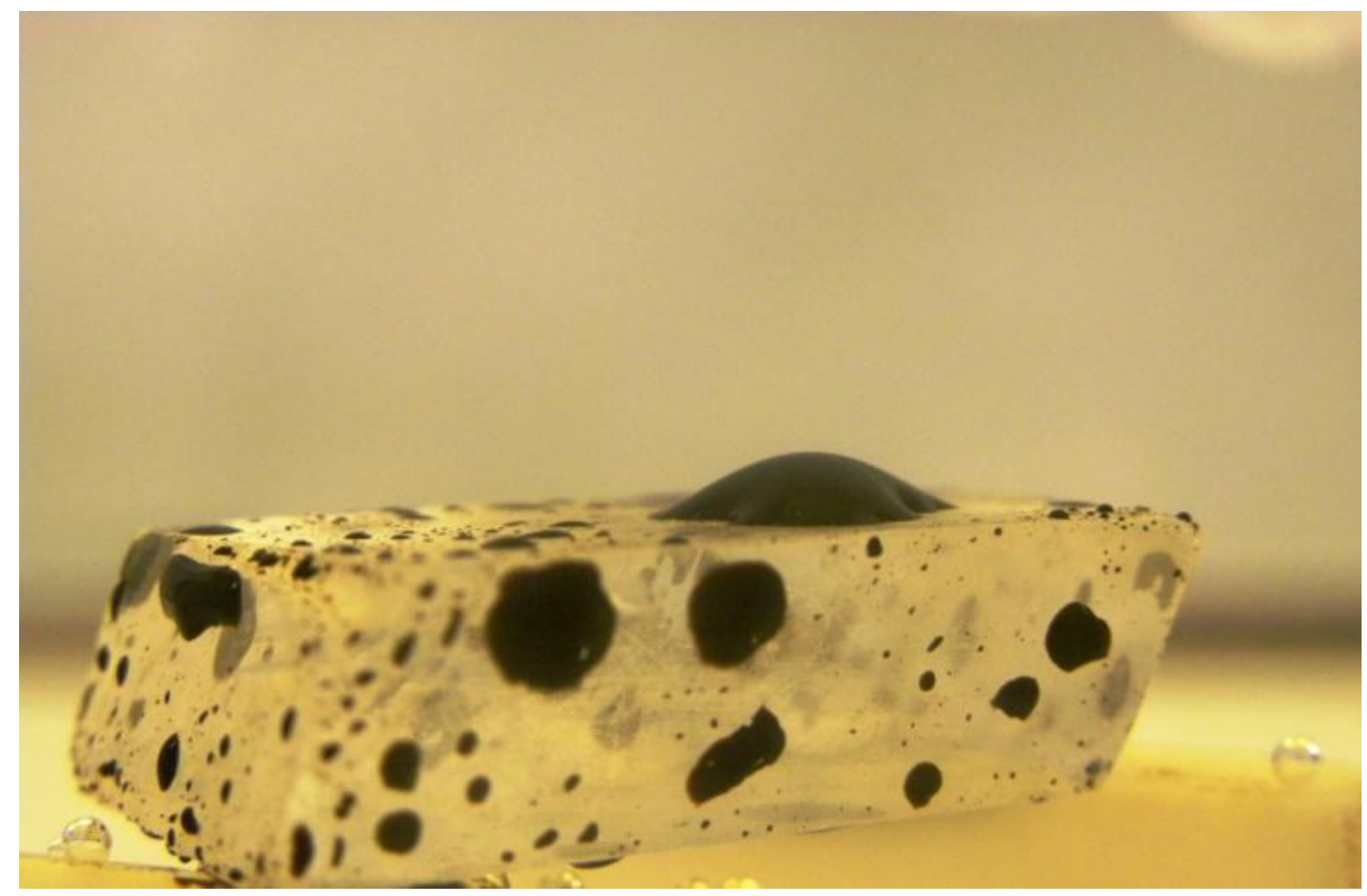

$0.2 \mathrm{wt} \% \mathrm{NP}-50$ in injection brine

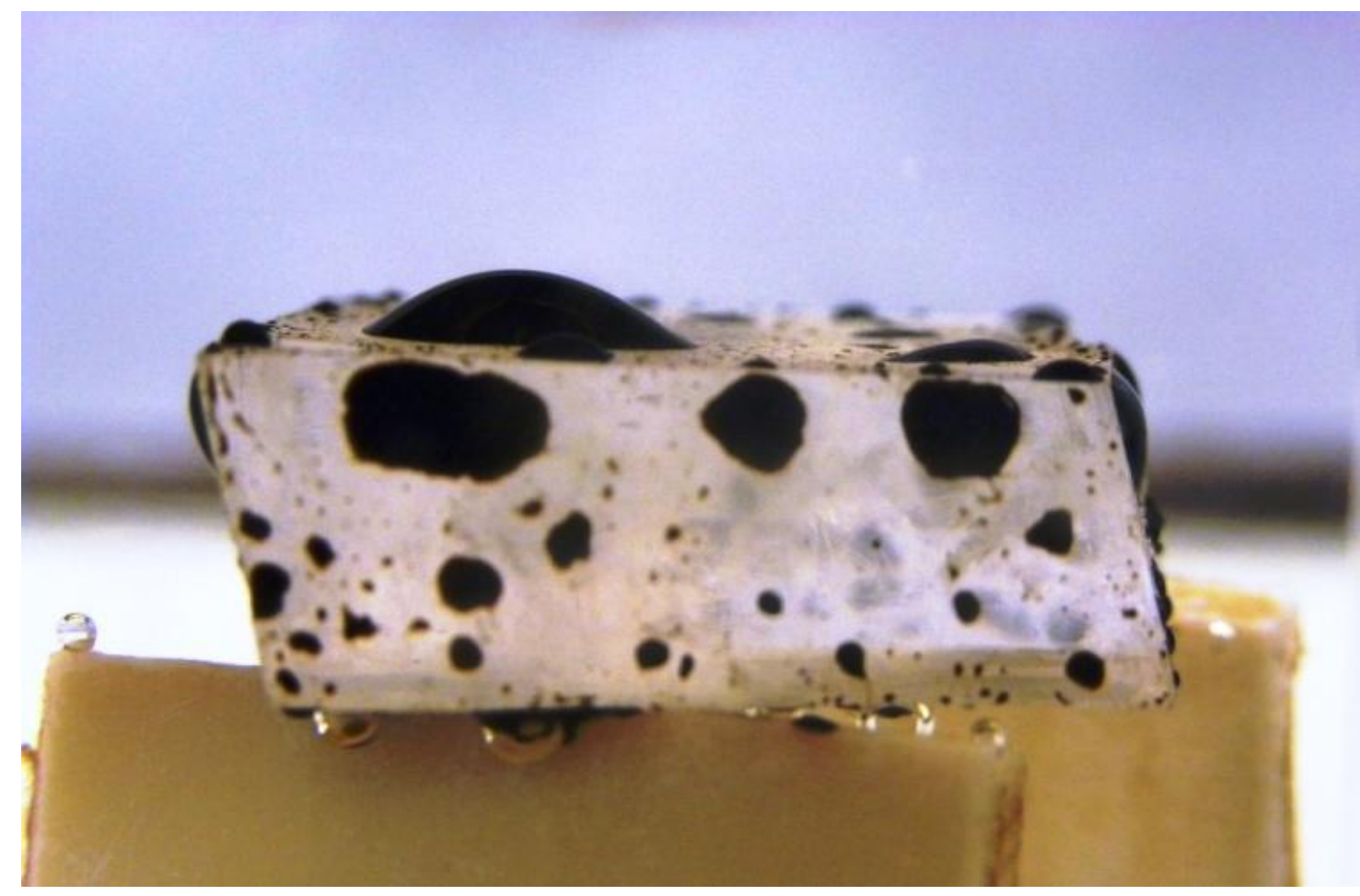

$0.2 \mathrm{wt} \% \mathrm{NP}-70$ in injection brine

Figure 4-3: Contact angle in Nonyl Phenol ethoxylates 


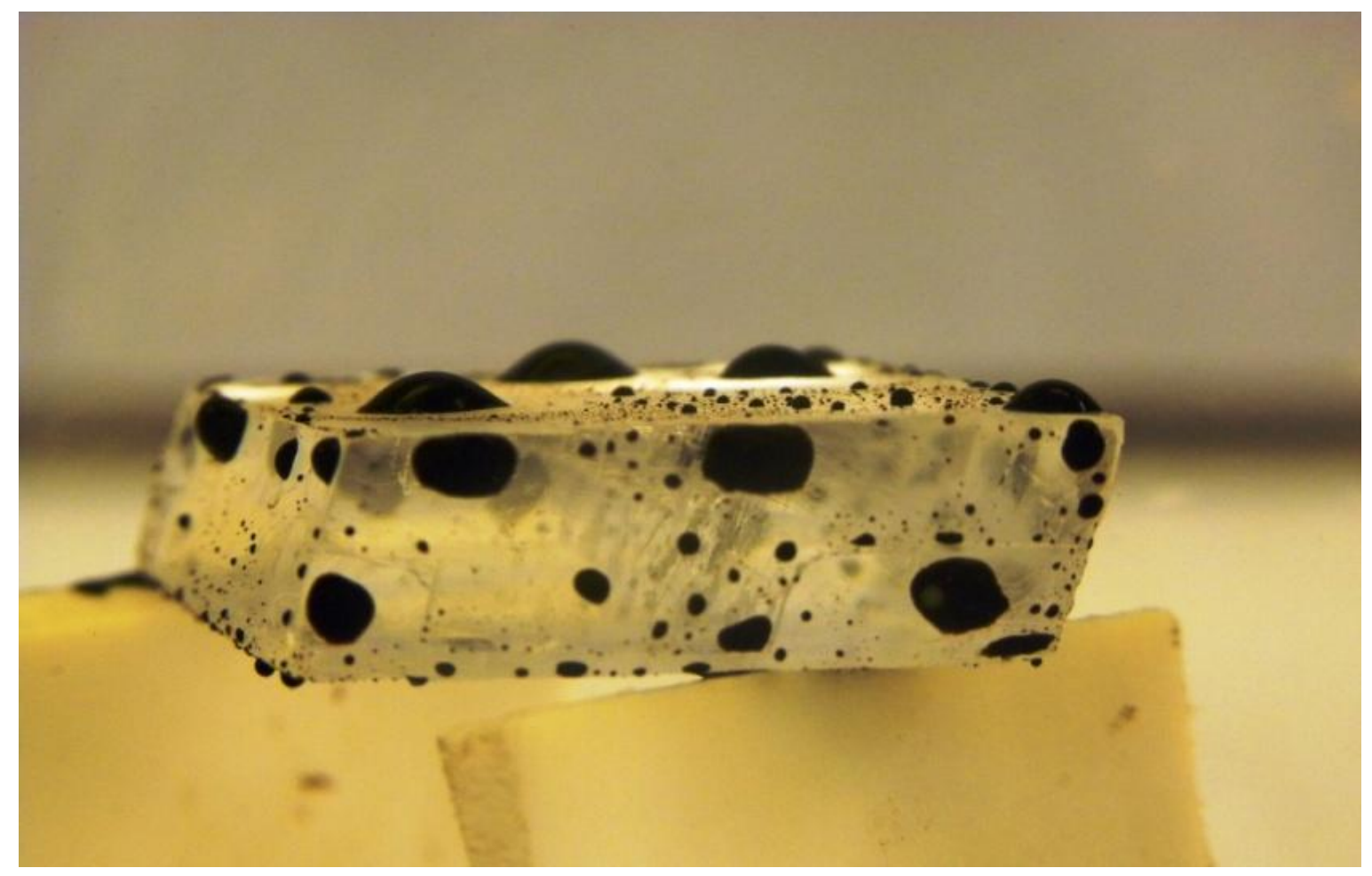

$0.2 \mathrm{wt} \% 15-\mathrm{S}-15$ in injection brine

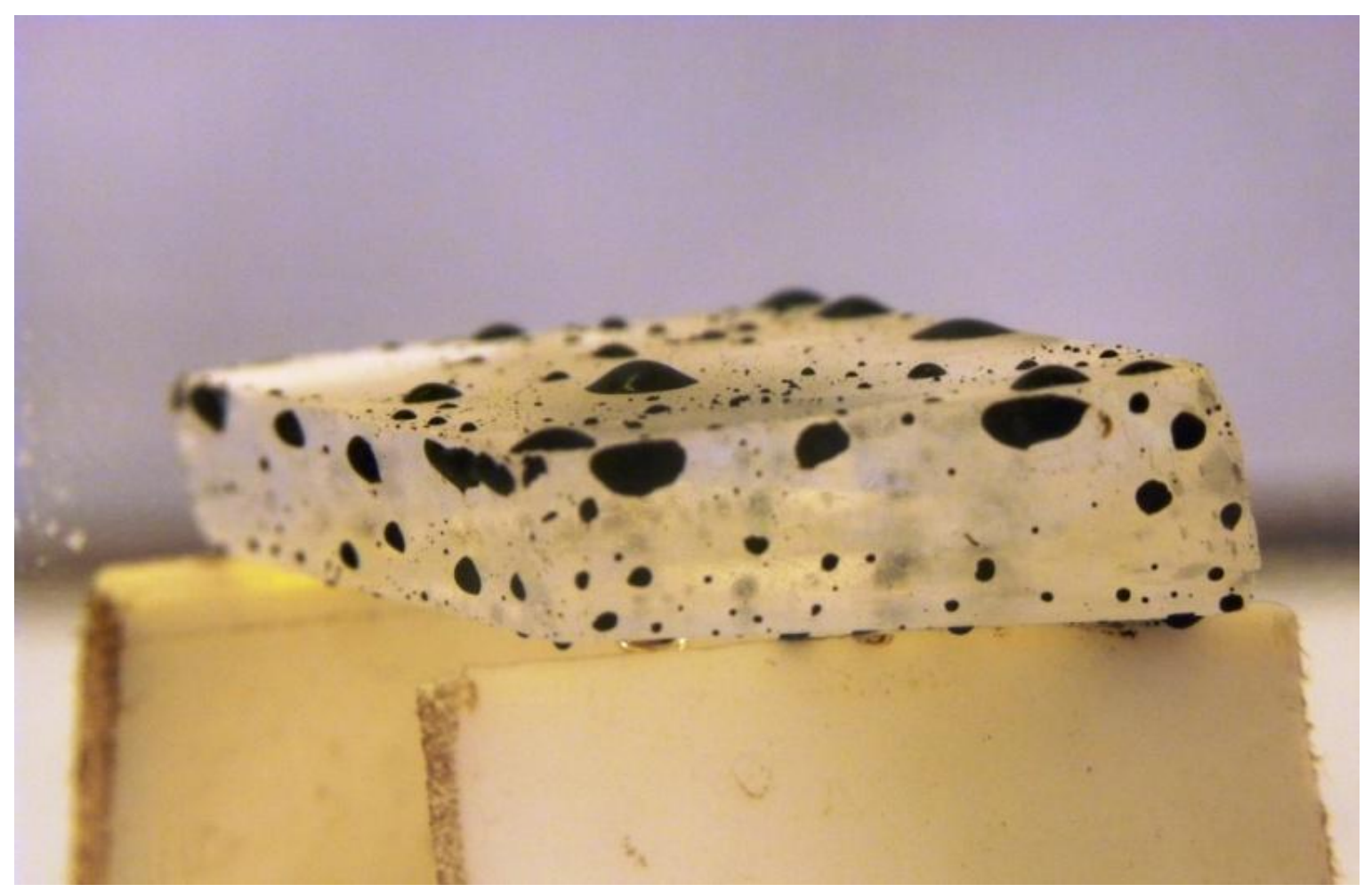

$0.2 \mathrm{wt} \%$ 15-S-20 in injection brine 51 


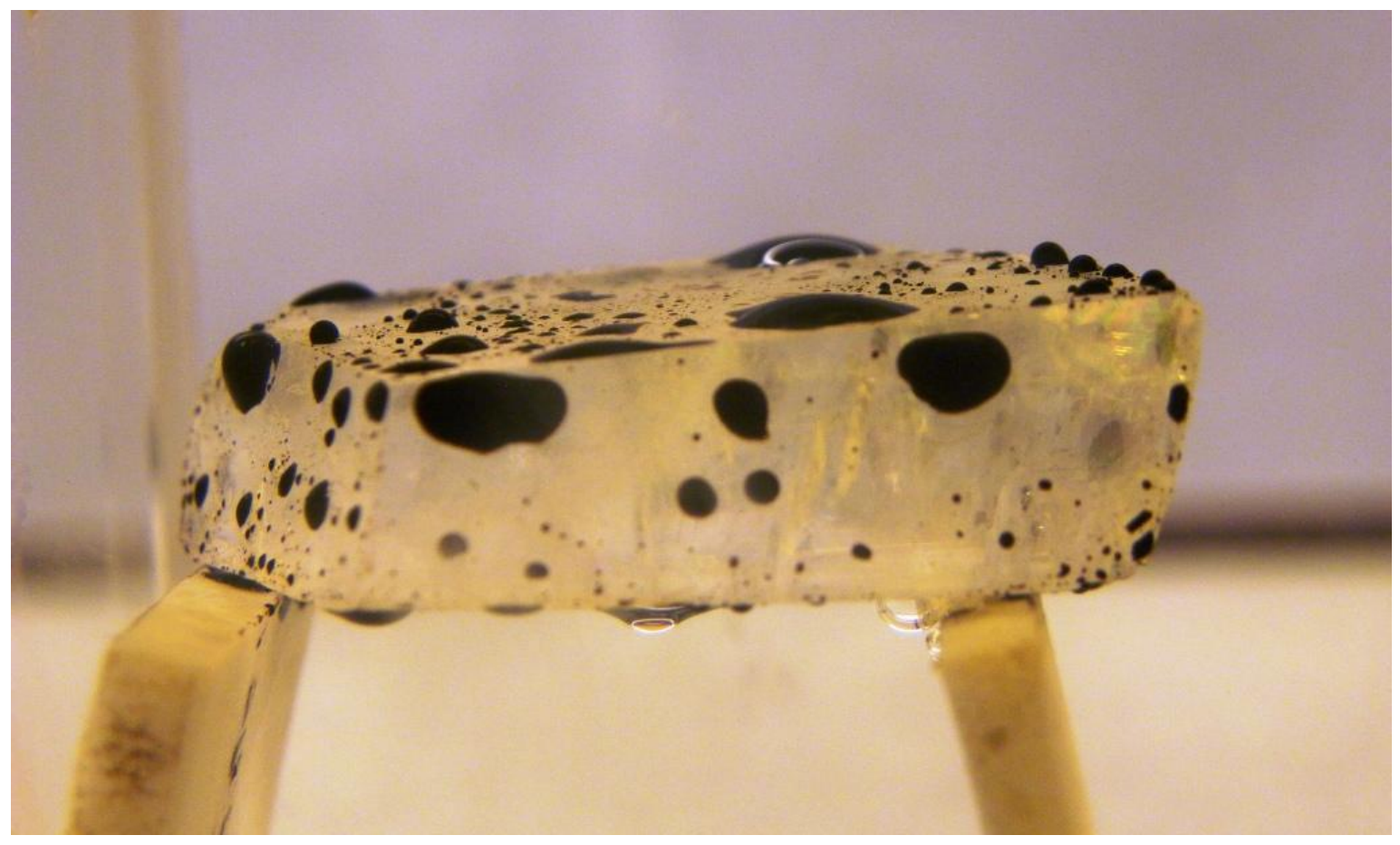

$0.2 \mathrm{wt} \% 15-\mathrm{S}-30$ in injection brine

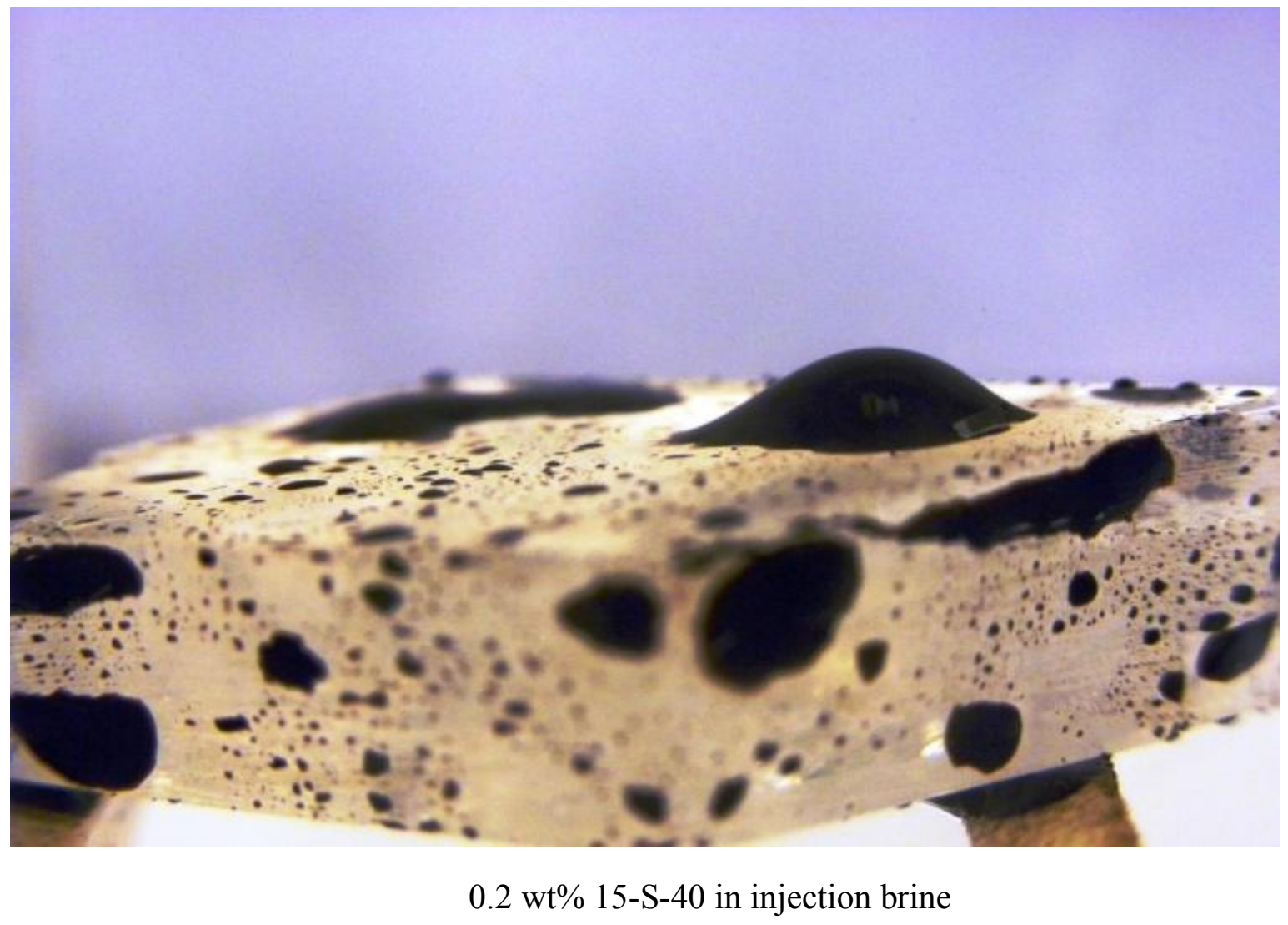

Figure 4-4: Contact angle in 15-S ethoxylates 


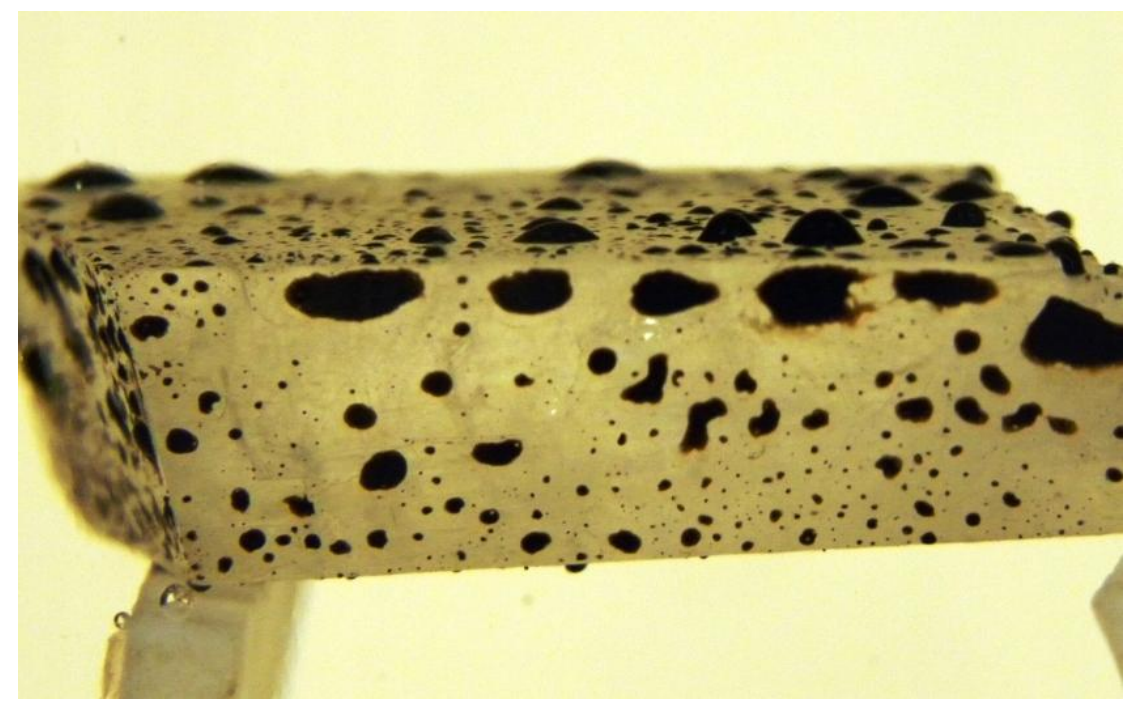

$0.1 \mathrm{wt} \% \mathrm{AV}-70$ in injection brine

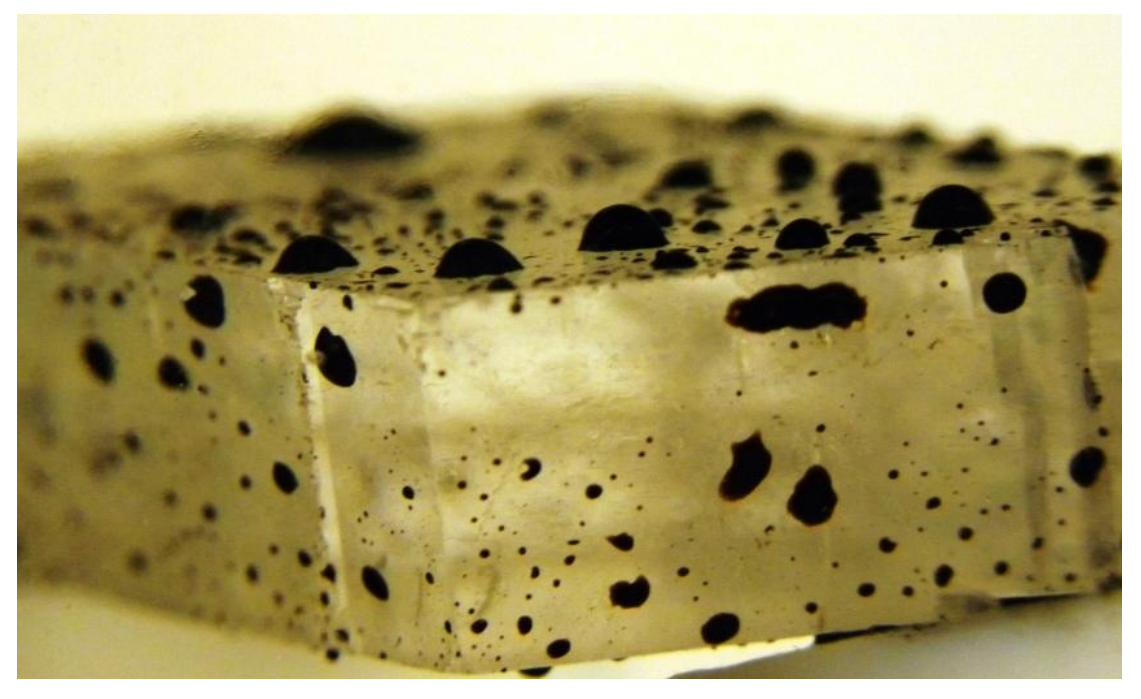

$0.1 \mathrm{wt} \% \mathrm{AV}-150$ in injection brine

Figure 4-5: Contact angle in anionic surfactants 


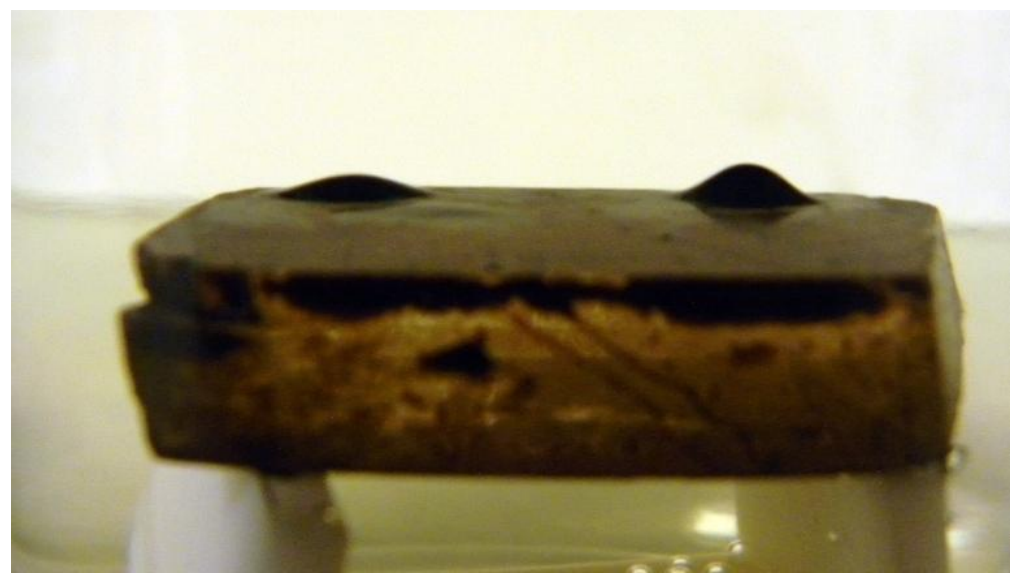

$1 \mathrm{wt} \% \mathrm{C}-50$ in injection brine

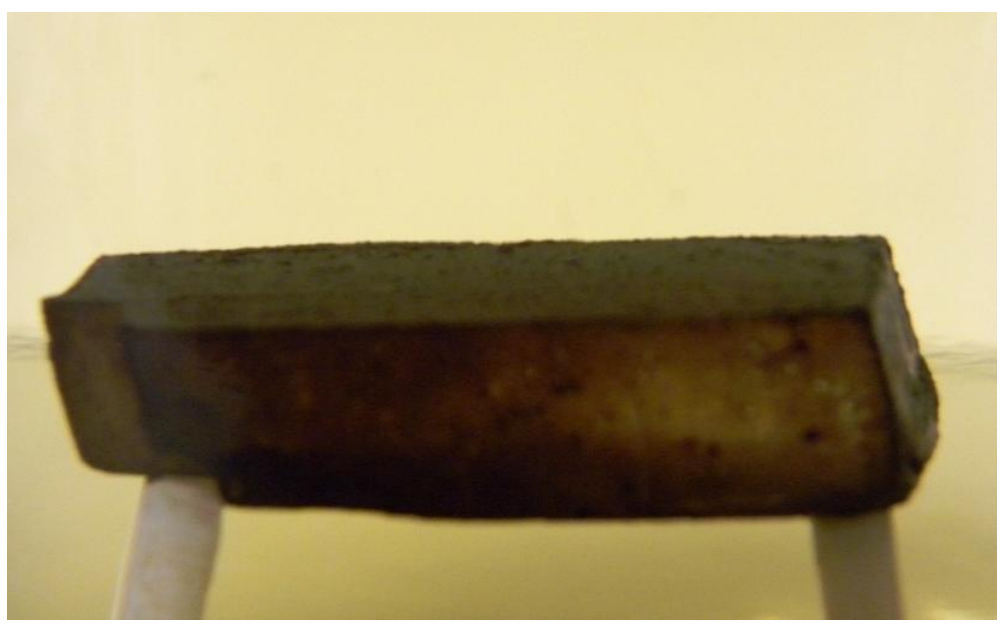

$1 \mathrm{wt} \% \mathrm{~T}-50$ in injection brine

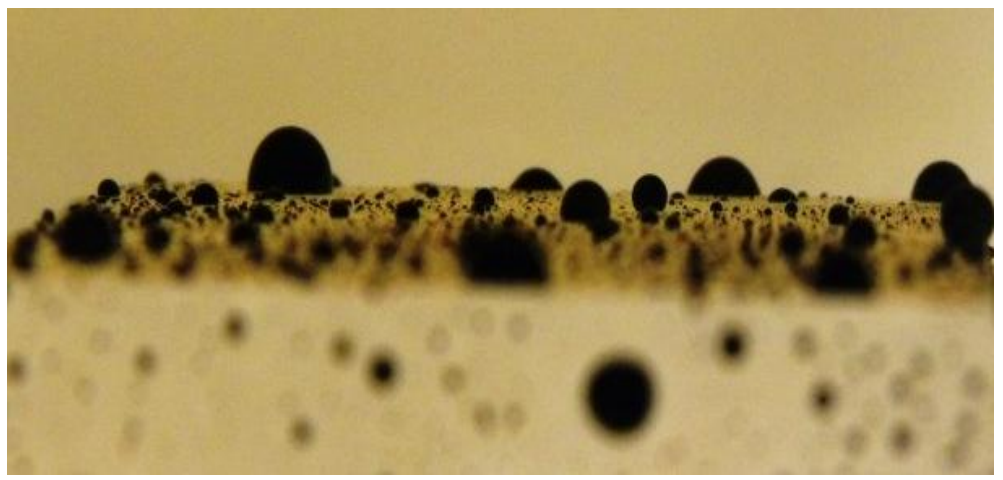

$1 \mathrm{wt} \%$ DTAB in injection brine

Figure 4-6: Contact angle in cationic surfactants 


\subsubsection{Dual surfactant systems}

Among the dual surfactant systems tested in this research, two of them appeared promising for wettability alteration. These two are $0.2 \mathrm{wt} \% \mathrm{NP}+0.1 \mathrm{wt} \% \mathrm{DTAB}$ and 0.2 $w t \% 15-S+0.1 w t \%$ DTAB, which showed wettability alteration from initial oil-wet to final intermediate-wet (Figure 4-7). Both of these surfactant systems were further used for spontaneous imbibitions experiments.

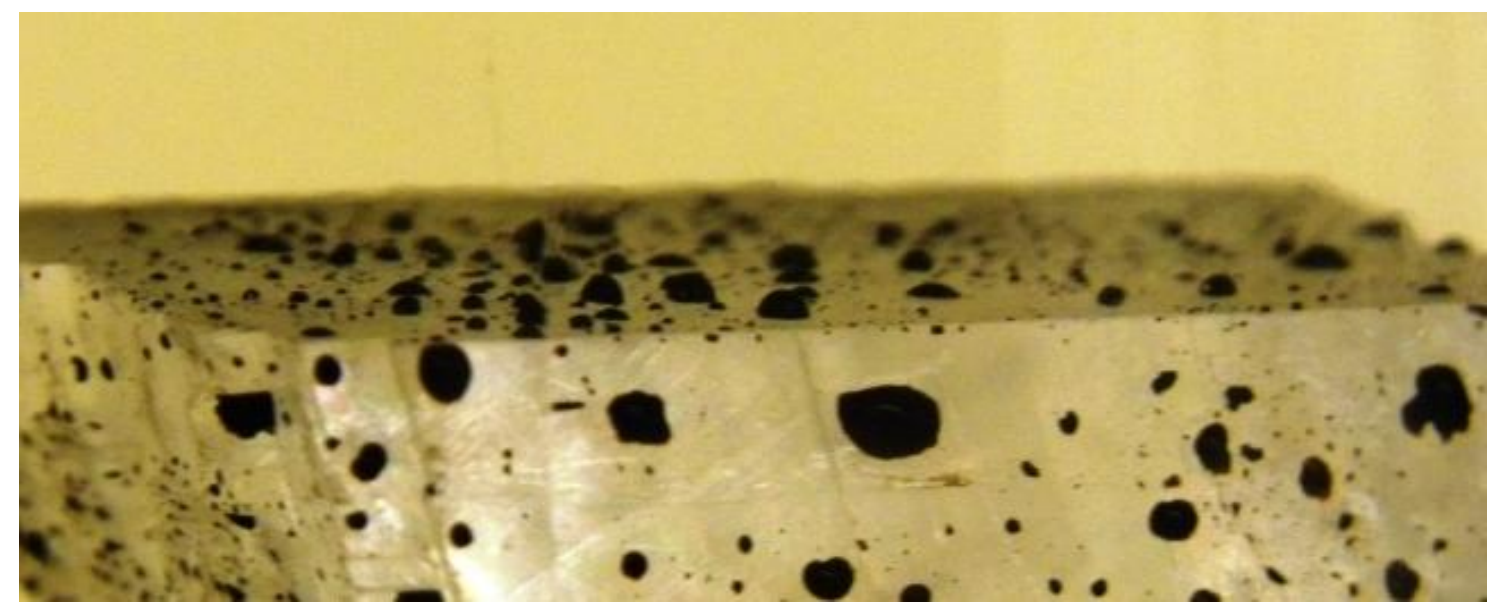

$0.2 \mathrm{wt} \% 15-\mathrm{S}+0.2 \mathrm{wt} \%$ DTAB in injection brine

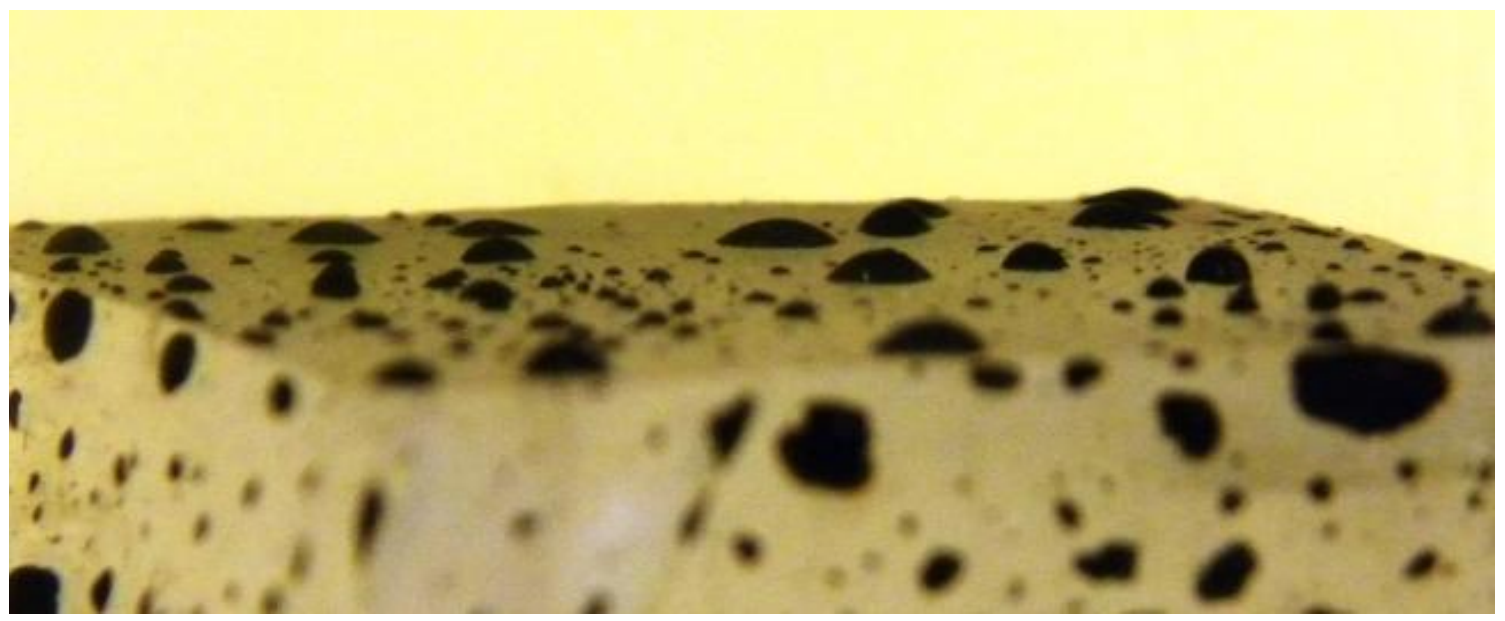

$0.2 \mathrm{wt} \% \mathrm{NP}+0.2 \mathrm{wt} \% \mathrm{DTAB}$ in injection brine

Figure 4-7: Contact angle in dual surfactant systems 


\subsubsection{Effect of divalent ions on wettability alteration}

The composition of divalent ions in the injection brine was varied such that the ionic strength remained the same (Table 4-3). It has been mentioned in the literature on the effects on wettability alteration due to divalent ions alone. 8 type of brines were made to check their effect on wettability alteration. They amount of salts in various brine have been tabled below. For example, a brine with a brine core of $0 \mathrm{Mg} 0 \mathrm{Ca} 4 \mathrm{~S}$ (in the table) will contain 4 times $\mathrm{SO}_{4}{ }^{2-}$ compared to injection brine but no $\mathrm{Mg}^{2+}$ and $\mathrm{Ca}^{2+}$.

\begin{tabular}{|c|c|c|c|c|c|}
\hline Brine Code & $\begin{array}{c}\mathrm{NaCl} \\
\text { (gm/liter) }\end{array}$ & $\begin{array}{c}\mathrm{MgCl}_{2} .6 \mathrm{H}_{2} \mathrm{O} \\
(\mathrm{gm} / \mathrm{liter})\end{array}$ & $\begin{array}{c}\mathrm{CaCl}_{2} .2 \mathrm{H}_{2} \mathrm{O} \\
(\mathrm{gm} / \text { liter })\end{array}$ & $\begin{array}{c}\mathrm{Na}_{2} \mathrm{SO}_{4} \\
\text { (gm/liter) }\end{array}$ & $\begin{array}{l}\mathrm{NaHCO}_{3} \\
\text { (gm/liter) }\end{array}$ \\
\hline $\mathrm{Mg} \mathrm{Ca} 0 \mathrm{~S}$ & 46.43 & 17.85 & 1.80 & 0.0 & 0.17 \\
\hline $\mathrm{Mg} \mathrm{Ca} 2 \mathrm{~S}$ & 35.97 & 17.85 & 1.80 & 12.69 & 0.17 \\
\hline $\mathrm{Mg} \mathrm{Ca} 4 \mathrm{~S}$ & 25.52 & 17.85 & 1.80 & 25.8 & 0.17 \\
\hline $4 \mathrm{Mg} 0 \mathrm{Ca} 0 \mathrm{~S}$ & 17.47 & 71.39 & 0.0 & 0.0 & 0.17 \\
\hline $4 \mathrm{Mg} 0 \mathrm{Ca} \mathrm{S}$ & 12.24 & 71.39 & 0.0 & 6.35 & 0.17 \\
\hline $0 \mathrm{Mg} 5 \mathrm{Ca} \mathrm{S}$ & 43.88 & 0.0 & 9.02 & 6.35 & 0.17 \\
\hline $0 \mathrm{Mg} 0 \mathrm{Ca} 4 \mathrm{~S}$ & 37.70 & 0.0 & 0.0 & 25.38 & 0.17 \\
\hline
\end{tabular}

Table 4-3: Composition of brines with varying divalent ion concentration 
The brine with brine code $0 \mathrm{Mg} 5 \mathrm{Ca} \mathrm{S}$ gave a precipitation on preparation, therefore it was not used for wettability alteration experiments. The results of the contact angle experiments are tabled below (Table 4-4);

\begin{tabular}{|c|c|c|}
\hline Brine & $\begin{array}{l}\text { Initial contact } \\
\text { angle }\end{array}$ & Final contact angle \\
\hline $\mathrm{Mg} \mathrm{Ca} 0 \mathrm{~S}$ & Oil wet & $\sim 140^{\circ}-150^{\circ}$ \\
\hline $\mathrm{Mg} \mathrm{Ca} 2 \mathrm{~S}$ & Oil wet & $\sim 130^{\circ}-140^{\circ}$ \\
\hline $\mathrm{Mg} \mathrm{Ca} 4 \mathrm{~S}$ & Oil wet & $\sim 110^{\circ}-120^{\circ}$ \\
\hline $4 \mathrm{Mg} 0 \mathrm{Ca} 0 \mathrm{~S}$ & Oil wet & $\sim 70^{\circ}-90^{\circ}$ \\
\hline $4 \mathrm{Mg} 0 \mathrm{Ca} \mathrm{S}$ & Oil wet & $\sim 90^{\circ}-120^{\circ}$ \\
\hline $0 \mathrm{Mg} 5 \mathrm{Ca} 0 \mathrm{~S}$ & Oil wet & $\sim 150^{\circ}$ \\
\hline $0 \mathrm{Mg} 0 \mathrm{Ca} 4 \mathrm{~S}$ & Oil wet & $\sim 70^{\circ}-90^{\circ}$ \\
\hline
\end{tabular}

Table 4-4: Results of contact angle experiments

Below are the pictures (Figure 4-8) of these contact angle experiments after the calcite/oil is equilibrated with these brines; 


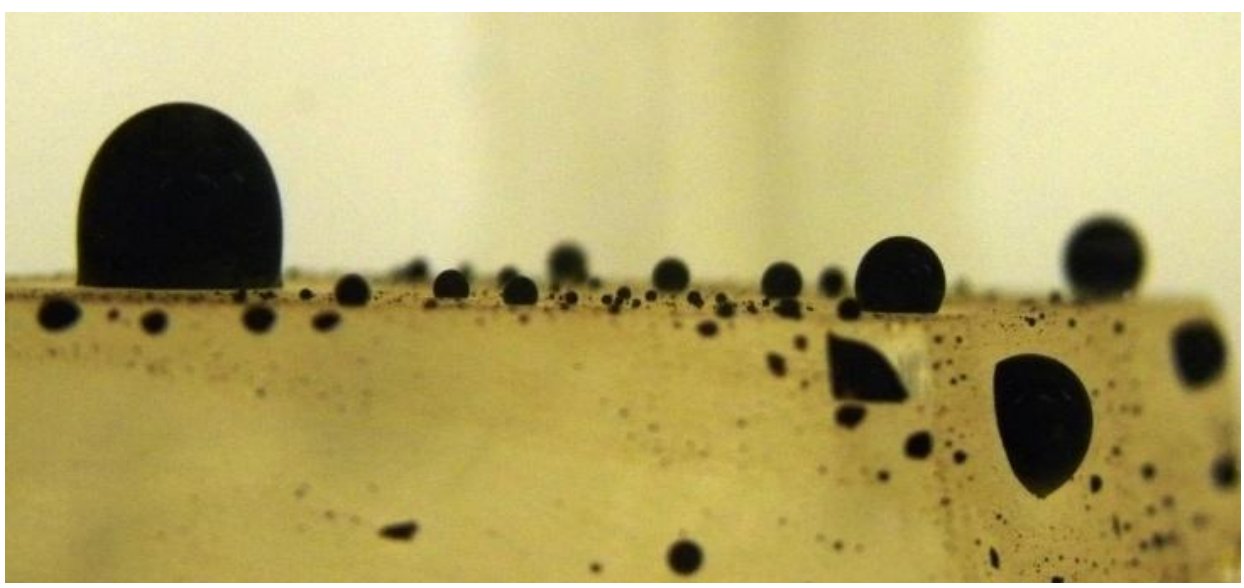

0Mg0Ca4S

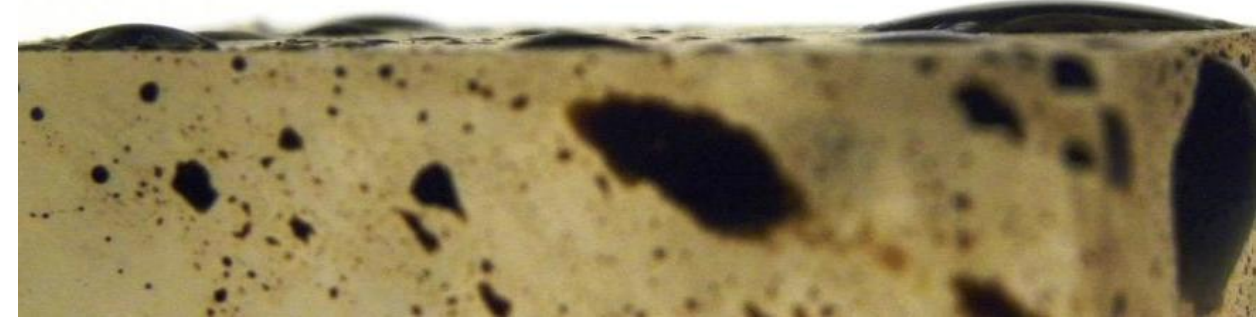

0Mg5Ca0S

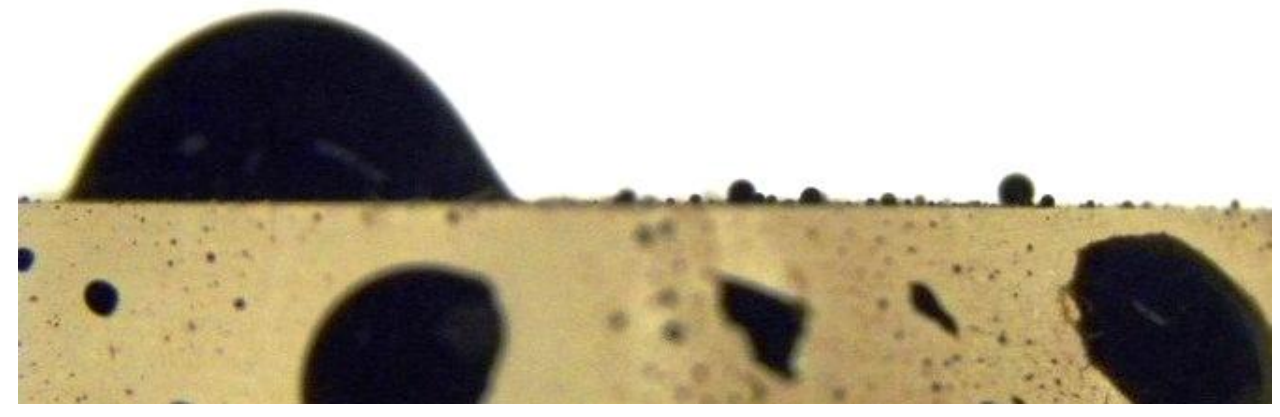

$4 \mathrm{Mg} 0 \mathrm{Ca} 0 \mathrm{~S}$ 


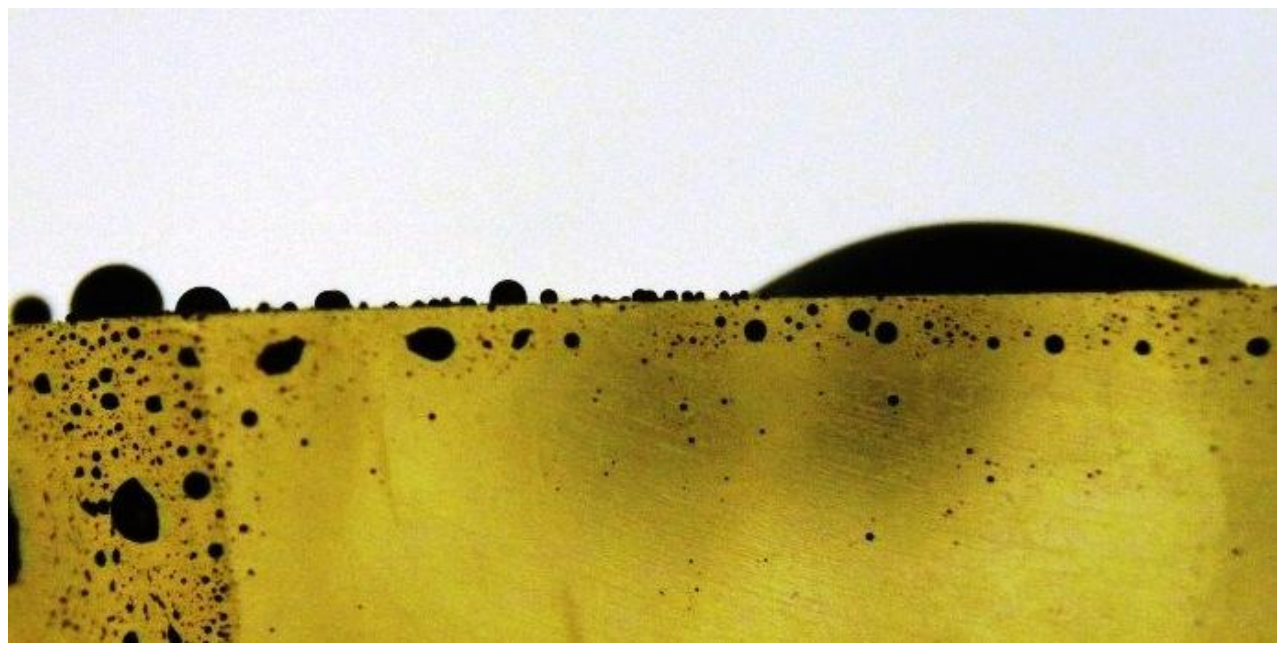

$4 \mathrm{Mg} 0 \mathrm{CaS}$

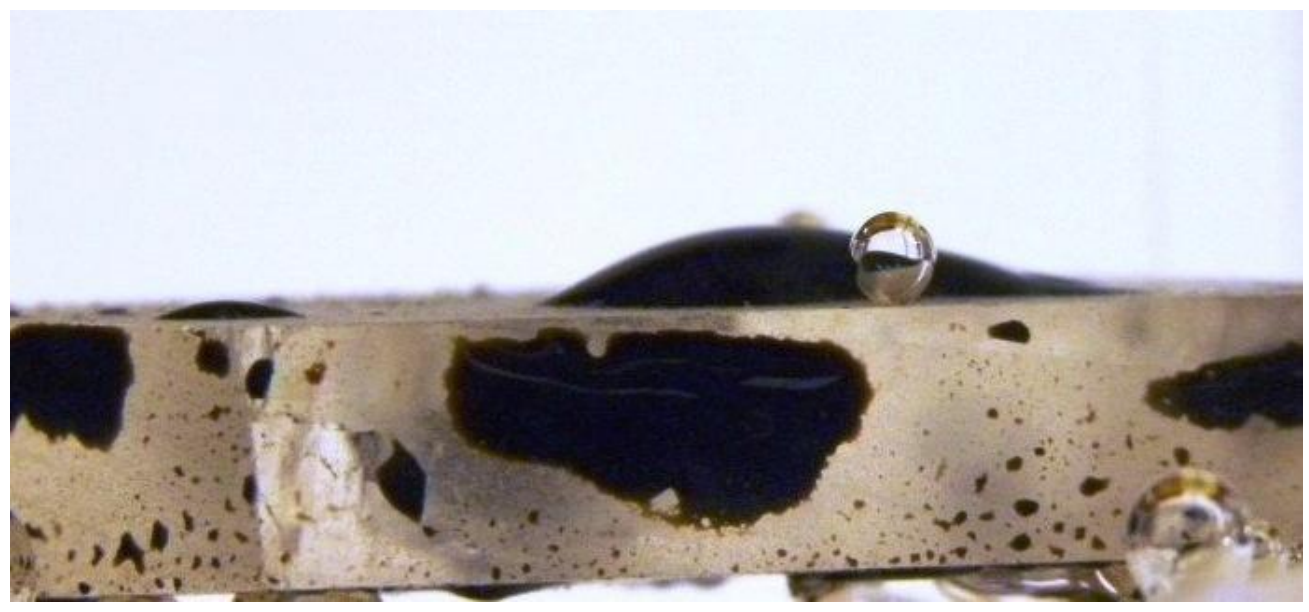

$\mathrm{MgCa} 0 \mathrm{~S}$

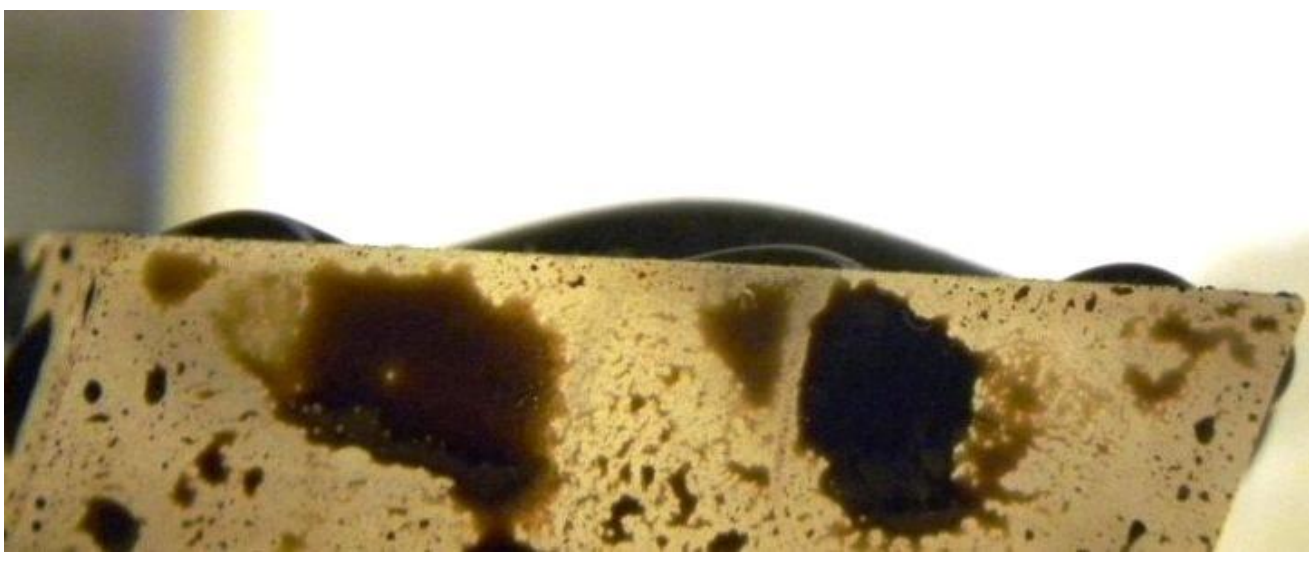

$\mathrm{MgCa} 2 \mathrm{~S}$

59 


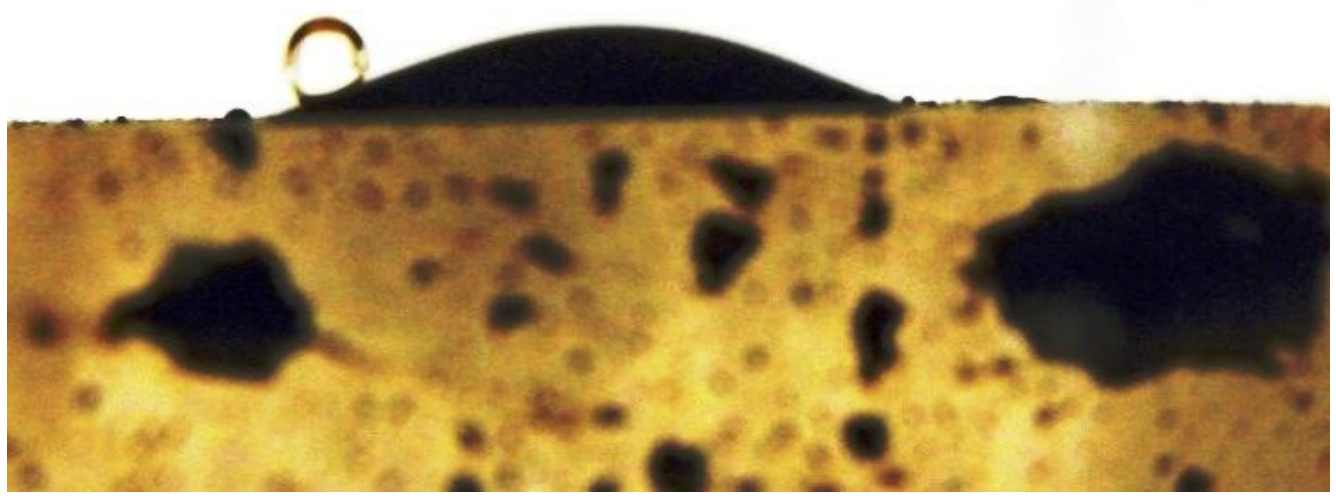

$\mathrm{MgCa} 4 \mathrm{~S}$

Figure 4-8: Contact angle experiment using various brines

3 types of brine gave the most wettability alteration on calcite plate; $0 \mathrm{Mg} 0 \mathrm{Ca} 4 \mathrm{~S}$, $4 \mathrm{Mg} 0 \mathrm{CaS}, 4 \mathrm{Mg} 0 \mathrm{Ca} 0 \mathrm{~S}$, suggesting the effect of sulphate and magnesium ion on wettability alteration. It was observed that $0 \mathrm{Mg} 5 \mathrm{Ca} 0 \mathrm{~S}$ gave oil wet character to calcite plate. Imbibition experiment was tried with $0 \mathrm{Mg} 0 \mathrm{Ca} 4 \mathrm{~S}$ and its detail will be presented in next section.

\subsection{SPONTANEOUS IMBIBITION}

Spontaneous Imbibition is the second step to confirm the effectiveness of wettability altering surfactants. Table 4-5 lists the cores, surfactants, and final recovery by spontaneous imbibitions. These are the surfactants which looked promising with calcite plate expts. Since, these experiments take more than a month to complete, only limited number of experiments were conducted. 


\begin{tabular}{|c|c|c|c|c|c|c|}
\hline \multirow[t]{2}{*}{$\begin{array}{l}\text { Expt. } \\
\text { no. }\end{array}$} & \multicolumn{4}{|c|}{ Core plug properties } & \multirow[t]{2}{*}{ Surfactant/Brine } & \multirow[t]{2}{*}{$\begin{array}{r}\text { Recovery } \\
\text { (\%OIP) }\end{array}$} \\
\hline & Length(in.) & Dia.(in.) & $\Phi(\%)$ & $\mathbf{k}(\mathbf{m d})$ & & \\
\hline 1 & 1.97 & 1.46 & 26.8 & 338.2 & Formation Brine & $10.2 \%$ \\
\hline 2 & 1.35 & 1.48 & 25.4 & 660.6 & Formation Brine & $14.6 \%$ \\
\hline 3 & 1.87 & 1.46 & 25.1 & 88.3 & Injection Brine & $9.6 \%$ \\
\hline 4 & 1.65 & 1.48 & 19 & 28.8 & $0 \mathrm{Mg} 0 \mathrm{Ca} 4 \mathrm{~S}$ & $42 \%$ \\
\hline 5 & 1.97 & 1.46 & 26.8 & 338.2 & $\begin{array}{c}0.2 \mathrm{wt} \% \mathrm{NP}+0.2 \\
\mathrm{wt} \% \mathrm{DTAB}\end{array}$ & $73.7 \%$ \\
\hline 6 & 1.49 & 1.48 & 24.8 & 775 & $\begin{array}{c}0.2 \mathrm{wt} \% \mathrm{NP}+0.2 \\
\mathrm{wt} \% \text { DTAB }\end{array}$ & $81.4 \%$ \\
\hline 7 & 1.35 & 1.48 & 25.4 & 660.6 & $\begin{array}{c}0.1 \mathrm{wt} \% \mathrm{NP}+0.2 \\
\text { wt } \% \text { DTAB }\end{array}$ & $73.4 \%$ \\
\hline 8 & 1.63 & 1.50 & 25.6 & 343.9 & $\begin{array}{c}0.2 \mathrm{wt} \% \mathrm{NP}-30+ \\
0.2 \mathrm{wt} \% \text { DTAB }\end{array}$ & $5.7 \%$ \\
\hline 9 & 1.52 & 1.50 & 23.1 & 664 & $\begin{array}{c}0.2 \mathrm{wt} \% \mathrm{NP}-50+ \\
0.2 \mathrm{wt} \% \text { DTAB }\end{array}$ & $13.3 \%$ \\
\hline 10 & 1.87 & 1.46 & 25.1 & 88.3 & $\begin{array}{c}0.2 \mathrm{wt} \% 15-\mathrm{S}+0.2 \\
\mathrm{wt} \% \text { DTAB }\end{array}$ & $9.6 \%$ \\
\hline
\end{tabular}


Table 4-5 (continued)

\begin{tabular}{|c|c|c|c|c|c|c|}
\hline 11 & 1.59 & 1.47 & 24.3 & 59.4 & $0.05 w t \%$ TDA30EO & $20.5 \%$ \\
\hline 12 & 1.98 & 1.47 & 23.7 & 42.7 & $1 \mathrm{wt} \%$ DTAB & $72 \%$ \\
\hline
\end{tabular}

Table 4-5: Spontaneous imbibition tests with and without surfactants

Expt. 1- 3 show that the imbibition recovery from restored state core plugs in presence of either formation brine or injection brine is low (10-15\%). The oil imbibing out of the core sticks to the core surface in the form of films suggesting that these cores are mixed-wet. During Expt. 4, a brine with different ionic composition (of the divalent ions) but same TDS compared to injection brine was used. This brine is coded $0 \mathrm{Mg} 0 \mathrm{Ca} 4 \mathrm{~S}$ (no magnesium, no calcium and 4 times the amount of sulphate compared to injection brine). Among other brine with varying divalent ion concentration used during calcite plate experiment, this brine was the most effective in changing the wettability of oil-wet calcite plate to water-wet and it also recovered $42 \%$ of OIP during imbibition.

Since most of the non-ionic surfactants were aqueous unstable at $100^{\circ} \mathrm{C}$, only TDA30EO was used for imbibition experiment. It should be noted that the wettability alteration on calcite plate at low concentration of TDA30EO $(0.05 \mathrm{wt} \%)$ was better compared to other non-ionic surfactants. Even though the oil imbibing out beaded up on the top surface of core plug (also on the sides initially) suggesting wettability alteration, only $20 \%$ of OIP (oil remaining after brine imbibtion) was recovered in this experiment.

Among the cationic surfactants, only DTAB (1 wt $\%)$ was used for imbibition experiment, and it recovered $72 \%$ of OIP (after brine imbibitions). This surfactant has been used extensively by other researchers (Austad and Stadnes, 2000). Further, we need 
to perform imbibition experiment with lower concentration of DTAB to get the optimum concentration. $\mathrm{CTAB}$ was aqueous unstable with injection brine at $100^{\circ} \mathrm{C}$ and was not used for imbibition.

Since one of the goals of this study was to find surfactant systems which can be used at dilute concentrations, the emphasis was on dual surfactant systems in the imbibitions experiments. During the contact angle experiments, the most wettability alteration was observed for the lowest member of a homologous series of non-ionic surfactants. Therefore, among the dual surfactant systems, systems made with NP and 15$\mathrm{S}$ were used. In Expt. 5, $0.2 \mathrm{wt} \% \mathrm{NP}+0.2 \mathrm{wt} \%$ DTAB recovered as much as $73.7 \%$ of OIP by spontaneous imbibition. This experiment was repeated again with a different core plug to verify its efficacy and again the recovery was $81.4 \%$ of OIP (Expt. 6). We decided to half the amount of surfactant but $0.1 \mathrm{wt} \% \mathrm{NP}+0.1 \mathrm{wt} \%$ DTAB was aqueous unstable at $100^{\circ} \mathrm{C}$; so we conducted the experiment using $0.1 \mathrm{wt} \% \mathrm{NP}+0.2 \mathrm{wt} \%$ DTAB. The recovery was around $73.4 \%$ of OIP (Expt. 7). After the success of dual surfactant system consisting of NP ethoxylates, we used systems made of higher members of same homologous series, NP-30 (0.2 wt $\%$ NP-30 + 0.2 wt $\%$ DTAB $)$ and NP-50 (0.2 wt $\%$ NP$50+0.2 \mathrm{wt} \%$ DTAB) for imbibitions experiments (Expt. 8, 9). Similar to the trend observed during calcite plate expt., the recovery here decreased for higher members of same homologous series. Further, $0.2 \mathrm{wt} \% 15-\mathrm{S}+0.2 \mathrm{wt} \%$ DTAB recovered only around $9.6 \%$ of OIP (Expt. 10).

These results show that (1) some of the surfactants which could alter wettability on calcite plate experiment do not recover much oil in spontaneous imbibition; therefore calcite plate experiment should only be used as a screening step, (2) spontaneous imbibition experiments are more definitive and more realistic, and (3) oil recovery by 
imbibitions decreases as the number of ethoxy groups increase for the same homologous series of non-ionic surfactants (which were used to make dual-surfactant systems).

Mattax and Kyte (1962) proposed the following equation for scaling of imbibition results for different oil/brine/rock systems

$$
t_{d}=C t \sqrt{\frac{k}{\phi}} \frac{\sigma}{\mu_{w}} \frac{1}{L^{2}}
$$

where $t_{d}$ is dimensionless time, $C$ the unit conversion factor $(C=0.018849), t$ the imbibitions time in minutes, $k$ permeability in md, $\Phi$ fractional porosity, $\sigma$ the IFT in dynes/cm, $\mu_{\mathrm{w}}$ water viscosity in $\mathrm{cp}$ and $L$ a characteristic length of the core plug. This equation assumes constant water-wet wettability and similar oil and water viscosity (Ma and Morrow, 1993). This dimensionless time takes into account the variation in core size, permeability, IFT, and viscosity between experiments.

We used this equation to compare the imbibitions results of the dual surfactant systems in Table 3. Figure 4-9 shows the oil recovery for some of the dual surfactant systems and for $1 \mathrm{wt} \%$ DTAB (Expt. 5-7, 10, 12) as a function of time. The two experiments with $0.2 \mathrm{wt} \% \mathrm{NP}-10+0.2 \mathrm{wt} \% \mathrm{DTAB}$ (performed with two separate core plugs) have similar recovery but different recovery rates. When the recovery is plotted against the dimensionless time, both the recoveries look similar (as shown in Figure 410), conforming the repeatability of results for this surfactant system. The final oil recovery with $0.1 \mathrm{wt} \% \mathrm{NP}-10+0.2 \mathrm{wt} \%$ DTAB is similar to $0.2 \mathrm{wt} \% \mathrm{NP}-10+0.2 \mathrm{wt} \%$ $\mathrm{DTAB}$, but the recovery rates in dimensionless time are quite different. $1 \mathrm{wt} \%$ DTAB also performs similar to the dual surfactant system $0.2 \mathrm{wt} \% \mathrm{NP}+0.2 \mathrm{wt} \%$ DTAB as evident from the recovery vs. dimensionless time plot. 


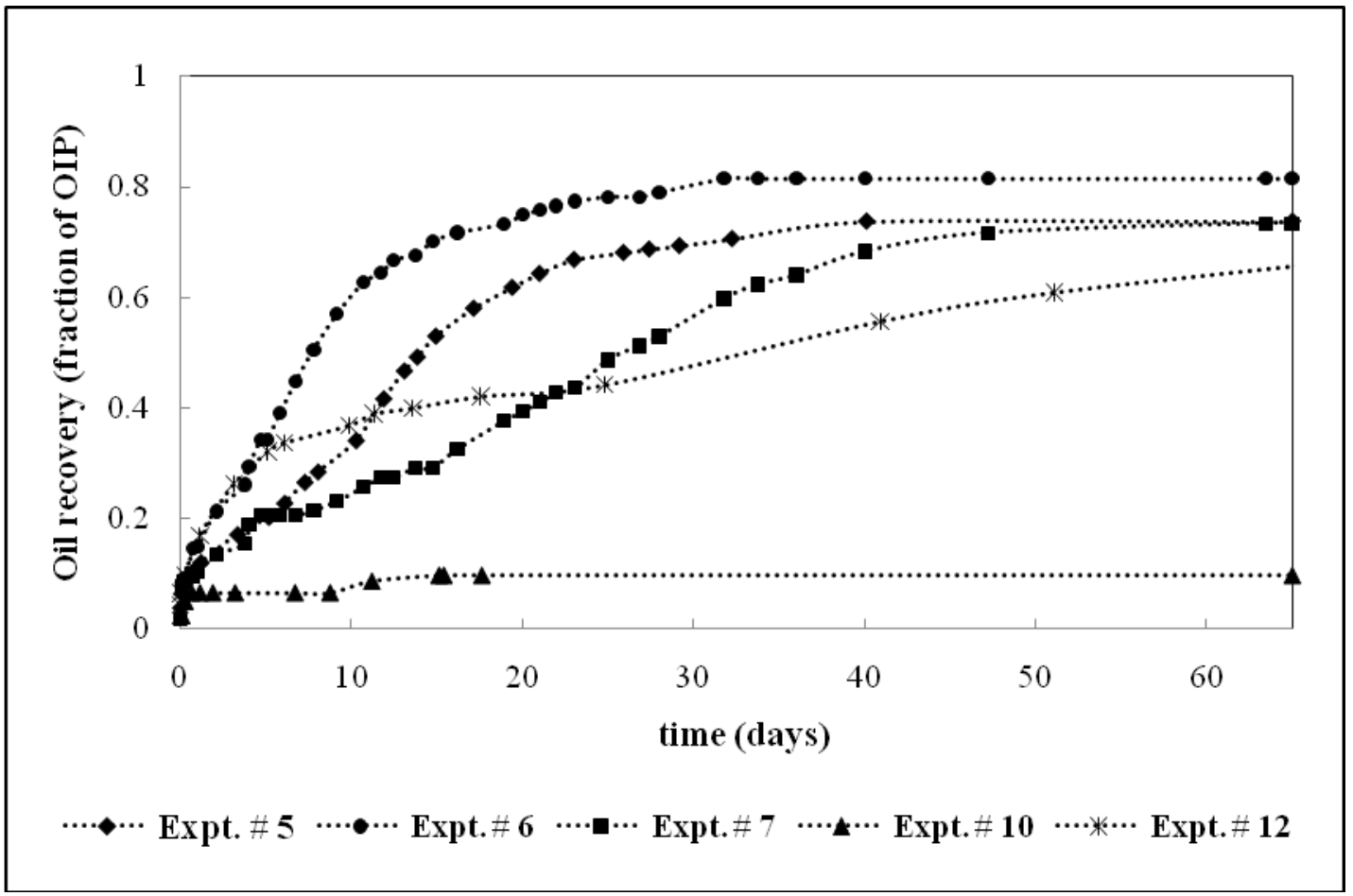

Figure 4-9: Oil recovery during imbibition vs. time

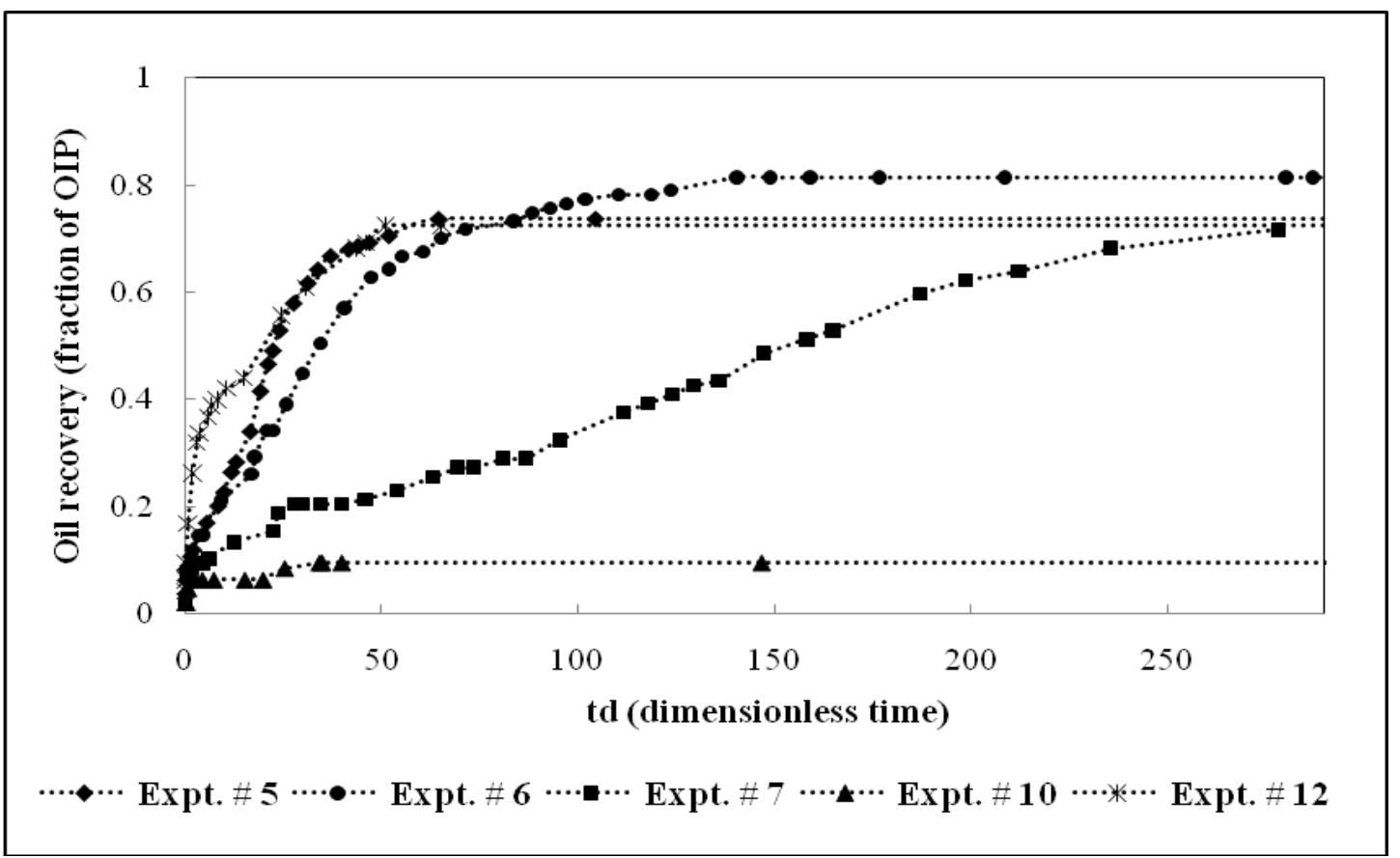

Figure 4-10: Oil recovery during imbibition vs. dimensionless time 


\subsection{CORE FLOOD}

Because the dual surfactant system $0.2 \mathrm{wt} \% \mathrm{NP}+0.2 \mathrm{wt} \%$ DTAB gave large spontaneous imbibition, it was used for the modified water-flood. This was the best system (dilute concentration, high oil recovery, and high recovery rate during imbibition) among those tested in this study. During the waterflood and the modified waterflood, the core was first flooded with brine/surfactant at $0.06 \mathrm{ml} / \mathrm{min}$ (interstitial velocity $=1 \mathrm{ft} /$ day) for $5 \mathrm{PV}$. Then the flow rate was stepped up to $1 \mathrm{ml} / \mathrm{min}$ (interstitial velocity $=17 \mathrm{ft} /$ day) and $5 \mathrm{PV}$ of injection brine was flooded through the core. Finally the flow rate was stepped up to $10 \mathrm{ml} / \mathrm{min}$ ((interstitial velocity $=167 \mathrm{ft} /$ day) and an additional $10 \mathrm{PV}$ of injection brine was injected through the core. As mentioned before, this was done to observe the rate dependence of residual oil saturation for these carbonate cores. Table 46 summarizes the properties of the core composite.

\begin{tabular}{|l|l|}
\hline & 6.0 \\
\hline Length (in.) & 1.5 \\
\hline Diameter (in.) & 24.5 \\
\hline Porosity (\%) & $120.7 / 85$ \\
\hline Air / Brine Permeability (md) & 0.61 \\
\hline Oil End Point Rel. Perm., So=Soi & \\
\hline
\end{tabular}

Table 4-6: Core composite properties 


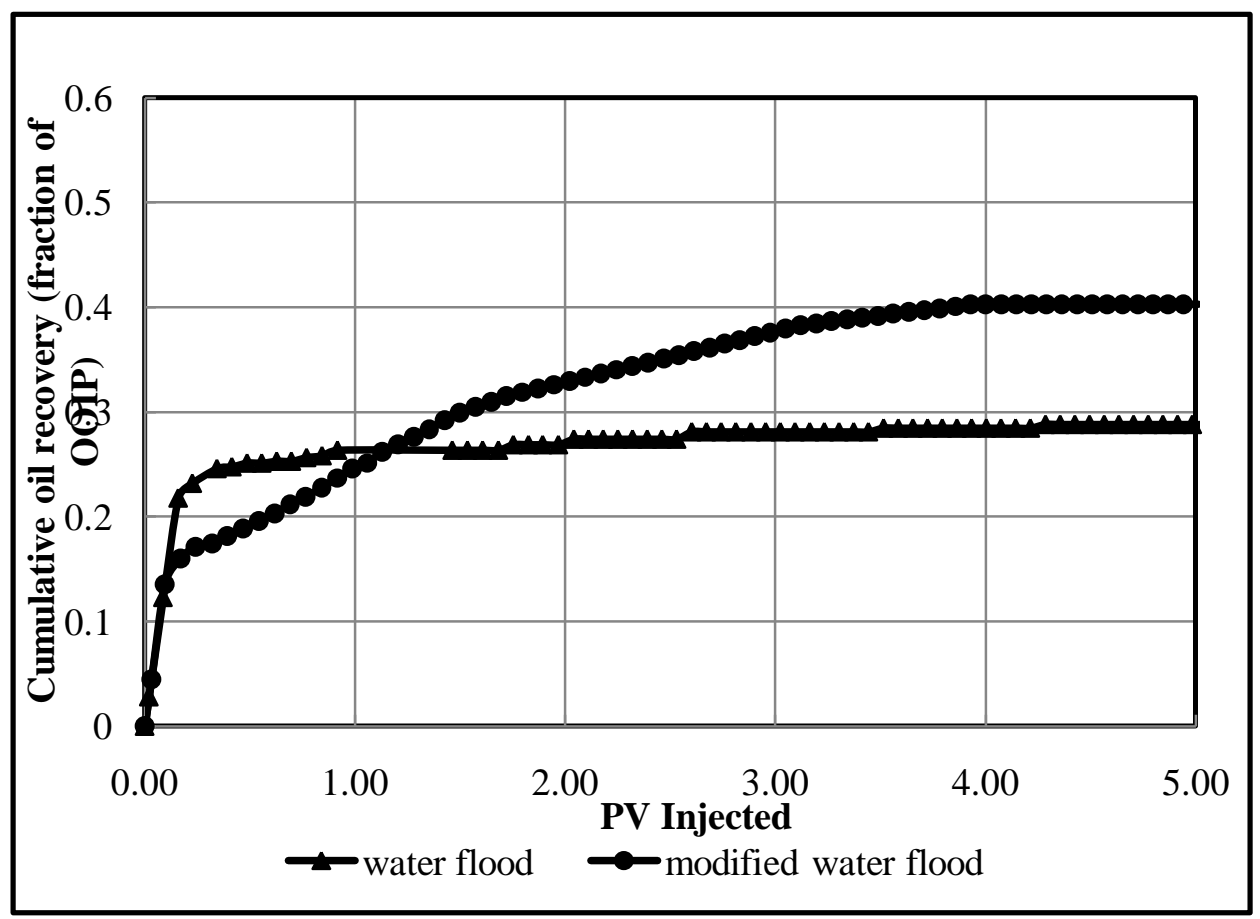

Figure 4-11: Oil recovery during water-flood and modified water-flood

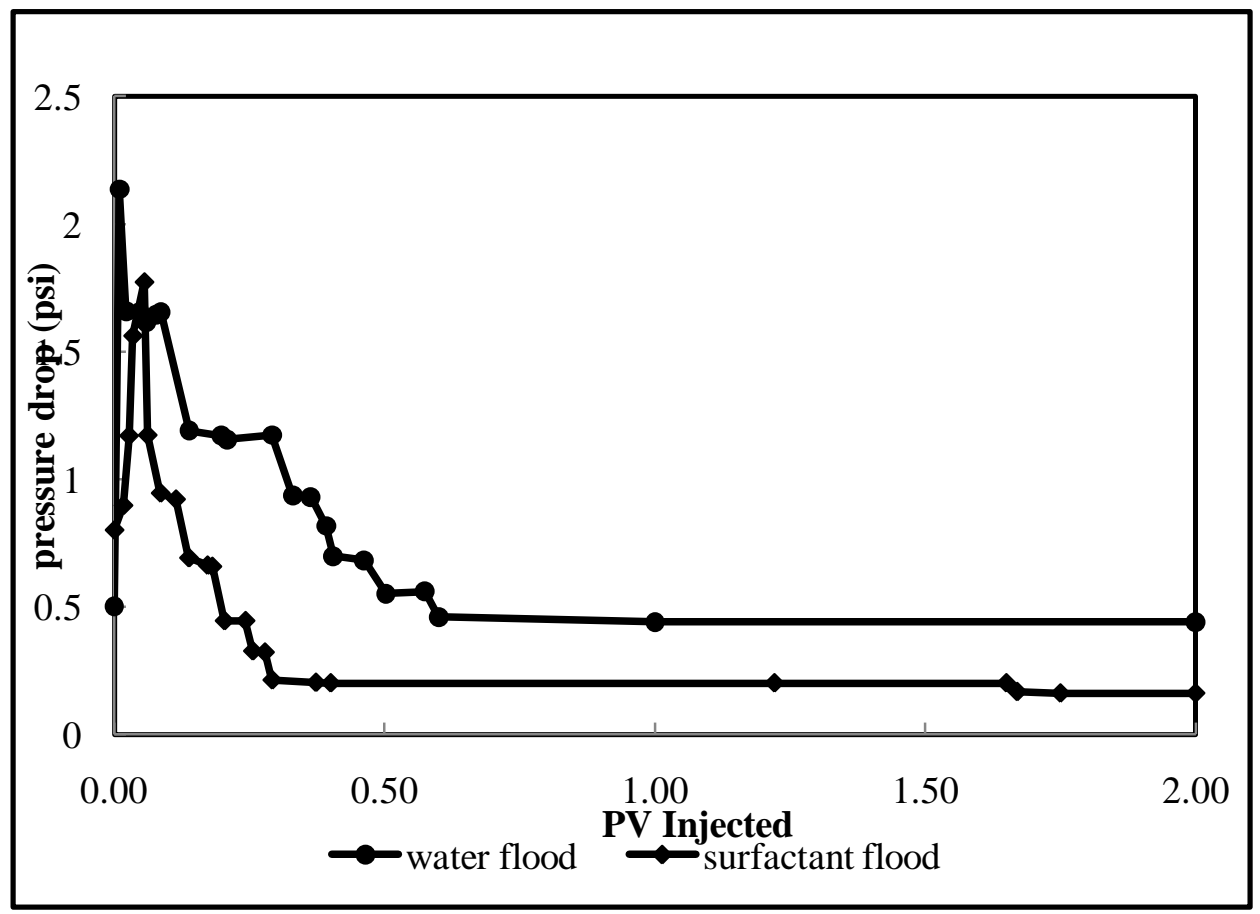

Figure 4-12: Pressure drop during water-flood and modified water-flood 
Table 4-7 summarizes the water flood and surfactant enhanced modified waterflood results. For the first $5 \mathrm{PV}$ injected at $1 \mathrm{ft} /$ day, the cumulative oil recovery is higher for the modified water flood (40\% OOIP) compared to that of the water-flood (29\% OOIP). This difference is very significant. By addition of the wettability altering surfactant in dilute concentration, the secondary waterflood oil recovery can be improved a lot. There is no polymer, alkali, or co-solvent in this chemical flood. These floods were conducted at typical field flow rates. Figure 4-11 compares the cumulative oil recovery of waterflood to modified waterflood for the first 5 PVs. A lot of oil is produced after breakthrough in the surfactant modified water-flood. The time dependence of the oil recovery is very accurate for the modified water-flood; it may be slightly corrupted by the back pressure regulator volume for the water-flood (but the final cumulative recovery number is accurate). Figure 4-12 shows the pressure drop for the two water-floods. The maximum pressure drop is under $2 \mathrm{psi} / \mathrm{ft}$ in both cases, a reasonable value for fields. The pressure drop was slightly lower in the case of the surfactant modified water-flood.

\begin{tabular}{|c|c|c|}
\hline & Water-Flood & $\begin{array}{c}\text { Modified Water- } \\
\text { Flood }\end{array}$ \\
Soi & 0.71 & 0.70 \\
\hline Surfactant Injected@0.06 $\mathrm{ml} / \mathrm{min}(\mathrm{PV})$ & None & 1.2 \\
\hline Brine Injected@0.06 ml/min (PV) & 5 & 3.8 \\
\hline
\end{tabular}


Table 4-7 (continued)

\begin{tabular}{|c|c|c|}
\hline Oil recovery (\%OOIP) in first 5PV & $29 \%$ & $40 \%$ \\
\hline Brine Injected@1 ml/min (PV) & 5 & 5 \\
\hline Oil recovery (\%OOIP) in second 5PV & $25 \%$ & $15 \%$ \\
\hline Brine Injected@10 ml/min (PV) & 10 & 10 \\
\hline Oil recovery (\%OOIP) in last 10 PV & $3 \%$ & $61 \%$ \\
\hline & & \\
\hline
\end{tabular}

Table 4-7: Summary of core flood results

The second $5 \mathrm{PV}$ of flooding occurred at $17 \mathrm{ft} /$ day, an artificially high velocity. $25 \%$ OOIP was recovered in the water-flood compared to $15 \%$ OOIP in the modified water-flood. This shows that even the waterflood is sensitive to the capillary number at low capillary numbers. This observation was also made for carbonate waterfloods by Kamath et al. (2001). 3-6\% OOIP oil was recovered in the last 10 PV injection at 167 $\mathrm{ft} /$ day. Most of the recoverable oil was recovered prior to this flow rate injection. The 
end-point brine permeability was calculated after the core was flooded with $10 \mathrm{PV}$ of brine at $10 \mathrm{ml} / \mathrm{min}$. As the total oil recovery was similar for both the floods, the end-point brine permeability was also similar.

Surfactant adsorption was done for this core flood by measuring the effluent surfactant concentration using HPLC+ (Dionex). Both the surfactants in the dual surfactant system, DTAB and NP-10 showed distinct peak on HPLC analysis (around 14 minutes and 19 minutes respectively). Figure 4-13 shows graph of surfactant concentration in effluent w.r.t to PV injected,

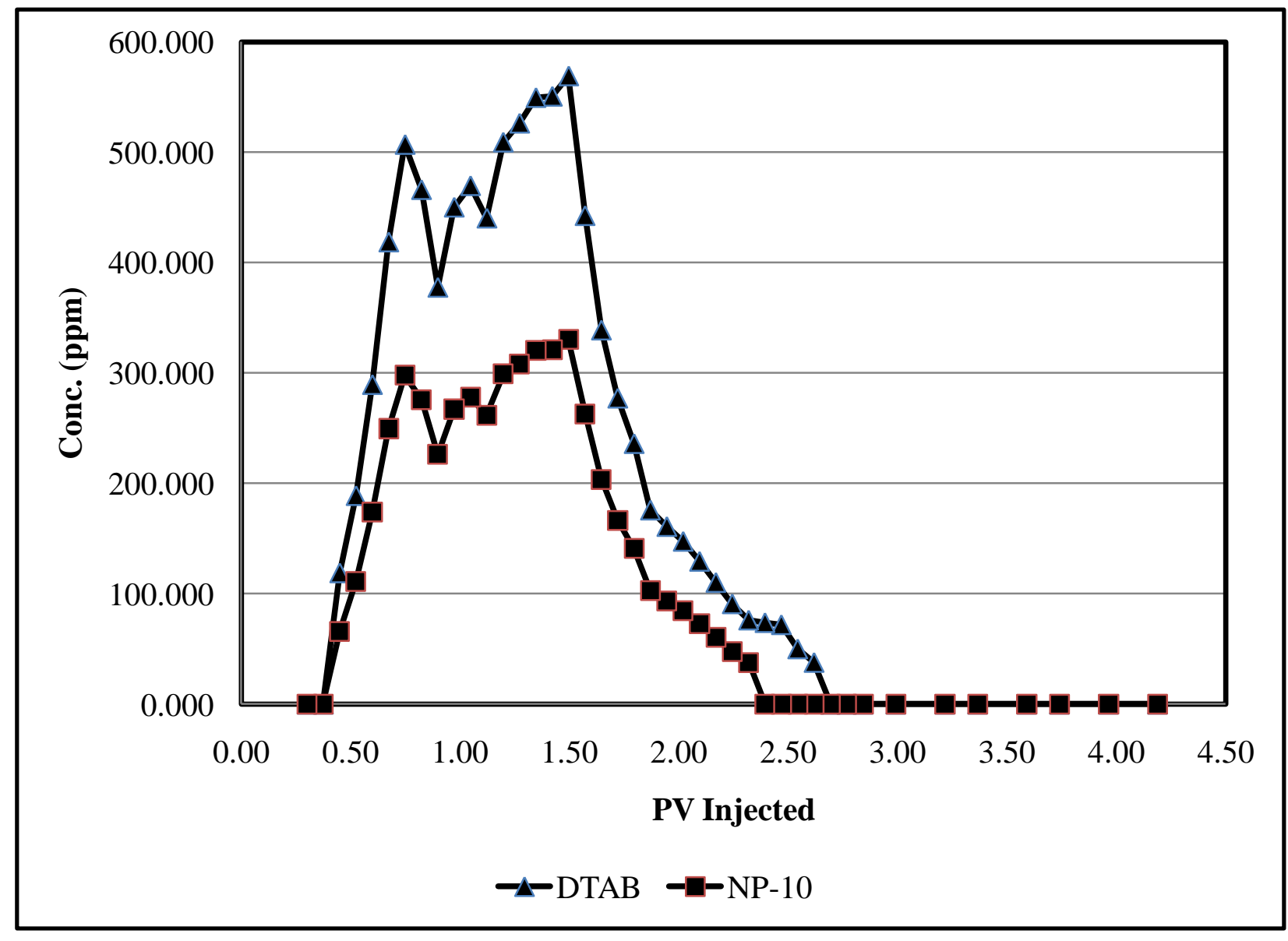

Figure 4-13: Surfactant concentration in effluent for modified water flood 
The amount of surfactant injected was $2000 \mathrm{ppm}(0.2 \mathrm{wt} \%)$ each of NP-10 and DTAB for about 1.2 pore volume. The surfactant injected was $0.28 \mathrm{mg} / \mathrm{gm}$ of rock for both the surfactants and the adsorption was $0.24 \mathrm{mg} / \mathrm{gm}$ of rock ( $84 \%$ adsorbed) for NP10 and $0.20 \mathrm{mg} / \mathrm{gm}$ of rock ( $72 \%$ adsorbed) for DTAB. Almost all of the surfactant is adsorbed, and the surfactant adsorption is far below the norms in low IFT laboratory corefloods. During real production, this is beneficial as it avoids the costs of surface separation of surfactants.

A waterflood was performed after the modified water flood to conform the wettability alteration of the core composite during the flood. At the end of modified water flood, the core composite was at $\mathrm{S}_{\text {or }}$ and saturated with injection brine. Without replacing injection brine with formation brine (to ensure that the wettability doesn't change), the core composite was saturated with oil using centrifugation. This core composite was then used for waterflood. The details of this waterflood are tabulated below (Table 4-8);

\begin{tabular}{|c|c|}
\hline & $\begin{array}{c}\text { Waterflood post } \\
\text { surfactant flood }\end{array}$ \\
\hline Soi & 0.71 \\
\hline Brine Injected@0.06 ml/min (PV) & 5 \\
\hline Oil recovery $(\%$ OOIP) in first 5PV & $44 \%$ \\
\hline
\end{tabular}


Table 4-8 (continued)

\begin{tabular}{|c|c|}
\hline Brine Injected@1 ml/min (PV) & 5 \\
\hline Oil recovery (\%OOIP) in second 5PV & $16 \%$ \\
\hline Brine Injected@10 ml/min (PV) & 10 \\
\hline Oil recovery (\%OOIP) in last 10 PV & $1 \%$ \\
\hline Brine End Point Rel. Perm. at Sorw & \\
\hline
\end{tabular}

Table 4-8: Summary of core flood results

The recovery from this waterflood is very similar to the surfactant flood (recovery at flow rate of $1 \mathrm{ft} /$ day is slightly more than the surfactant flood). The relative permeability was calculated (using JBN method) for the initial waterflood and waterflood post the secondary surfactant flood. It is to be noted that the brine end point rel. perm in the Table 4-8 above is 0.65 compared to 0.39 for water flood done before surfactant flood (Table 4-7). But this is calculated (using step changes in flowrate) after $\sim 10 \mathrm{PV}$ of brine have been injected in the core composite at very high flow rate $(10 \mathrm{ml} / \mathrm{min} \approx 167$ 
$\mathrm{ft} /$ day). This is different from the relative permeabilities calculated (using JBN method) during the injection of first $5 \mathrm{PV}$ of brine at low flow rate $(0.06 \mathrm{ml} / \mathrm{min} \approx 1 \mathrm{ft} /$ day $)$. 


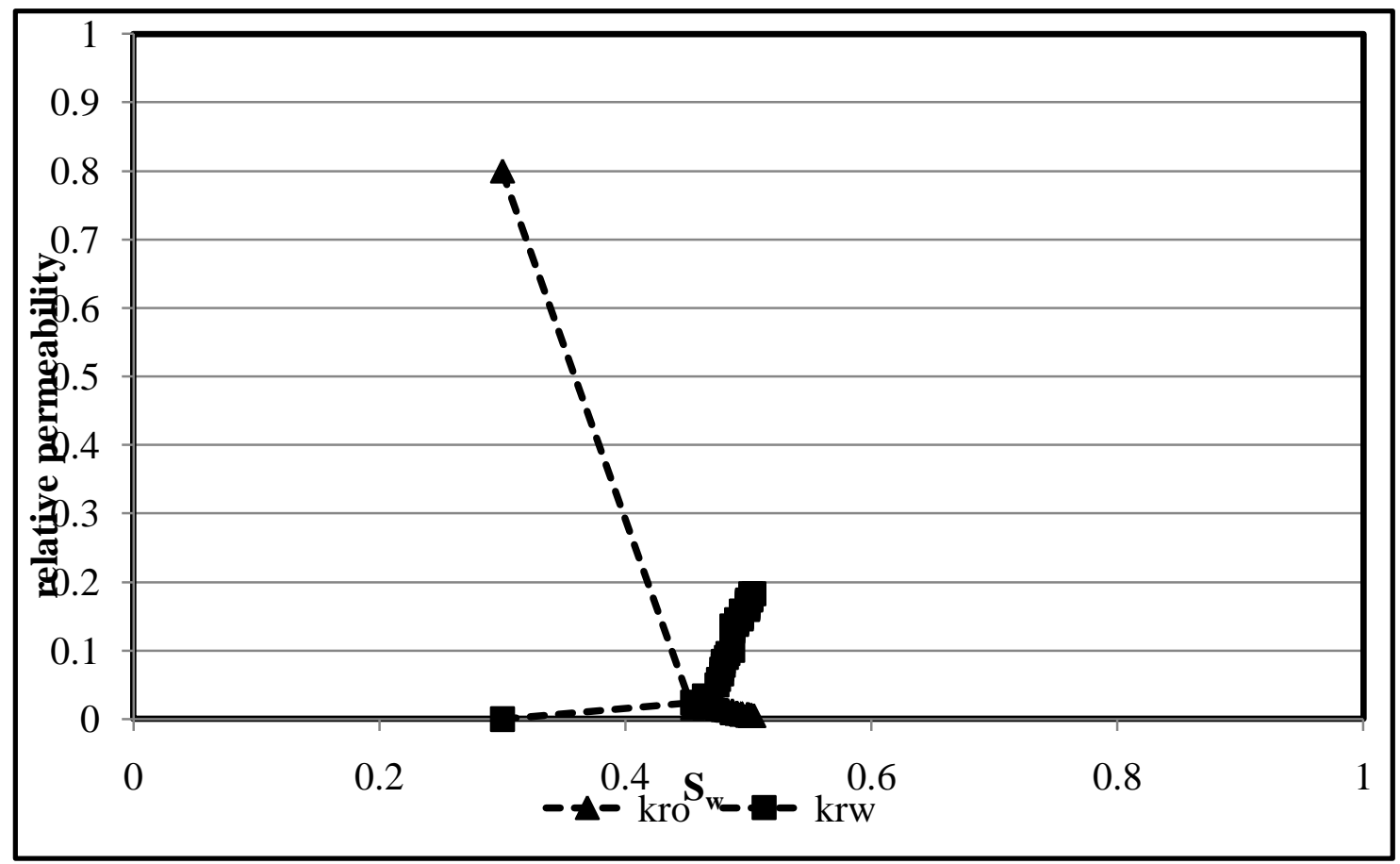

Figure 4-14: Relative permeability calculation for waterflood before surfactant flood

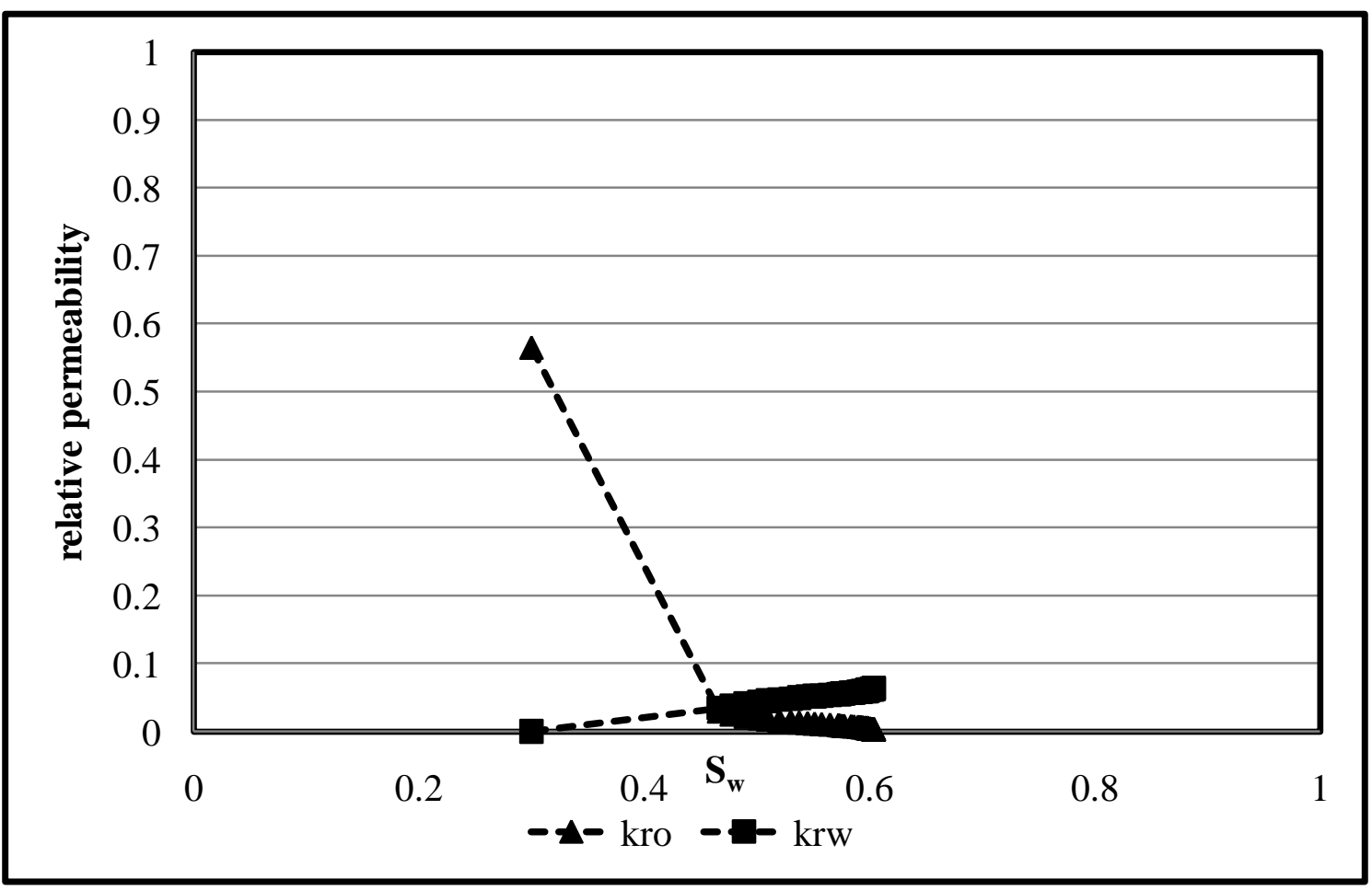

Figure 4-15: Relative permeability calculation for waterflood post surfactant flood 
Figure 4-14 and 4-15 show relative permeability for waterflood pre and post surfactant flood. It is evident from these graphs that the wettability has indeed changed towards water-wet after the surfactant flood.

An important thing to note about the quality of data recorded during the core flood experiments. These corefloods are carried out at reservoir temperature of $100^{\circ} \mathrm{C}$, so it becomes necessary to pressure the coreflood apparatus using a back pressure regulator (BPR). The BPR contributes to the overall dead volume of the system (the fluid chamber inside BPR depends on its type; spring loaded small size BPR may have 2-3 $\mathrm{ml}$ of dead volume where as diaphragm loaded BPR with external pressure requirement have typically $5-10 \mathrm{ml}$ of dead volume). Along with that, the mechanism to sustain pressure upstream of BPR is by allowing the produced liquid to flow through thin channels (see the fluid chamber below). Figure 4-16 is picture of BPR (Swagelok) used during these corefloods.
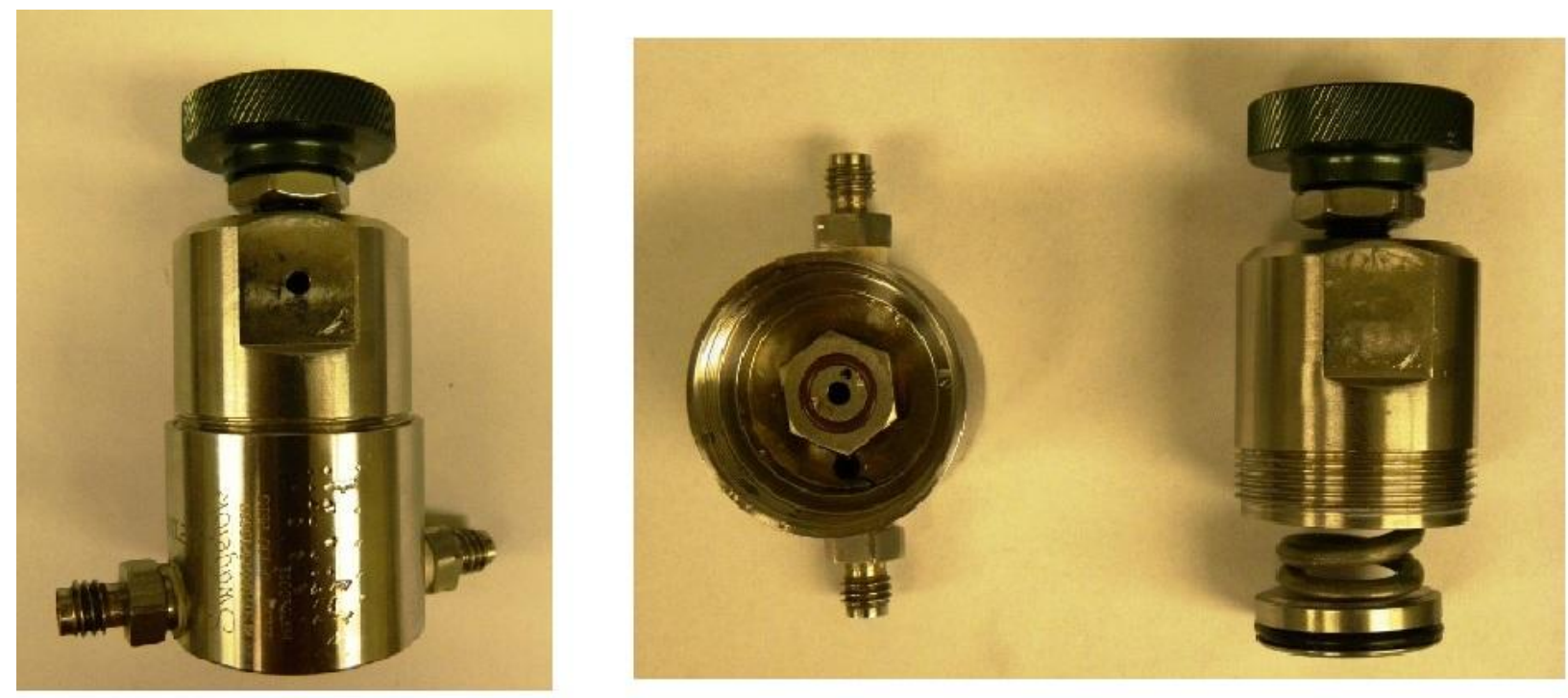

Figure 4-16: Whole BPR (left), fluid chamber (middle) and spring loaded piston (right) 
All the wettability altering surfactants used in this research have an IFT of more than 1 dynes/cm with the oil ( 3 orders of magnitude higher than ultra low IFT floods). After breakthrough in a waterflood or modified waterflood, (high oil/water IFT), the ratio of oil and water produced before BPR and after BPR is slight different. Two observations were made here, 1) if smaller slugs of oil in water are entering BPR, large slugs of oil in water were exiting BPR and 2) the amount of liquid collected in fixed time was varying $\pm 15 \%$. This effects the oil cut calculation (but not the overall recovery) and might affect the relative permeability calculations.

This study shows that secondary waterflooding with a dilute wettability altering surfactant can improve the oil recovery rate significantly in the laboratory scale. Further research should be conducted for the scale-up of this process. 


\section{Chapter 5: Conclusions}

Wettability alteration to improve water flood oil recovery for a high salinity, high temperature carbonate reservoir using dilute surfactants has been studied using contact angle measurements, spontaneous imbibition experiments and modified waterflood (secondary surfactant flood).

\subsection{CONCLuSIONS}

Based on the studies, the following conclusions can be made;

1) As the number of EO groups in the same homologous series of non-ionic surfactants increases, the water-wetness of the calcite plate decreases.

2) Varying the ionic composition of injection brine altered the wettability. Strong water-wet character was observed for $0 \mathrm{Mg} 0 \mathrm{Ca} 4 \mathrm{~S}$ and $4 \mathrm{Mg} 0 \mathrm{Ca} 0 \mathrm{~S}$.

3) Dimensionless time for spontaneous imbibition verifies the repeatability of experiments as well as gives a basis to compare different surfactant systems.

4) Dual surfactant systems are suitable for wettability alteration in high temperature, high salinity reservoirs due to aqueous stability.

5) Mixture of cationic and non-ionic surfactants in dilute concentration can recover about $70-80 \%$ of the oil by spontaneous imbibition.

6) Core flood shows that secondary waterflooding with a dilute wettability altering surfactant can improve the oil recovery significantly in the laboratory-scale over that of a waterflood. The first 5 PV oil recovery increased from $29 \%$ OOIP to $40 \%$ OOIP.

7) Water flood done after the secondary surfactant flood revealed wettability alteration towards water-wet (using relative permeability measurements). 


\subsection{FUTURE DIRECTIONS}

Below is the list of experiments and simulations which can be studied in future;

1) Spontaneous imbibtion experiment using dual surfactants made using anionic and non-ionic surfactants (Alkoxy sulfonates and Alkyl ethoxylates).

2) Tertiary surfactant flood using the dual surfactant system used for secondary flood.

3) Builiding a simulation model using the imbibition, relative permeability and core flood data. 


\section{References}

Anderson, W. G.: "Wettability Literature Survey-Part 1: Rock/Oil/Brine Interactions and the Effects of Core Handling on Wettability," Journal of Petroleum Technology, October 1986.

Anderson, W. G.: "Wettability Literature Survey-Part 2: Wettability Measurement," Journal of Petroleum Technology, November 1986.

Anderson, W. G.: "Wettability Literature Survey-Part 4: Effects of Wettability on Capillary Pressure," Journal of Petroleum Technology, October 1987.

Anderson, W. G.: "Wettability Literature Survey-Part 5: The Effects of Wettability on Relative Permeability," Journal of Petroleum Technology, November 1987.

Anderson, W. G.: "Wettability Literature Survey-Part 6: The Effects of Wettability on Waterflooding," Journal of Petroleum Technology, December 1987.

Adibhatla, B., \& Mohanty, K. K.: "Oil Recovery from Fractured Carbonates by Surfactant-Aided Gravity Drainage: Laboratory Experiments and Mechanistic Simulations," SPEREE, 11, 119-130 (2008).

Chilingar, G. V. and Yen, T. F.: "Some Notes on Wettability and Relative Permeabilities of Carbonate Reservoir Rocks, II," Energy Sources (1983) 7, No. 1, 67-75.

Gupta, R. and Mohanty, K. K.: "Temperature Effects on Surfactant-Aided Imbibition into Fractured Carbonates," SPE Journal, 15 (3), 588-597 (2010).

Gupta, R. and Mohanty, K. K.: "Wettability alteration of Fractured Carbonate Reservoirs," SPE 110204, proceedings of SPE ATCE, Anaheim, California, 11-14 November 2001.

Hagoort, J.: "Oil Recovery by Gravity Drainage," SPEJ, 20(3), 139-150, June 1980.

Hirasaki, G. and Zhang, D.L.: "Surface Chemistry of Oil Recovery from Fractured, OilWet, Carbonate Formation," SPEJ, 9(2), 151-162 (June 2004).

Jadhunandan, P. P. and Morrow, N. R.: "Effect of Wettability on Waterflood Recovery for Crude-Oil/Brine/Rock Systems," SPERE, 10 (1), 40-46 (1995).

Kamath, J., Meyer, R. F., Nakagawa F. M.: "Understanding Waterflood Residual Oil Saturation of Four Carbonate Rock Types," SPE 71505, proceedings of SPE ATCE, New Orleans, Louisiana, 30 September-3 October 2001.

Kralchevsky, P. A., Danov, K. A., Kolev, V. L., Gurkov, T. D., Temelska, M. I. and Brenn, G.: "Detachment of Oil Drops from Solid Surfaces in Surfactant Solutions: Molecular Mechanisms at Moving Contact Line," Ind. Eng. Chem. Res., 44, 1309-1321 (2005). 
Ma, S. and Morrow, N. R.: "Similarity of Pore Structure and the Selection of Core Samples for Tests of Scaling," Proceedings of the $9^{\text {th }}$ Wyoming EOR Symposium, Casper, Wyoming, 12-13 May, 1993.

Ma, S., Zhang, X., and Morrow, N.R., "Influence of Fluid Viscosity on Mass Transfer between Rock Matrix and Fractures," Journal of Canadian Petroleum Technology, 38(1999), 25-30.

Morrow, N. R.: "Wettability and Its Effect on Oil Recovery," Journal of Petroleum Technology, December 1990.

Manrique, E.J., Muci, V.E., Gurfinkel, M.E.: "EOR field experiences in carbonate reservoirs in the United States," SPE 100063, proceedings of SPE/DOE on Improved oil Recovery Symposium, Tulsa, Oklahoma, 22-26 April 2006.

Mattax, C. C. and Kyte, J. R.: "Imbibition Oil Recovery from Fractured, Water Drive Reservoir," SPEJ, 177-84 (June 1962).

Roehl, P.O. and Choquette, P.W.: "Carbonate Petroleum Reservoirs," Springer-Verlag, New York (1985).

Salathiel, R. A.: "Oil Recovery by Surface Film Drainage In Mixed-Wettability Rocks," JPT, 25 (100, 1216-1224 (1973).

Schechter, D.S., Zhou, D. and Orr, F.M., "Low IFT and Drainage," Journal of Petroleum Science and Engineering, 11(1994): 283-300.

Schott, H. and Royce A. E.: "Effect of Inorganic Additives on Solutions of Nonionic Surfactants VI: Further Cloud Point Relations," Journal of Pharmaceutical Sciences, 73 (6), 793-799 (1984).

Schott, H.: "A Linear Relation between the Cloud Point and the Number of Oxyethylene Units of Water-Soluble Nonionic Surfactants Valid for the Entire Range of Ethoxylation," Journal of Colloid and Interface Science, 260 91), 219-224 (2003).

Seethepalli, A., Adibhatla, B., and Mohanty, K.K.: "Physicochemical Interactions During Surfactant Flooding of Fractured Carbonate Reservoirs," SPEJ, 9 (4), 411-418 (December, 2004).

Strand, S., Puntervolt, T., and Austad, T.: "Effect of Temperature on Enhanced Oil Recovery from Mixed-wet Chalk Cores by Spontaneous Imbibition and forced Displacement using Seawater,' Energy \& Fuels, 22, 3222-3225 (2008).

Standnes, D.C. and Austad, T.: "Wettability alteration in chalk 2.Mechanism for wettability alteration from oil-wet to water-wet using surfactants," J. Petroleum Science and Engineering, 28, 123-143 (2000).

Standnes, D.C. and Austad, T., "Wettability alteration in carbonates: Interaction between cationic-surfactant and carboxylates as a key factor in wettability alteration from 
oil-wet to water-wet conditions," Colloids and Surfaces A: Physicochemical Engineering Aspects, 216, 243-259 (2003).

Strand, S., Hogensen, EJ, and Austad, T.: "Wettability Alteration of Carbonates; Effect of Potential determining Ions $(\mathrm{Ca}+2, \mathrm{SO} 4-2)$ and Temperature," Colloids \& Surfaces, 275, 1-10 (2006).

Treiber, L. E., Archer, D. L. and Owens, W. W.: "A Laboratory Evaluation of the Wettability of Fifty Oil Producing Reservoirs", SPEJ, December 1972.

Tweheyo, M. T., Zhang, P., Austad, T.: "Wettability alteration and improved oil recovery by spontaneous imbibition of seawater into chalk: Impact of the potential determining ions $\mathrm{Ca}^{2+}, \mathrm{Mg}^{2+}$, and $\mathrm{SO}_{4}{ }^{2-"}$, Colloids and Surfaces A: Physicochem. Eng. Aspects 301 (2007) 199-208.

Xie, X., Weiss, W.W., Tong, Z., and Morrow, N.R.: "Improved Oil Recovery from Carbonate Reservoirs by Chemical Stimulation", SPE 89424, proceedings of the Symposium on Improved Oil Recovery, Tulsa, 17-21 April, 2004.

Wu, Y., Shuler, P., Blanco, M., Tang, Y. and Goddard, W. A.: "A Study of Wetting Behavior and Surfactant EOR in Carbonates with Model Components", SPE 99612, proceedings of symposium on Improved Oil Recovery, Tulsa, 22-26 April, 2006.

Yousef, A.A., Al-Saleh S., Al-Kaabi, A., and Al-Jawfi, M.: "Laboratory investigation of novel oil recovery method for carbonate reservoirs," SPE 137634, Canadian Unconventional Resources \& International Petroleum Conference, Calgary. 